\title{
Descrição da Proveniência de Dados para Extração de Conhecimento em Sistemas de Informação de Hemoterapia
}

\author{
Fernanda Nascimento Almeida
}

\author{
TESE APRESENTADA AO PROGRAMA \\ INTERUNIDADES EM BIOINFORMÁTICA DA \\ UNIVERSIDADE DE SÃO PAULO PARA \\ OBTENÇÃO DO TÍTULO DE DOUTOR EM \\ CIÊNCIAS
}

\begin{abstract}
Programa: Interunidades em Bioinformática
Orientadora: Profa. Dra. Ester Cerdeira Sabino

Co-Orientador: Prof. Dr. João Eduardo Ferreira
\end{abstract}

Durante o desenvolvimento deste trabalho a autora recebeu auxílio financeiro da CAPES.

São Paulo, maio de 2012. 



\section{Descrição da Proveniência de Dados para Extração de Conhecimento em Sistemas de Informação de Hemoterapia}

\footnotetext{
Esta versão definitiva da tese contém as correções e alterações sugeridas pela Comissão Julgadora durante a defesa da versão original do trabalho, realizada em 23/05/2012.
}

\section{Comissão Julgadora:}

- Profa. Dra. Ester Cerdeira Sabino (orientadora) - Faculdade de Medicina da USP

- Profa. Dra. Anna Bárbara de Freitas Carneiro Proietti - Fundação Hemominas

- Profa. Dra. Sandra Fátima Menosi Gualandro - Faculdade de Medicina da USP

- Prof. Dr. Luciano Antonio Digiampietri - EACH - USP Leste

- Prof. Dr. Luciano Vieira de Araújo - EACH - USP Leste 
Dedico aos mens amados pais, Marcio e Tereza, pelo esforço, empenho e dedicaçăo que sempre depositaram em mim.

Acreditar e amar faz todo e qualquer ideal se tornar possivel. 


\section{Agradecimentos}

Agradeço aos meus orientadores, os professores João Eduardo Ferreira e Ester Cerdeira Sabino, por terem compartilhado um pouco do seu conhecimento comigo e por esta oportunidade.

Agradeço a professora Gisela Tunes da Silva (IME-USP) que supervisionou toda a parte de análise descritiva dos dados e classificação e, ajudou a fazer a análise de sobrevivência sugerida nesta tese que foi usada como resultado adicional. Agradeço também aos colaboradores deste trabalho, os professores Alfredo Mendrone Júnior (Fundação Pró-Sangue) e George Schreiber (Fundação Pró-Sangue), pelas contribuições e sugestões feitas ao longo do desenvolvimento desta tese.

Agradeço aos professores Anna Bárbara Proietti (Hemoninas), Sandra Gualandr (Faculdade de Medicina-USP), Luciano Digiampietri (EACH-USP) e Luciano Araújo (EACH-USP), pelos inúmeros comentários, sugestões, correções e ideias dadas que auxiliaram a tornar esta versão final da tese mais detalhada.

Agradeço a Coordenação de Aperfeiçoamento de Pessoal de Nível Superior (CAPES) pela concessão da bolsa de doutorado, a Fundação Pró-Sangue pelo fornecimento dos dados e ao programa de Pós-Graduação Interunidades em Bioinformática da USP pela oportunidade. 
Agradeço a Patrícia Martorelli, pela presteza, profissionalismo, dedicação e carinho sempre oferecidos.

Agradeço aos amigos Pedro Paulo da Silva e Kelly Braghetto pela ajuda, importantes críticas e incentivo dados durante o período de desenvolvimento desta tese. Deixo meus agradecimentos aos amigos, Eloiza Rezende, Daniel Cordeiro, Pedro Losko e aos colegas do Laboratório de Banco de Dados do IME pelos momentos de descontração e apoio.

Não poderia esquecer de agradecer a minha irmã, Caroline N. Almeida, o meu sobrinho Victor Hugo Almeida, por vibrarem a cada mínima conquista e, ao Saul Leite, por estar sempre ao meu lado nos momentos em que mais precisei. Por fim, gostaria além de dedicar agradecer aos meus pais, por sempre estarem ao meu lado apoiando todas as decisões que tomei até chegar aqui. 


\section{Resumo}

O Hemocentro São Paulo é responsável por manter um banco de dados com informações sobre cada doação ou tentativa de doação de sangue. No entanto, os dados desse banco de dados não possuem a qualidade requerida pelas ferramentas/técnicas de análise. Por essa razão, fica difícil utilizar tais dados para estabelecer relações sistemáticas entre as variáveis armazenadas. A principal contribuição desta tese é a descrição da proveniência para atributos selecionados usando critérios de classificação definidos por especialistas. Este trabalho mostra que é possível fazer investigações detalhadas usando a descrição dos dados sem a necessidade de alterar a estrutura do banco de dados.

Durante o período de 1996 a 2006, 1.469 .505 doadores foram responsáveis por mais de 2.8 milhões de doações. Após a descrição da proveniência, foram obtidos 252.301 doadores do sexo masculino e 133.056 doadores do sexo feminino e que atenderam aos critérios de inclusão usados nesta tese. Dos 385.357 doadores incluídos na análise, 21.954 (5,7\%) tiveram suas doações adiadas devido a seus baixos níveis de hematócrito, 3.850 (1,5\%) eram do sexo masculino e $18.104(13,6 \%)$ do sexo feminino. Os resultados obtidos demonstram que, embora os intervalos de espera entre as doações de sangue sejam grandes entre os doadores do sexo feminino e masculino, as mulheres são recusadas mais cedo, por risco de desenvolver anemia, do que os homens. 
Aproximadamente $12,84 \%$ das mulheres e $1,21 \%$ dos homens desenvolveriam hematócrito baixo antes da sétima doação. Os dados sugerem que indivíduos com baixo nível de hematócrito devem esperar mais tempo antes de executarem a próxima doação. Portanto, é importante compreender se existe uma ligação entre a doação de sangue e a diminuição no nível de hematócrito, a fim de evitar resultados indesejáveis para os doadores de sangue.

O modelo de proveniência apresentado nesta tese não foi definido de acordo com os modelos de proveniência genéricos já implementados. Esta tese apresenta um modelo de proveniência que foi capaz de acrescentar informações semânticas para adquirir conhecimento de um experimento in silico. Um dos principais objetivos foi desenvolver uma abordagem baseada em declarações, tentando responder a importantes questionamentos biológicos. O modelo descrito combina ricas informações em cada processo usando declarações, e se baseia no conhecimento de especialistas. Esta tese também utilizou estatística descritiva e Análise de Sobrevivência. Finalmente, com a validação do modelo em um domínio conhecido, é pretendido expandir esse método para outros sistemas de informação voltados para hemoterapia.

Palavras-chave: proveniência de dados, experimentos in silico, anemia, doadores de sangue, doação de sangue total. 


\section{Abstract}

The São Paulo Blood Center is responsible to maintain a database with information on each donation. However, this database does not have the quality required by techniques of analysis. For this reason, it is difficult to use it directly to establish systematic relationships between the variables. The main contribution of this paper is a provenance description of attributes selected using classification criteria defined by specialists. We show that it is possible to make detailed investigations using the data description without the need to change the structure of the database.

During 1996 - 2006, 1,469,505 donors were responsible for more than 2.8 million of donation. After the provenance description, we obtained 252,301 male and 133,056 female that met our inclusion criteria. Of the 385,357 donors included in the analysis, $21,954(5.7 \%)$ were deferred due to low hematocrit, 3,850(1.5\%) were males and $18,104(13.6 \%)$ were females. Our results show that, although the intervals between donations for female and male donors are wider, women presented anemia earlier than men. Approximately $12,84 \%$ of the females and $1,21 \%$ of the males would develop low hematocrit before the $7^{\text {th }}$ donation. Our data suggest that individuals with low hematocrit level should wait longer before the next donation. Therefore, it is important to understand if there is a connection between blood donation and decrease in hematocrit level in order to prevent undesirable outcomes to blood donors. 
The provenance model presented here was not defined according to the generic provenance models already implemented. This thesis presents a provenance model that is able to add semantic information to acquire knowledge of an in silico experiment. One of the main purposes is to develop an approach based on declarations in order to answer biological questions. The provenance model described in this paper combines rich information for each process using the declarations, each having expert knowledge as a basis. To evaluate this provenance model we use descriptive statistics and Survival Analysis. Finally, with the validation of the model in a known domain, we intent to apply and validate this provenance model to other hemotherapy information systems.

Keywords: data provenance, in silico experiments, anemia, blood donors, whole blood donations. 


\section{Sumário}

\begin{tabular}{l|c} 
Lista de Figuras & $\mathbf{x}$
\end{tabular}

Lista de Tabelas $\quad$ xii

1 Introdução

1.1 Considerações Preliminares. . . . . . . . . . . . . . . . 1

1.2 Hipótese. . . . . . . . . . . . . . . . . . . 7

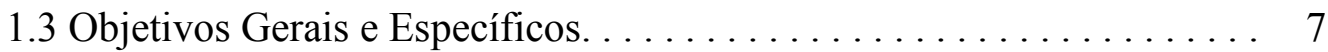

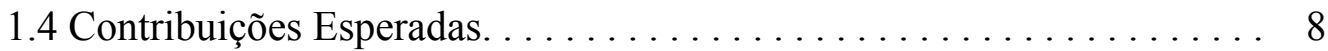

1.5 Organização do Trabalho. ...................... 9

2 Revisão Bibliográfica $\quad 10$

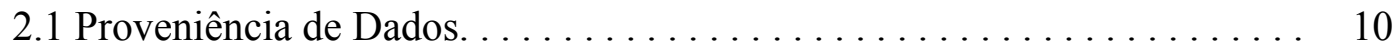

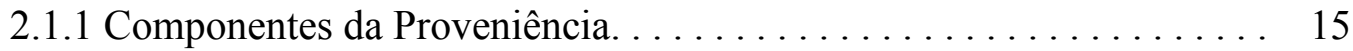

2.1.2 Modelos de Proveniência. . . . . . . . . . . . . . . . . . . 18

2.1.3 Sistemas de Proveniência. .................... 23

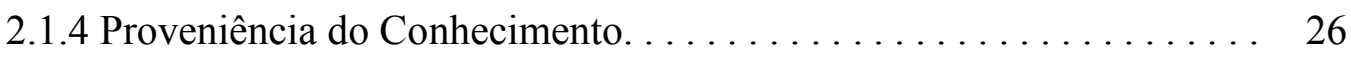

2.2. Anemia em Doadores de Sangue. . . . . . . . . . . . . . 28

2.3. Análise de Sobrevivência. . . . . . . . . . . . . . . . . 36

3 Modelo de Proveniência 39

3.1 Classificação dos Dados. . . . . . . . . . . . . . . . . . . 46

3.1 .1 Critérios de Inclusão. . . . . . . . . . . . . . . . . . . . . . . . . . 48

3.2 Estágio de Validação e Análise dos Dados. . . . . . . . . . . . . . . 54

3.3 Infra-estrutura de Software. . . . . . . . . . . . . . . 55

4 Resultados $\quad 56$ 
6 Conclusão $\quad 76$

$\begin{array}{lr}\text { 6.1 Considerações Finais } & \mathbf{7 6}\end{array}$

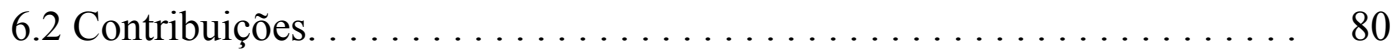

6.2.1 Trabalhos Publicados em Anais de Eventos (completo). . . . . . . . 80

6.2.2 Trabalhos Publicados em Anais de Eventos (resumo) . . . . . . . 80

6.2.3 Artigos Completos Submetidos. . . . . . . . . . . . . . . . . 80

6.3 Direcionamentos Futuros. . . . . . . . . . . . . . . . . 81

$\begin{array}{lr}\text { Referências Bibliográficas } & \mathbf{8 2}\end{array}$ 


\section{Lista de Figuras}

Figura 1.1. Perfil individual dos doadores de sangue separados por sexo feitos para verificar a existência de possíveis padrões de comportamento nos níveis de medição de hemoglobina no sangue dos doadores em relação ao tempo de doação (do período de 2003 a 2006). Para este exemplo foram usados somente resultados obtidos dos testes de micro-hematócrito.

Figura 3.1. Exemplos de problemas recorrentes no banco de dados de doadores de sangue. (A) Erro de digitação na tabela 'qtpeso' (que armazena o peso dos indivíduos). O indivíduo apresenta um peso de $788 \mathrm{Kg}$, o que demonstra um erro grosseiro de digitação; (B) Exemplo de inconsistência. Neste caso, um indivíduo esta presente na tabela de doadores ('cd_doacao'), entretanto, não há nenhum registro do mesmo na tabela de triagens ('cd_triagem'). Isso não pode acontecer já que todos os indivíduos, obrigatoriamente, passam pela triagem antes de efetuar uma doação.

Figura 3.2 Grafo direcionado das atividades "Seleção de Dados - DS\#1" e "Etapa de Transformação do Conjunto de Dados - DS\#2". Os retângulos representam as atividades e os círculos representam os conjuntos de dados.

Figura 3.3 Diagrama de atividades e dados desenvolvido especificamente para o domínio de doadores de sangue da FPS

Figura 3.4 Diagrama que representa o conjunto de regras que (critérios de inclusão) e populações esperadas.

Figura 3.5 Grafo ać́clico direcionado para representar o primeiro critério de inclusão (IC\#1) e o processo (P\#1) criado para transformar $\mathrm{Hb}$ em Hct. Os retângulos representam as atividades e os círculos representam os conjuntos de dados intermediários.

Figura 3.6 Grafo acíclico direcionado para representar o segundo critério de inclusão (IC\#2) e as projeções intermediárias de dados obtidas. Os retângulos representam as atividades e os círculos representam os conjuntos de dados intermediários.

Figura 3.7 Grafo acíclico direcionado para representar o terceiro critério de inclusão (IC\#3). Os retângulos representam as atividades e os 
círculos representam os conjuntos de dados intermediários.

Figura 3.8 Modelo de proveniência gerado especificamente para analisar dados baseado nas declarações previamente definidas. Os filtros e regras são representados como processos. Em azul estão as populações de interesse geradas para este trabalho

Figura 4.1 Descrição das populações de estudo da Fundação PróSangue/Hemocentro de São Paulo, no período de 1996 a 2006...........

Figura 4.2 Proporção acumulada dos doadores que desenvolveram LHct, de acordo com o número de doações prévias.

Figura 4.3 Curva de sobrevivência estimada de acordo com o primeiro nível de Hct

(a)

e idade (b).

Figura 4.4 Média dos intervalos entre as doações para a população de doadores anêmicos e não-anêmicos de acordo com o número de doações executadas, separados pelo sexo.

Figura 4.5 Médias do Hct, com intervalo de confiança de 95\%, entre doadores não-anêmicos, separados por sexo.

Figura 4.6 Média dos níveis de Hct encontrados na última doação para os doadores anêmicos e não-anêmicos, separados pelo sexo

Figura 4.7 Proporção de recusas nos grupo de doadores de estudo de acordo com o ultimo intervalo entre as doações ou visitas. Para a construção destes gráficos foi computado o intervalo das doações, um por doador. Para os doadores não-anêmicos, foi computado o intervalo das doações da última doação de sangue total durante o período de estudo. Para os doadores anêmicos, foram computador os intervalos entre a última doação de sangue e visitas, na qual o doador foi recusado. Os doadores foram classificados de acordo com sexo, nível de Hct e doação antes da última visita/doação. 


\section{Lista de Tabelas}

Tabela 3.1. Dados úteis e confiabilidade dos atributos pré-selecionados para análise

Tabela 4.1. Número e porcentagem de doadores de repetição anêmicos nos 11 anos de seguimento pelo gênero, idade, intervalo entre as doações e Hct inicial e final.

Tabela 4.2. Estimativas da tabela de vida para os grupos de doadores que atenderam aos critérios de inclusão. 


\section{Capítulo 1}

\section{Introdução}

\subsection{Considerações Preliminares}

A partir da década de 90, as tarefas dos experimentos in silico começaram a ser disseminadas e executadas em larga escala pela comunidade científica. Isso provocou um aumento na procura por recursos computacionais que atendessem a grande demanda de dados gerados por esses experimentos. Com isso, a necessidade de gerenciar dados se tornou fundamental para extrair análises mais eficientes, principalmente para aqueles oriundos de fontes heterogêneas ou com qualidade variável.

Uma solução comum para essa demanda está nas funcionalidades viabilizadas pelas áreas de banco de dados científicos e data warehousing, que oferecem apoio a diferentes projetos, principalmente, gerenciamento, organização, manutenção e disponibilização de dados. Na Bioinformática, dois exemplos clássicos da utilização de banco de dados científicos são os sistemas destinados a gerenciar dados biológicos, como o NCBI (www.ncbi.nlm.nih.org) e o EBI (http://www.ebi.ac.uk/). Ainda na biologia, existem outros bancos de dados que também cumprem a função de gerenciamento e administração de dados, como GenBank (http://www.ncbi.nlm.nih.gov/genbank/), UniProt 
(http://www.uniprot.org/), PDB (http://www.rcsb.org/pdb/home/home.do), dentre muitos outros. No entanto, o crescente interesse na utilização de banco de dados, algumas vezes ingênua outras vezes equivocada, implicaram na propagação de múltiplas representações imprecisas de um mesmo dado.

Por outro lado, as experimentações in vitro têm como princípio anotar as etapas seguidas para se chegar a um resultado desejado. Isso é importante, pois os cientistas são capazes de reproduzir os experimentos como também alterar os protocolos em caso de problemas ou sempre que julgarem necessário. O mesmo vem acontecendo com os experimentos in silico $^{1}$ (Stevens et al., 2007). Hoje, está cada vez mais evidente a necessidade de conhecer os processos pelos quais as análises foram obtidas, o que ajuda na interpretação dos resultados. Com isso, conhecer a história da derivação de um conjunto de dados e o processo pelo qual ele foi gerado vem se tornando uma tarefa importante na pesquisa científica. Portanto, armazenar os dados e os respectivos processos que o geraram pode ser uma importante ferramenta para ajudar o pesquisador a ter mais clareza sobre a autenticidade, legitimidade e confiabilidade de uma análise.

No que se refere aos bancos de dados hospitalares, sabe-se que os mesmos armazenam, em geral, informações dos pacientes (como consultas médicas, resultados de exames, medicamentos prescritos, diagnósticos de doenças, dentre outras informações). Nesses casos, múltiplas representações de dados podem se tornar um problema grave. Além disso, muitos desses bancos de dados são alimentados manualmente. Na maioria das vezes não há processos que limitem a inserção de dados, nem rotinas destinadas à correção, validação e normalização desses dados. Isso propicia a inserção e consequente propagação de erros. Como consequência disso as informações e resultados vindos desses

\footnotetext{
${ }^{1}$ A expressão in silico é usada para indicar algo ocorrido "em ou por meio de uma simulação computacional". A expressão foi criada a partir das expressões in vivo e in vitro, frequentemente usadas na Biologia (Fonte: http://pt.wikipediaorg/wiki/In silico).
} 
bancos de dados podem não ter muita utilidade, pois o especialista nem sempre é capaz de julgar adequadamente quão confiável é o resultado obtido. Geralmente, esse problema acontece porque as informações e as regras usadas para gerar o conjunto de dados nem sempre são preservadas.

Para atender as limitações dos bancos de dados científicos, a literatura e a pesquisa na área de banco de dados têm utilizado o conceito de proveniência que tem como principal finalidade armazenar as informações que representam a história do dado (Buneman et al., 2000; Álvarez et al., 2006; Freire et al., 2008). Em geral, essas informações podem auxiliar no processo de derivação dos dados, demonstrando as etapas de transformação do conjunto de dados primários (dados obtidos em sua forma original das fontes de dados). Essa abordagem vem sendo amplamente empregada em trabalhos na área de bancos de dados científicos. Outra área que emprega a proveniência é a de bancos de dados Geográficos. Esses bancos de dados adotam a proveniência para auxiliar no processamento e identificação de imagens (Braga \& Banon, 2008). Existem outros trabalhos VisTrails (Bavoil et al., 2005; Scheidegger et al., 2007), Panda (Ikeda \& Widom, 2010), Taverna (Oinn et al., 2006), Kepler (Bowers et al. 2006, 2007 e 2008), Pegasus (Miles et al., 2007), REDUX (Barga \& Digiampietri, 2008), e Swift (Clifford et al., 2008) que empregam a proveniência baseada em workflows científicos. Nesses casos, a proveniência foi usada como um recurso de rastreabilidade para armazenar o histórico de execução de um dado experimento (Silmmhan et al., 2005; Moreau et al., 2007a; Freire et al., 2008). A proveniência também pode ser empregada para auxiliar o pesquisador a obter mais clareza sobre o contexto do trabalho e consequentemente sobre 
a qualidade, viabilidade e confiabilidade de todo o processo envolvido no experimento in silico.

Uma das principais motivações biológicas para o desenvolvimento desta tese é a caracterização do comportamento dos doadores de sangue que são recusados para uma doação regular por apresentarem risco de desenvolver anemia sob a ótica da proveniência de dados. Para o desenvolvimento desta tese foi escolhida a Fundação PróSangue/Hemocentro de São Paulo que possui um banco de dados destinado a armazenar as doações ou tentativa de doações de sangue. Na Fundação existem também registros adicionais referentes aos procedimentos das doações, conhecidos como triagem - que é um formulário submetido ao candidato a doação no dia de sua ida ao hemocentro. Essa triagem contém basicamente: dados pessoais do potencial doador, motivos da doação e informações da bolsa de sangue (quando houver). As doações, além dos dados clínicos também armazenam resultados de exames laboratoriais, tais como: chagas, sífilis, hepatite, vírus T-linfotrópicos humanos - HTLV (Human T Lymphotropic Virus Type 1) e vírus da imunodeficiência humana - HIV (Human Immunodeficiency Virus).

Numa primeira tentativa exploratória desta tese, procuraram-se classes ou padrões de comportamentos nos dados do Hemocentro de São Paulo, aplicando-se métodos de agrupamento para testar a viabilidade do emprego da proveniência. Para isso, as seguintes variáveis foram relacionadas: sexo, idade, quantidade de doações e níveis de medição de hemoglobina no sangue. Como resultado, foram obtidos os gráficos apresentados na Figura 1.1. Entretanto, infelizmente, tais gráficos demonstram a incapacidade de se detectar relacionamento sistemático entre as variáveis analisadas, apenas foram 
observadas nuvens de dados inexpressivas sem uma abordagem que considerasse a proveniência de dados.

(a) Sexo Feminino

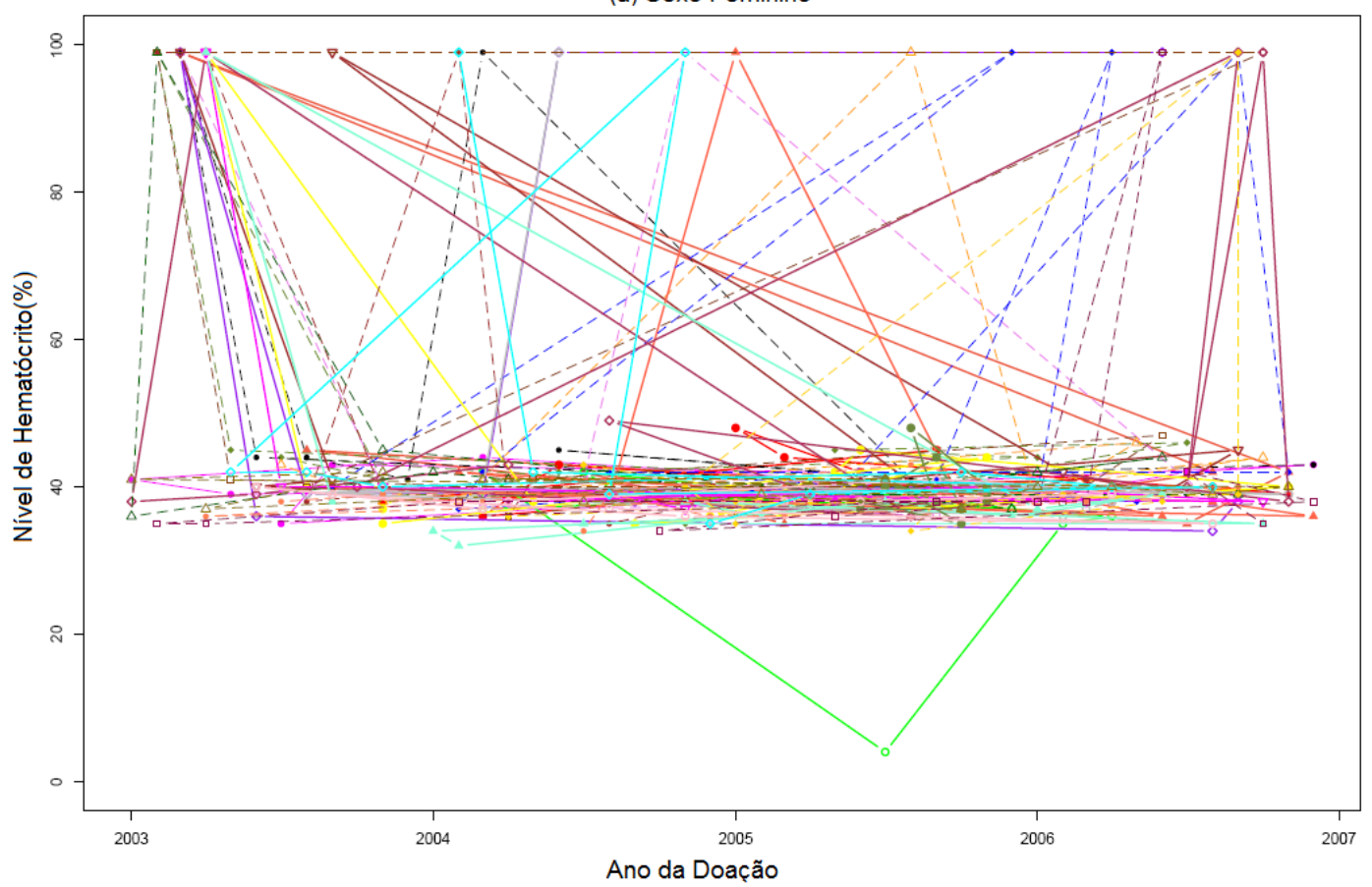

(b) Sexo Masculino

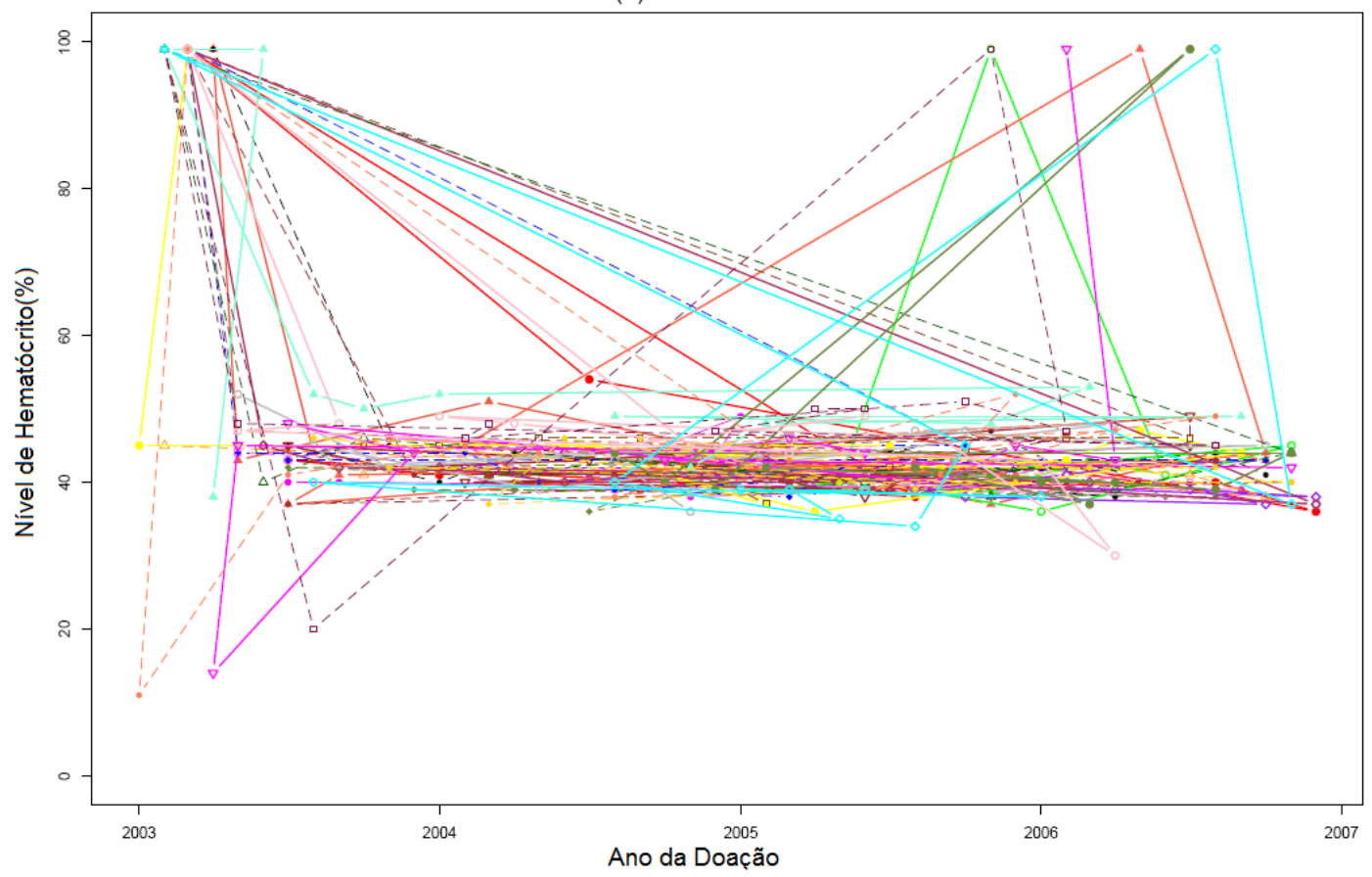

Figura 1.1. Perfil individual dos doadores de sangue separados por sexo feitos para verificar a existência de possíveis padrões de comportamento nos níveis de medição de 
hemoglobina no sangue dos doadores em relação ao tempo de doação (do período de 2003 a 2006). Para este exemplo foram usados somente resultados obtidos dos testes de micro-hematócrito.

$\mathrm{Na}$ segunda abordagem o objetivo foi o de averiguar a existência de oscilações, tendências, ou padrões dos níveis de hemoglobina no sangue dos indivíduos que doaram com regularidade. Para isso, foram estipuladas faixas, desconsiderando registros inválidos, para doadores que efetuaram mais de uma doação regular de sangue. Entretanto, assim como mencionado anteriormente, nenhuma observação relevante pôde ser feita. Apenas foram vistas apenas nuvens de dados.

Nas verificações iniciais, os resultados não foram representativos e isto pode ser atribuído à qualidade inadequada dos dados aliada à falta de descrição da proveniência para esse tipo de experimento (Almeida et al., 2010). Para analisar o banco de dados da Fundação Pró-Sangue e aplicar métodos computacionais de forma adequada, é importante contar com o conhecimento científico de pesquisadores. Somente assim, é possível obter análises mais eficientes e confiáveis. O uso puro e simples de modelos matemáticos de classificação, Descoberta de Conhecimento em Banco de Dando (do inglês, Knowledge Discovery in Databases - KDD) e Sistemas Especialistas se tornou inviável para este trabalho. Tais modelos não são capazes de detectar relacionamentos sob um conjunto de dados com pouca qualidade e incompleto (Almeida et al., 2010).

A proposta desta tese visa a demonstrar que o conhecimento dos pesquisadores se torna um importante aliado para o delineamento de um experimento in silico e, permite a extração de resultados com informação mais confiável e respostas mais precisas. No entanto, diferente de muitos trabalhos que empregam proveniência, esta tese não possui aplicações $W e b$ e não se destina à integração de fontes de dados heterogêneas. Aqui foi 
analisada apenas uma fonte de dados conhecida, o banco de dados da Fundação PróSangue. A proveniência, então, foi usada para rastrear cada evento ou decisão tomada pelos pesquisadores para obter um tipo específico de resposta. A principal contribuição desta tese é a descrição da proveniência de modo a auxiliar que pesquisadores de outros hemocentros brasileiros possam reproduzir o mesmo tipo de análise e/ou propiciar outras análises nesta área.

\subsection{Hipótese}

É possível obter uma proveniência mais qualificada quando sua descrição está aliada a tarefas computacionais bem caracterizadas por meio de conceitos definidos por especialistas na área de interesse. Com isso será possível mensurar a qualidade e

confiabilidade do conjunto de dados resultante. É possível também, dispor de um método de classificação semântico dos dados a fim de proporcionar análises mais eficientes e respostas mais precisas.

\subsection{Objetivos Gerais e Especificos}

O objetivo deste trabalho é o desenvolvimento de um modelo de descrição de dados capaz de incorporar declarações definidas por especialistas para obter um conjunto de dados com maior qualidade. Essa descrição propiciará respostas mais confiáveis sobre um determinado fenômeno biológico. Para isso, é importante: 
1. Criar um esquema que seja capaz de facilitar a criação do modelo de atividades e armazenamento da proveniência.

2. Definir uma estrutura que auxilie a classificação e predição de amostras ainda não conhecidas. Essa estrutura deve ser composta de registros referentes ao conjunto de treinamento e a eles devem-se adicionar questionamentos definidos pelos especialistas.

3. Demonstrar a viabilidade da proveniência como método de descrição de dados, dos processos e das respostas obtidas usando métodos estatísticos.

\subsection{Contribuições Esperadas}

Dentre as contribuições deste trabalho, podem ser citadas:

- Desenvolvimento de um esquema teórico que pode auxiliar na implementação de um modelo de proveniência específico para pesquisas em bancos de dados de doadores de sangue;

- Criação de um critério de separação de classes baseado em conceitos ou perguntas, diferente dos demais amplamente divulgados, e de fácil entendimento para pesquisadores de hemocentros;

- Desenvolver um método que auxilie a compreender os motivos que levam a recusas por risco de desenvolvimento de anemia entre os doadores de repetição da Fundação Pró-Sangue/ Hemocentro de São Paulo; 
- Melhorar as análises e proporcionar à diferentes grupos de pesquisa que analisam doação de sangue uma visão beneficiada dos grupos de doadores pertencentes aos seus hemocentros, para que possam gerar novas análises e, consequentemente, elevar a qualidade das doações de sangue.

\subsection{Organização do Trabalho}

No Capítulo 2, é feita a contextualização do método proposto e do problema de interesse. Nesse capítulo são descritos os conceitos e definições no âmbito da proveniência em diferentes abordagens. Em seguida, é descrito o cenário de aplicação do método, as doações de sangue, e o método estatístico usado para a análise dos dados.

No capítulo 3, é descrita a metodologia proposta. No Capítulo 4 e 5, são apresentados e discutidos os resultados gerados por meio dos métodos de análise e validação do experimento. No Capítulo 6, é apresentada a conclusão deste trabalho e, por fim, são expostas as principais contribuições e trabalhos futuros. 


\section{Capítulo 2}

\section{Revisão Bibliográfica}

Esta revisão abrange três aspectos. O primeiro apresenta os principais conceitos sobre proveniência de dados, suas aplicações e as informações que podem ser obtidas a partir de sua utilização. O segundo refere-se ao domínio de aplicação que foi usado neste estudo. O terceiro aspecto a ser abordado nesta revisão refere-se ao método de análise aplicado para fazer inferências e investigações sobre as projeções de dados.

\subsection{Proveniência de Dados}

Proveniência de Dados é bem compreendida no contexto de artes e bibliotecas digitais (Moreau et al., 2000; Tan, 2008; Moreau et al., 2007a; Moreau et al., 2007b). Nesses dois contextos, ela se refere à documentação histórica de um objeto de arte ou ao processo de documentação do ciclo de vida de objetos digitais (Moreau et al., 2007a; Moreau et al., 2007b). Devido à documentação histórica de um objeto, o mesmo obtém certa autoridade, permitindo que estudiosos compreendam e sejam capazes de avaliar, com maior precisão, a importância e o contexto de aplicação daquele objeto em relação a outros trabalhos (Moreau et al., 2007b). Nesse sentido, a proveniência auxilia na 
determinação da autenticidade e consequente valorização de um objeto de arte (Moreau et al., 2000). Caso a proveniência fosse produzida por sistemas computacionais, a fim de determinar trabalhos de arte, o usuário, em uma aplicação mais detalhada, obteria melhor interpretação e julgamento sobre a qualidade do dado (Moreau et al., 2007a; Moreau et al., 2007b). Para isso, métodos computacionais devem ser transformados, no intuito de construir uma proveniência qualificada, de modo que ela possa ser recuperada, analisada e bem fundamentada (Moreau et al., 2007a).

O principal fundamento da proveniência é recolher os indícios quanto ao tempo, lugar e, se for o caso, a pessoa responsável pela criação, produção, descoberta ou inserção do dado. Técnicas de análise comparativa, pareceres de peritos e os resultados de vários tipos de testes científicos também podem ser utilizados para esse fim, mas o que de fato institui a proveniência é a sua documentação (Almeida et al., 2010; Tan, 2008).

Existem diferentes sinônimos empregados para denotar o termo proveniência de dados (Buneman et al., 2000; Brown \& Stonebraber 1995; Spery et al., 1999; Buneman et al., 2001; Bose et al., 2002). No trabalho apresentado por Buneman et al. (2001), o termo proveniência é utilizado para fazer referência à origem do dado e o termo "pedigree" se referencia ao histórico de como aquele dado foi produzido ou derivado.

Juntamente com os sinônimos existem as definições para o termo proveniência (Buneman et al., 2000; Almeida et al., 2010). A definição mais clássica foi descrita por Buneman et al. (2000) afirmando que é a documentação complementar de um determinado dado que contém a descrição de "como", "quando", "onde" e "por que" ele foi obtido e "quem" o obteve (Buneman et al., 2001). Nessa mesma linha estão Woodruff et al. (1997), afirmando que proveniência não somente inclui a origem do dado 
(identificação, responsável pelo dado, data de criação), mas também os processos aplicados a ele (algoritmos e seus respectivos parâmetros). Segundo Simmhan et al. (2005), proveniência de dados está mais voltada aos processos de investigação e armazenamento da origem de uma parte do dado, bem como sua movimentação entre os bancos de dados. Já Lanter et al. (1991), a linhagem do dado derivada de um produto (em geral empregado a Sistemas de Informação Geográficos) como, informações que descrevem os materiais e as transformações aplicadas para produzir o dado (Lanter et al., 1991). Nesse caso, a proveniência não somente está associada com o produto de dados, mas também aos processos de criação e viabilização do dado (Buneman et al., 2000). A definição de proveniência descrita por Lanter et al. (1991) foi expandida por Greenwood et al. (2003). O trabalho apresentado por Greenwood et al. (2003) propõe a utilização de um processo para registrar metadados em experimentos baseados em fluxo de atividades (do inglês, workflow), anotações e apontamentos feitos por pesquisadores. Pode-se ainda considerar proveniência como a derivação de uma fonte particular de dados na tentativa de especificar o estado de um item (Moreau et al., 2007b). Como pôde ser visto a definição do termo proveniência pode variar de acordo com o interesse do usuário e com o contexto do estudo. Nesse sentido, proveniência é uma abordagem baseada em conceitos e definições e não uma técnica. Isso acarreta derivação quanto à forma, propriedade e ênfase da aplicação do método. Uma representação computacional da proveniência, no entanto, torna-se crucial para aqueles usuários que desejam analisar, raciocinar e decidir se confiam ou não nos dados eletrônicos (Moreau et al., 2007b). Proveniência pode também ser vista sob dois aspectos, derivação de um objeto ou registro da execução de um processo (seja ele destinado ou não à derivação de um dado). 
A maioria das pesquisas que utilizam a proveniência visa ao armazenamento de dados advindos da Web, e-Science ou bibliotecas digitais. Em geral, o que acontece é: os dados, em um banco de dados, são movidos para outro banco de dados quando consultas ou programas são executados; e assim, é feita uma descrição especificando as relações entre as fontes envolvidas (Tan, 2008). Nesses casos, a menos que haja um esforço coletivo para manter a proveniência de forma explícita, quando um dado é movimentado, tais informações são perdidas no processo de transformação do banco de dados (Tan, 2008). Nesse cenário, a descrição completa da proveniência de dados implicaria em traçar a versão correta do dado e também localizá-lo em outras versões (Tan, 2008). Para isso, cada versão do banco de dados deveria ser mantida, bem como os relacionamentos com suas respectivas versões alteradas. Sabe-se ainda que, versões mais recentes podem sofrer modificações quanto ao conteúdo ou estrutura. Para resolver esse problema Tan (2008) recomenda que uma documentação daquilo que sofreu derivação seja feita, o que manteria os relacionamentos entre as versões.

$\mathrm{Na}$ pesquisa em banco de dados, a proveniência auxilia no processo de rastreamento e sinalização da origem dos dados, como também sua movimentação entre diferentes fontes de dados (Silmmhan et al., 2005). Com o declínio dos custos de armazenamento de dados em hardware, tornou-se comum a integração de bancos de dados, ou seja, construir um novo banco de dados usando outros já existentes. O mesmo acontece no campo da biologia molecular. Nessa área, somente uma pequena parcela dos bancos de dados disponíveis recebem diretamente dados procedentes de experimentos in vitro (Tan, 2008). Com isso, os dados tendem a possuir alto nível de proveniência, já que, além de terem passado por vários outros bancos de dados, podem ter sofrido 
transformações, como: modificações, traduções e complementações. Assim sendo, parte da solução para registrar a origem dos dados está baseada em anexar a proveniência como componente dos bancos de dados (Wong et al., 2005). Contudo, o gerenciamento desses dados traz novos problemas à comunidade científica de banco de dados, uma vez que tecnologias convencionais de banco de dados não podem ser diretamente aplicadas (Buneman et al., 2001). Além disso, de acordo com Buneman et al. (2001), a inserção de novos dados requer métodos de desenvolvimento mais sofisticados. Portanto, alguns esforços importantes para incluir proveniência em banco de dados estão em andamento (Buneman et al., 2001; Tan., 2008; Chapman et al., 2008).

No trabalho apresentado por Braga \& Banon (2008), preconiza-se que somente um sistema computacional com a mínima intervenção do usuário seja capaz de gerenciar adequadamente a proveniência (desde a criação até sua publicação). Entretanto, os autores afirmam que não existe um modelo comum que possa ser aplicado para o gerenciamento da proveniência e que talvez nem haja um. Isso consequentemente acarreta alguns desafios computacionais, relacionados à criação, armazenamento, publicação, busca e preservação da proveniência. Ainda, segundo esses autores, se a proveniência for armazenada de forma adequada, em meios seguros e confiáveis, a probabilidade de sua preservação aumenta, caso contrário, sua existência será comprometida.

Atualmente, tem-se tornado natural o usuário se perguntar sobre a confiabilidade de um determinado conjunto de dado consultado. O que torna cada vez mais evidente a importância de conhecerem-se os processos de derivação do dado, e não somente sua 
origem e, assim determinar a qualidade e principalmente a confiabilidade da informação que se esta extraindo de um bando de dados.

Na Bioinformática, diferentes campos de pesquisa agem de maneira independente. Em geral, esses grupos produzem repositórios de dados e ferramentas analíticas que operam sobre os dados de forma isolada (Almeida et al., 2010). Como a comunidade das ciências biológicas é heterogênea, existem vários grupos nas áreas de Biologia, Biomedicina e Medicina gerando diferentes tipos de dados. O volume crescente do conjunto de dados, advindos de experimentos in vitro, o desenvolvimento de novas ferramentas de manipulação e a facilidade de disponibilização dos dados geraram um aumento considerável de dados heterogêneos com qualidade desconhecida; o que resultou em um esboço de conclusões que não são completamente justificáveis quando se verificam as técnicas seguidas. Além disso, as informações são instáveis, isto é, estão sujeitas a constantes atualizações. Esses fatos levaram os pesquisadores a perceber que proveniência em Biologia, Biomedicina e em Medicina está se tornando um pré-requisito indispensável para o entendimento da informação nessas áreas.

\subsubsection{Componentes da Proveniência}

Quando se trata de tarefas computacionais, existe uma variedade de mecanismos que ajudam no processo de modelagem como, programas de computadores, rotinas, workflows ou ferramentas desenvolvidas que atendem a uma finalidade específica. Em alguns casos, tarefas mais complexas requerem associação com outras ferramentas, fontes de dados, bibliotecas específicas, ou serviços Web. Entretanto, para assegurar a reprodutibilidade de uma tarefa computacional é importante ter a descrição de cada etapa 
e os parâmetros usados. Nesse sentido, ordenar e organizar os processos computacionais e também guardar informações dos $\log s$ de execução dos programas pode auxiliar na documentação e reprodução dos resultados. Entretanto, uma desvantagem vista nessas abordagens é quanto à verificação manual das tarefas, ou seja, quando uma rotina precisa ser modificada ou quando o arquivo de log necessita ser manipulado (Freire et al., 2008).

São muitos os trabalhos que possuem finalidades específicas. Atualmente, a maioria deles adota abordagens que podem fornecer linguagens específicas para tarefas simples ou complexas, como workflows ou sistemas já fundamentados. Essas abordagens permitem também a captura de processos complexos em vários níveis de detalhamento. Além disso, registram sistematicamente informações da proveniência que serão necessárias para automação, reprodutibilidade e colaboração de resultados (Freire et al., 2008).

O conceito da abstração está também relacionado a tarefas computacionais. Sua finalidade é promover a separação de tarefas complexas e representá-las em diferentes níveis de granulosidade. Muitas vezes a abstração é empregada para ocultar detalhes na representação de um workflow. Isso simplifica a visualização como também melhora a compreensão das atividades envolvidas (Freire et al., 2008).

Na proveniência, quando se trata de tarefas computacionais, existem duas formas: prospectiva e retrospectiva. Na proveniência prospectiva, as etapas de seguimento (ou processos) adotadas para a geração de um dado produto são capturadas, permitindo o registro das especificações das tarefas computacionais empregadas. Já no que tange a proveniência retrospectiva, a finalidade é capturar as etapas que foram executadas, além das informações a respeito do ambiente usado para a derivação de um produto específico 
de dados, como detalhes do $\log$ de execução de uma determinada tarefa computacional. Nela são capturados preferencialmente informações sobre a entrada e saída dos dados, execução do usuário e tempo inicial e final da execução. Entretanto, a proveniência retrospectiva não é dependente da presença da prospectiva, pois permite a captura de execução dos processos sem ter a necessidade de saber a sequência de atividades envolvidas (Freire et al., 2008).

Um importante componente da proveniência é a obtenção de informações sobre causalidade. Nesse componente é guardada a descrição do processo (ou sequência dos passos) que, junto com dados de entrada e seus respectivos parâmetros, levam à criação de um conjunto de dados final. Assim as dependências dos processos são usadas para documentar sua criação, bem como auxiliar na reprodução e validação desse processo. A causalidade pode ser inferida tanto para a proveniência prospectiva como para a retrospectiva (Freire et al., 2008).

Outro componente-chave para a proveniência são as informações definidas pelo usuário, a documentação. Por serem dados, em geral, advindos dos processos de anotação, não são capturados automaticamente. Com isso, possuem diferentes níveis de granulosidade e podem estar associados a diferentes componentes da proveniência prospectiva como da retrospectiva. Esse tipo de registro se torna muito importante, pois contém informações sobre decisões tomadas e observações feitas pelo usuário (Freire et al., 2008). 


\subsubsection{Modelos de Proveniência}

Em um mundo ideal, cientistas e usuários deveriam ser capazes de reproduzir os resultados de seus experimentos fazendo re-execuções prévias, neste caso, computacional (Moreau et al., 2007b). A ideia é compreender por que duas execuções aparentemente idênticas e com a mesma entrada produzem resultados distintos. Dessa forma, Moreau et al. (2007b) ressaltam a importância de determinar o envolvimento do tipo de conjunto de dados, algoritmos ou serviços empregados no processo de derivação desses resultados.

Ainda segundo Moreau et al. (2007b), usuários, revisores e auditores deveriam ser capazes de verificar as metodologias ou os critérios empregados para chegar a um determinado resultado. Também evidenciam a necessidade de estabelecer quais instrumentos foram usados para a captura de uma fonte de dados. Nesse sentido, a principal observação é a já descrita na seção anterior; dados eletrônicos nem sempre contêm informações históricas que ajudariam o usuário final a ser capaz de fazer verificações importantes. Assim, não basta somente criar um método que armazene a origem desses dados. É necessário criar um protocolo para documentação e armazenamento que assegure o gerenciamento de todo o processo de documentação.

Em 2006, o Workshop Internacional de Proveniência e Anotação (International Provenance and Annotation Workshop - IPAW'06) envolveu interessados em proveniência de dados, documentação de processos, derivação e anotação de dados (Moreau et al., 2006; Moreau et al., 2007a). Nesse evento, a comunidade de pesquisa em proveniência percebeu a importância de se compreender a capacidade dos diferentes sistemas e também da representação usada para descrever proveniência, suas 
similaridades, diferenças além, da base lógica que motivou sua projeção (Moreau et al., 2007a).

Existem várias iniciativas cuja finalidade é criar métodos para descrever e/ou formalizar a proveniência de dados. A maioria delas possui aplicações de e-Science (Groth et al., 2006). No trabalho apresentado por Silmmhan et al. (2005), são discutidos vários sistemas de proveniência em e-Science. Alguns sistemas como o PASS (Holland et al., 2008) possuem uma central de execuções focada na reunião de informações pertinentes as rotinas em contexto de aplicações interativas (Groth et al., 2006). Outros sistemas como o Taverna (Oinn et al., 2006), usam workflow para organizar informações de proveniência referentes às rotinas (Groth et al., 2006). Em Chapman et al. (2008) são descritos uma série de algoritmos de formalizações de proveniência.

O trabalho descrito por Groth et al. (2006) apresentaram um tipo de modelo de proveniência baseado em uma central de processamento. Nesse trabalho, fornecem um mecanismo de empacotamento para capturar dados de proveniência produzidos por uma classe de aplicações comuns em e-Science. Entretanto, a finalidade do trabalho é reduzir o tamanho do grafo de proveniência para proporcionar maior eficiência (Groth et al., 2006).

Munroe et al. (2006), descrevem um tipo de documentação que pode ser implementada usando um XML Schema. O intuito do trabalho foi apresentar o Modelo de Dados para Documentação de Processos (do inglês, Data Model for Process Documentation), um modelo usado para organizar e representar a captura da proveniência relacionada a processos. O modelo apresentado permite a documentação das atividades executadas pelo workflow. Assim, são armazenadas as trocas de mensagens entre os 
atores (definidos como, serviços de entrada e saída de uma declaração ou quando o sistema é autônomo, os usuários) participantes da execução de um dado processo, além disso, permite ainda armazenar registros dos dados que foram usados ou produzidos. As declarações são constituídas de metadados que compõem um workflow, como também os dados usados e produzidos em uma dada atividade. Neste caso, toda descrição de uma atividade contém a documentação da etapa do workflow, neste contexto conhecida como p-declaração (do inglês, p-assertions). As p-declarações registram a execução de uma tarefa quando relacionam-na à execução de um programa por meio de metadados. Entretanto, esse modelo não permite a captura de dados usados pelos processos.

Outro trabalho que visa ao desenvolvimento de um modelo de proveniência padrão é o apresentado por Simmhan et al. (2005) e intitulado Karma. Nesse trabalho, os autores apresentam um sistema de desenvolvimento cuja finalidade é registrar a proveniência de dados utilizados e gerados por meio da chamada de serviços Web no processo de execução de workflows. O Karma coleciona a proveniência retrospectiva na forma de um fluxo de atividades destinado à investigação (Freire et al., 2008), também armazena a proveniência prospectiva usando uma linguagem de processo de negócios. Ele também explicita um modelo para a história da derivação de um produto de dado (Freire et al., 2008). No caso desse trabalho, tanto as tarefas como o próprio workflow são serviços Web. O modelo proposto permite a captura da proveniência por meio da descrição da execução de um processo, além do registro da proveniência de dados. Entretanto, sua utilização se restringe a registros de proveniência de tarefas e workflows voltada somente a serviços Web. 
Os projetos EU Provenance (The Provenance Project) e Provenance Aware Service Oriented Architecture - PASOA (Groth et al., 2006) são atividades recentes dirigidas a problemas voltados para a determinação da proveniência em aplicações genéricas e heterogêneas. Esses trabalhos têm sido conduzidos com o propósito de definir uma arquitetura na qual o desenvolvedor seja capaz de capturar informações sobre processos. A ideia é permitir questionamentos sobre a proveniência. $\mathrm{O}$ trabalho define também uma tecnologia com suporte imparcial para representar, capturar e consultar a proveniência. A aplicação pode ser feita usando uma proveniência mais qualificada, a qual analisa a aplicação dentro do contexto baseado em perguntas fornecidas pelos usuários. Os componentes são identificados na aplicação e deverão ser funcionalmente processados no registro da documentação (chamado neste contexto de p-declarações, similar ao apresentado por Munroe et al. [2006]). Com isso, fornecem um modelo padrão de dados que subsidia a coleta e organização de informações relativas à proveniência pelos desenvolvedores. $\mathrm{O}$ artigo descreve como o modelo pode ser aplicado em exemplos de experimentos de Bioinformática baseados em grid (Groth et al., 2006).

O Open Provenance Model (OPM), é outro modelo destinado a gerenciar registros de proveniência. Ele é resultado dos esforços do IPAW'06 (Moreau et al., 2007a; Moreau et al., 2007b; Moreau et al., 2008). A finalidade desse modelo é definir e disponibilizar uma representação genérica para proveniência para ser aplicada em diferentes áreas de pesquisa. Entretanto, para que sua utilização seja válida é necessário satisfazer requisitos básicos, como: $(i)$ permitir que informações de proveniência sejam compartilhadas entre os sistemas; ( $i$ i) permitir que desenvolvedores construam e permutem ferramentas com o modelo de proveniência; (iii) definir a proveniência de forma precisa; (iv) manter uma 
representação digital da proveniência para que qualquer objeto seja produzido por um sistema computacional; (v) permitir múltiplos níveis de descrição; (vi) definir um conjunto de funções que identifiquem inferências válidas na representação da proveniência.

Para representar o OPM, assume-se que objetos da proveniência (digitais ou não) são representados por um grafo de causalidade anotado, que é acíclico direto, enriquecido com anotações, e fornecem informações pertinentes à execução. Um grafo de proveniência é definido por ser um registro de execuções atuais e principalmente passadas e de forma alguma descrições de execuções futuras. O OPM visa à captura de dependências entre artefatos, processos e agentes. Por isso, um gráfico de proveniência é dito como sendo um grafo acíclico direcionado (GAD). Nesses GAD, os nós são os artefatos, agentes e processos e, as arestas representam as dependências entre suas fontes, denotando os efeitos e as causas (Moreau et al., 2009). Entretanto, o OPM possui um conjunto de regras básicas para que seja aplicado e elas são adotadas para gerar a

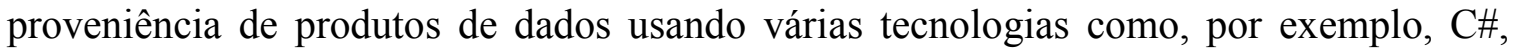
Java, Taverna (Oinn et al., 2006), PASS (Holland et al., 2008), VisTrails (Scheidegger et al., 2007), dentre outras. O OPM pode ser citado como um modelo abstrato. Contudo, sua formalização não se aplica a descrever documentos com representações internas ou, quando não são definidos protocolos para o armazenamento e consulta da proveniência (Moreau et al., 2009).

Embora existam vários tipos de modelos cujo intuito é a descrição da proveniência no âmbito mais genérico, a maioria dos trabalhos não dão atenção necessária a quando se deseja extrair conhecimento de um dado consumido, no qual 
apenas uma fonte foi usada. Outro fator limitante das abordagens descritas é a proveniência quando relacionada a processos. Muitas delas não se preocupam em registrar ou conhecer a importância de um determinado processo antes e após sua execução.

\subsubsection{Sistemas de Proveniência}

Como uma tentativa de solucionar parte dos problemas mencionados anteriormente, o projeto myGrid (Greenwood et al., 2003; Zhao et al., 2003) tem como principal objetivo a construção, administração e distribuição intensa de dados advindos de experimentos biológicos in silico. Os autores acreditam que os dados oriundos de experimentos in vitro associados com experimentos e-Science possuem pouco valor se outros cientistas não forem capazes de armazenar a proveniência desses dados. A intenção do projeto myGrid é potencializar o valor dos experimentos em e-Science, ou seja, gerados com o uso de recursos eletrônicos, como banco de dados, métodos computacionais, dentre outros. Para entender melhor o funcionamento desse projeto, suponha um dado biológico, por exemplo, uma sequência de DNA. Nesse caso, o myGrid gerará a proveniência desse dado, fornecendo: notas de onde o dado veio, informação sobre espécies a que pertencem, o responsável pela entrada dos dados, quando o dado foi inserido, sintaxe, semântica, dentre outras informações a respeito desse dado em particular. Em seguida, a proveniência será armazenada e compartilhada na Web com vários outros grupos de pesquisa. $\mathrm{O}$ projeto incluiu não apenas a proveniência, como também atalhos para outros projetos (direta ou indiretamente relacionados), indicativos de páginas da $W e b$, referências bibliográficas, dentre outros. 
Os processos dos bancos de dados (consultas, visualizações e mapeamentos) e as linguagens pelas quais eles são expressos são de claro interesse para a administração da informação. Eles introduzem separadamente, filtros e reagrupam fontes de dados a fim de popular os armazéns de dados (do inglês, data warehouses) e ferramentas de análises e visualização. Para isso, é necessário seguir os relacionamentos entre partes e pedaços das fontes de dados e das transformações. Nesse caso, afirmam que o relacionamento deve ser feito pela construção de um banco de dados próprio para armazenar os registros de proveniência (Tannem et al., 2008).

Uma iniciativa que trabalha com dados médicos foi descrita em Li et al.(2008). O projeto atua em parceria com o Centro para a Modelagem de Imunidade Pulmonar CMPI (criado com a associação das Universidades de Pittsburgh, Carnegie Mellon e de Michigan). Esse trabalho foi responsável por projetar e desenvolver uma plataforma de distribuição de dados, o DataXS, na qual dados experimentais, análises, e modelos são distribuídos para os projetos participantes (Li et al., 2008). O foco principal foi à criação de um sistema capaz de registrar e propagar dados vindos do processo de anotação. Dessa mesma forma, existem muitos projetos que lidam com a administração e propagação de dados de anotação como: DBNotes (Bhagwat et al., 2004), Mondrian (Geerts et al., 2006), ULDB (Benjelloun et al., 2006), BDBMS (Eltabakh et al., 2007) e MMS (Srivastava et al., 2007). Esses projetos utilizam a proveniência para manter o registro de onde o dado se originou, e não as etapas pelas quais os dados foram processados.

Em (Álvarez et al., 2006), a aplicação da proveniência se deu no contexto da administração e distribuição de transplante de órgãos. $O$ trabalho descreve o desenvolvimento de uma arquitetura orientada a serviços usando proveniência em 
sistemas médicos para auxiliar no processo de decisão de um transplante. Os autores ressaltam a necessidade de rastrear a origem das decisões e as etapas dos processos médicos realizados em cada paciente de transplante. Nesse trabalho, a proveniência foi usada para ajudar a determinar o autor envolvido em um importante procedimento médico (por exemplo, a decisão médica de uma morte cerebral), fornecendo uma interface integrada com o histórico médico de pacientes (como a disponibilização dos procedimentos médicos realizados em uma ou várias instituições). Os autores ressaltam que a utilização da proveniência tornou viável a realização de auditorias no sistema e permitiu que análises do desempenho do serviço de saúde fossem feitas.

O sistema EUROTRANSPLANT (International Foundation, www.eurptransplant.nl) é um trabalho similar àquele apresentado por Álvarez et al. (2006). Nesse sistema, todas as informações e decisões que são tomadas em um servidor central estão centralizadas. Também promove o registro de todas as atividades em um sistema padrão de registros, e as distribui. Além disso, combina tipos de tecnologias distintas para auxiliar no processo de tomada de decisões como apoio aos centros de transplante de órgãos.

$\mathrm{O}$ interesse em usar proveniência tem crescido, em especial pela comunidade de e-Science e até mesmo pela Bioinformática. Isso se deve ao fato de proveniência ter sido percebida como um componente importante para diversos tipos de tecnologias, como as baseadas em Sistemas Operacionais, Processos, mas é especialmente empregada naqueles baseados em workflow. Nesse último, sua finalidade é garantir que cientistas sejam capazes de reproduzir seus experimentos propiciando análises mais eficientes (Moreau et al., 2007). 
No que diz respeito à aplicação de proveniência voltada para descrição, classificação, extração do conhecimento e análise de dados para sistemas de informação de hemoterapia é novo. Sabe-se que as técnicas para obter a proveniência podem ser aplicadas em diferentes campos. Entretanto, é importante evidenciar que a organização e o tipo dos dados são particulares a cada domínio e, ter amplo conhecimento do contexto ao qual será aplicado (como, banco de dados, conjunto de dados e, principalmente, os processos de aquisição e tratamento dos dados) é fundamental para descrever sua proveniência (Almeida et al., 2010).

\subsubsection{Proveniência do Conhecimento}

Como já foi discutido nas sessões anteriores, atualmente cresce a necessidade dos grupos de pesquisa em determinar de onde provem a informação. Isso é importante para determinar a confiabilidade e permitir que o pesquisador raciocine sobre um determinado conjunto de dados. Todavia, fica cada vez mais evidente a importância de se obterem explicações sobre as etapas e regras (ou raciocínios) empregadas para se chegar a uma resposta ou conhecimento. Com isso, o usuário poderá saber quais manipulações foram feitas e de onde foram retiradas as informações. Assim, a proveniência do conhecimento foi criada para registrar as regras e raciocínios usados no processo de derivação de um conjunto de dados.

O termo proveniência do conhecimento (do inglês, Knowledge Provenance) é análogo à terminologia proveniência de dados (Silva et al., 2003). Essa abordagem inclui a fonte da chamada meta-informação, que se fundamenta em obter a descrição da origem de parte do conhecimento e o processo do conhecimento da informação. Isso 
inclui a descrição do método de raciocínio usado para gerar uma resposta (Silva et al., 2003). Entretanto, a proveniência do conhecimento inclui informações, como se fossem provas, a respeito do processo pelo qual o conhecimento chegou a uma base de conhecimentos. Esse processo pode incluir todo o raciocínio empregado para gerar informações conclusivas. Todavia, proveniência e proveniência do conhecimento têm as mesmas preocupações e motivações, diferindo quanto ao objetivo do registro que será capturado (Silva et al., 2003).

A proveniência do conhecimento propicia dois aspectos. Um, contendo a visão pessoal e mais abstrata sobre um documento e suas derivações, e outro, com uma compreensão mais específica de domínio de processamento dos dados ou do seu processo de execução (Stevens et al., 2007). O primeiro aspecto está ligado especificamente ao experimento e à pessoa e, conta com a contribuição direta do cientista. Já no segundo, pode receber contribuições advindas tanto do cientista como dos curadores da anotação sobre um dado (Stevens et al., 2007).

A proveniência do conhecimento dirigida a experimentações in silico deve conter informações o bastante para recriar esse experimento. Ela deve também permitir que o experimento seja validado e verificado pelas várias partes envolvidas no mesmo e na exploração dos dados. Portanto, é necessário que a proveniência contenha o mínimo de informações para a anotação de um experimento de bioinformática (Stevens et al., 2007). Assim, o conhecimento a respeito de um experimento in silico é uma abordagem significantemente importante para a administração do conhecimento na Bioinformática (Stevens et al., 2007). 


\subsection{Anemia em Doadores de Sangue}

A alta prevalência de anemia na população mundial tem sido motivo de preocupação para as organizações governamentais. A Organização Mundial da Saúde (OMS) publicou em 1989 uma monografia, baseada em estudos iniciados em 1968 e intitulada "Preventing and Controlling Iron Deficiency Anemia Through Primary Health Care", na qual se refere à deficiência de ferro como a causa mais comum de anemia nutricional. Em 1993, a OMS passou a considerar a carência de ferro como problema central e anemia como um indicador desse problema. Uma publicação proveniente de um encontro realizado, no ano de 1999, com integrantes da UNICEF (United Nations International Children's Emergency Fund), UNU (United Nations University), OMS e MI (Micronutrients Initiative), mostrou que 3,5 bilhões de pessoas em todo o mundo apresentam anemia por deficiência de ferro e que essa deficiência pode estar presente em 80\% da população mundial (Stolzfus et al., 2001).

Mais recentemente, a deficiência de ferro acompanhada ou não de anemia, foi responsabilizada por determinados eventos adversos. Foram encontradas na literatura atual referências a uma grande diversidade de patologias relacionadas com a deficiência de ferro e, no ano 2000, na África do Sul, 7,3\% das mortes pré-natais e 4,9\% das mortes maternas foram atribuídas à anemia por deficiência de ferro (Nojilana et al., 2007). Outro estudo realizado na Universidade de Toronto, no Canadá, revelou que crianças com anemia por deficiência de ferro sem associação com outras patologias apresentaram uma incidência 10 vezes maior de acidentes vasculares cerebrais do que o grupo controle (Maguire et al., 2007). A síndrome dos pés inquietos parece estar associada à deficiência 
de ferro e baixos níveis de ferritina no líquor (ou fluido cerebrospinhal) (Clardy et al., 2006).

A espoliação crônica de ferro é uma complicação bem caracterizada na doação regular de sangue. Uma bolsa de sangue coletada contém $500 \mathrm{ml}$ de sangue, se for considerado que ela possui aproximadamente $250 \mathrm{mg}$ de ferro e, assumindo que $1 \mathrm{ug} / \mathrm{L}$ de ferritina corresponde a 8mg de ferro estocado, esses estoques serão consumidos em uma única doação em indivíduos com ferritina abaixo de 32 ug/L e não serão repostos em um pequeno período apenas com dieta.

$\mathrm{Na}$ Dinamarca, por exemplo, a quantidade de ferro ingerida diariamente por meio da dieta varia de $15 \mathrm{mg}$ a $20 \mathrm{mg}$. Se a absorção for máxima (20\%), 3 a $4 \mathrm{mg} /$ dia serão absorvidos. Descontando o equivalente a $0,9 \mathrm{mg}$ (referente a quantidade diária de ferro perdida pelos homens) o ganho efetivo de ferro seria de 2,1 a 3,1 mg/dia. Portanto, após uma única doação de sangue, na qual 250 mg de ferro são perdidos, serão necessários de 80 a 119 dias para reposição da quantidade retirada (Milman et al., 1983; Sondergaard et al., 1984).

Os bancos de sangue têm investido muito na valorização dos doadores como forma de retribuir e incentivar as doações. Dentro desse cenário está o apoio aos doadores recusados por apresentarem sorologia positiva (como doenças que podem ser transmitidas pela transfusão sanguínea) ou por apresentarem níveis de hemoglobina ou hematócrito abaixo dos padrões permitidos para doação.

Para realizar um programa que possa orientar e tratar doadores recusados por apresentarem anemia no procedimento da triagem é necessário, inicialmente, estabelecer os valores que definem deficiência de ferro e anemia. Os parâmetros mais utilizados para 
avaliar os estoques de ferro são: ferritina e saturação de transferrina e, nível de hemoglobina/hematócrito no sangue. Este último é mais empregado para avaliar a presença de anemia em candidatos a doações de sangue.

A concentração de hemoglobina no sangue varia de acordo com o sexo e idade do indivíduo e, também pode variar de acordo com a altitude. Por isso, os valores de referência para determinar anemia foram estabelecidos tomando como base o nível do mar. De acordo com a OMS, anemia em indivíduos adultos é definida como sendo a concentração de hemoglobina abaixo de $13 \mathrm{~g} / \mathrm{dl}$ em homens e $11 \mathrm{~g} / \mathrm{dl}$ e $12 \mathrm{~g} / \mathrm{dl}$ em mulheres grávidas e não grávidas, respectivamente. Já, segundo Lee (1998a e 1998b), no nível do mar os limites de hemoglobina que indicam anemia são inferiores a $14 \mathrm{~g} / \mathrm{dl}$ para homens e $12 \mathrm{~g} / \mathrm{dl}$ para mulheres.

O mesmo acontece com os níveis de ferritina. Milman et al. (1983) realizaram um trabalho no qual compararam os níveis de ferritina e os depósito de ferro na hemossiderina da medula óssea de 53 pessoas normais de ambos os sexos, dos quais 16 eram doadores de sangue. A conclusão desse trabalho foi que existe correlação clara entre os níveis de ferritina sérica e os depósitos medulares de ferro, sendo que os depósitos de ferro estavam ausentes ou diminuídos em todos os indivíduos com ferritina menor que 15 ug/L, enquanto os depósitos de ferro medular estavam normais em todos com ferritina maior que $30 \mathrm{ug} / \mathrm{L}$. No intervalo entre 15 a $30 \mathrm{mg} / \mathrm{L}$ de ferritina, havia tanto indivíduos com estoques normais como reduzidos.

Embora tenha mostrado de maneira evidente a correlação entre os valores de ferritina e os estoques de ferro, Milman et al. (1983) comenta que não há consenso entre os pesquisadores sobre qual é o valor de corte que delimita a deficiência evidente dos 
estoques de ferro da ausência desses depósitos. Para Cook et al. (1992) o valor crítico é de 12 ug/L. Já, Milman et al. (1983) e Worwood (1996) argumentam que o valor de corte é $15 \mathrm{ug} / \mathrm{L}$ e finalmente Halberg et al. (1991) consideram $16 \mathrm{ug} / \mathrm{L}$ como o valor a ser considerado para definir a ausência dos estoques de ferro (Milman et al., 1998). Para a OMS o valor de referência da ferritina é de $30 \mathrm{ug} / \mathrm{L}$ (Milman et al., 1998).

Previamente a todas as doações de sangue, a concentração de hemoglobina e/ou hematócrito do candidato à doação de sangue deve ser determinada em uma amostra de sangue obtida no dia da doação. Os objetivos desse teste são: (i) impedir a doação de sangue de indivíduos anêmicos e; (ii) assegurar uma concentração mínima de hemoglobina no sangue doado. Esses cuidados garantem uma dose terapêutica satisfatória para o receptor na unidade coletada.

No Brasil, a Portaria RDC 153 de julho de 2004 regida pelo Ministério da Saúde, estabelece os valores mínimos aceitáveis de hemoglobina e hematócrito para uma doação de sangue (Mendrone et al., 2009). Tais valores são: $13 \mathrm{~g} / \mathrm{dl}$ de hemoglobina e 39\% de hematócrito para homens e $12,5 \mathrm{~g} / \mathrm{dl}$ de hemoglobina e $38 \%$ de hematócrito em mulheres. Na mesma Portaria, o Ministério da Saúde também determinou o intervalo mínimo que deve ser respeitado entre as doações de sangue. Esse intervalo deve ser de oito semanas e de doze semanas para homens e para mulheres, respectivamente.

No trabalho apresentado por Milman \& Sondergaard (1984), os autores analisaram 1.348 doadores do sexo masculino, sendo 72 doadores de primeira-vez (indivíduos que efetuaram apenas uma única doação de sangue) e os demais com 1 a 100 doações anteriores. Inicialmente, eles compararam doadores de primeira-vez e doadores com até quatro doações em um ano. Nesse grupo, não houve diferenças significativas 
entre os valores médios de ferritina nos doadores de primeira-vez, quando comparado com doadores com uma ou duas doações anteriores. Entretanto, foi observada diferença significativa entre esses dois grupos e a média de ferritina nos doadores com três ou mais doações anteriores $(\mathrm{p}<0.001)$. Valores de ferritina inferiores a $15 \mathrm{ug} / \mathrm{L}$ foram encontrados somente em doadores com quatro ou mais doações. Aqueles que apresentaram valores menores que $10 \mathrm{ug} / \mathrm{L}$ foram observados em pessoas que efetuaram dez ou mais doações. No entanto, os autores não verificaram diferença relevante entre as médias da hemoglobina entre os doadores de primeira-vez e os doadores com doações anteriores. Baseado nos dados encontrados, os autores consideraram que o valor mínimo de hemoglobina de $13 \mathrm{~g} / \mathrm{dl}$, utilizado como valor de corte para doação de sangue, é baixo para a população masculina de Copenhagen, na Dinamarca. Os autores sugeriram, então, que esse valor fosse alterado para $13,8 \mathrm{~g} / \mathrm{dl}$, o qual englobaria $95 \%$ dos doadores do sexo masculino (Milman \& Sondergaard, 1984; Milman et al.,1991). Ainda de acordo com Milman \& Sondergaard (1984) e Milman et al. (1991), 1,3\% dos doadores com duas doações em um ano, e 7,9\% dos doadores com quatro doações também observados em um ano apresentaram ausência nos depósitos de ferro (ferritina $<15 \mathrm{ug} / \mathrm{L}$ ). Os autores concluíram que mais relevante que o número de doações é a frequência com que elas ocorrem.

O trabalho realizado em Chandigarh, na Índia, analisou a ferritina de acordo com a quantidade de doações feitas (Mittal et al., 2006). Foram analisados 400 doadores de sangue e divididos em quatro grupos de acordo com o número de doações no período de um ano. Assim, foram formados os seguintes grupos, zero, uma, duas e três doações anteriores. Para o grupo de doadores de primeira-vez, a porcentagem de doadores com 
ferritina abaixo de $15 \mathrm{ug} / \mathrm{L}$ foi maior entre as mulheres. Nos grupos com uma, duas ou três doações anteriores, não houve diferenças significativas entre homens e mulheres. No entanto, houve um número maior de doadores com ferritina menor que $15 \mathrm{ug} / \mathrm{L}$ o grupo de estudo foi comparado com outros trabalhos. Neste sentido, foram considerados aptos para doação de sangue os candidatos voluntários com hemoglobina acima de 12,5 g/dl. Os autores concluíram que a maior porcentagem de doadores com ferritina abaixo de 15 ug/L nos doadores indianos pode ser relacionada a fatores nutricionais ou a fatores genéticos que predisponham à diminuição nos estoques de ferro (Mittal et al., 2006).

Em Lamas et al. (1994), os valores de ferritina de 500 doadores e 200 voluntários normais de ambos os sexos foram estudados. A concentração média de ferritina nos homens foi de $86 \mathrm{ug} / \mathrm{L}$ e $27,1 \mathrm{ug} / \mathrm{L}$ nas mulheres. Entre as mulheres, $14 \%$ do grupo controle versus $46 \%$ daquelas com quatro doações no período de um ano apresentaram ferritina abaixo de 15 ug/L. Para os homens, esse valor esteve presente em 14\% daqueles que fizeram quatro doações em um ano. Os autores concluíram que a deficiência de ferro ocorre tanto em homens quanto em mulheres após a primeira doação. Embora seja mais acentuada nas mulheres, uma vez que estas apresentam menores reservas de ferro. Viram também que a ferritina é o melhor marcador para avaliar os depósitos de ferro e que o método é simples. Outra observação feita foi que o teste da ferritina deve ser feito antes da primeira doação de sangue. Assim, viram que a suplementação de ferro deve ser feita para os doadores de repetição e naqueles com deficiência de ferro, em uma dose de $100 \mathrm{mg} /$ dia de sulfato ferroso por um período de 10 dias.

No artigo apresentado por Tardtong et al. (2000), foi feita a comparação dos valores de hemoglobina e ferritina sérica de 66 homens e 49 mulheres com múltiplas 
doações anteriores e com 16 homens e 23 mulheres em sua primeira doação. Os autores observaram que $8,7 \%$ das mulheres doadoras de primeira-vez apresentaram ferritina menor que 15 ug/L. Entre os indivíduos com doações anteriores, viram que 21,21\% dos homens e 32,65\% mulheres apresentaram ferritina sérica inferior a $15 \mathrm{ug} / \mathrm{L}$.

Em Cançado et al. (2001), avaliaram a presença da deficiência de ferro em 300 doadores de sangue da Santa Casa de Misericórdia de São Paulo. Nesse trabalho, procuraram estabelecer a frequência da doação de sangue na população de doadores. Entre os doadores analisados, 31,4\% foram doadores de primeira-vez e 68,7\% já haviam feito outras doações. A deficiência de ferro foi encontrada em 5,5\% dos homens e 31,7\% das mulheres. A frequência da deficiência de ferro foi maior entre os doadores de repetição do que nos doadores de primeira-vez, tanto para os homens (7,6\% versus $0 \%)$ quanto para as mulheres (41,5\% versus $18,5 \%)$.

Em 2005, Passos et al. (2005) publicaram um estudo piloto transversal e prospectivo realizado no Hemocentro do Amazonas com 528 doadores de sangue somente para o sexo masculino. O objetivo principal do trabalho foi verificar se os doadores desenvolviam sideropenia sem a presença de anemia após contínuas doações. Os doadores foram divididos em dois grupos, um constituído por 313 doadores com quatro ou mais doações consecutivas e ininterruptas, e outro grupo usado como controle contendo 215 doadores de primeira-vez. Observou-se que o nível de ferritina abaixo de $20 \mathrm{ug} / \mathrm{L}$ estava presente em 7,4\% dos doadores de primeira-vez e em 48,6\% dos doadores de repetição $(p<0,0001)$. O nível de ferritina inferior a $12 \mathrm{ug} / \mathrm{L}$ foi encontrado em 3,7\% dos doadores de primeira-vez e em $24,9 \%$ dos doadores de repetição. Estratificando o número de doações em 4, 5-9, 9-12 e acima de 12 e o nível de ferritina menor que 12 
ug/L, a distribuição encontrada foi a seguinte, 6,9\%, 30,3\%, 20,7\% e 34,69\%, respectivamente. Os autores concluíram que a quantidade de doações é um fator importante para a depleção dos estoques de ferro em doadores de repetição do Hemocentro do Amazonas.

O estudo apresentado por Djalali et al., (2006) comparou os efeitos da doação de sangue em 91 doadores iranianos do sexo masculino com uma, duas, três e quatro doações de sangue em um mesmo ano, com os efeitos em 63 indivíduos normais (grupo controle). Os níveis de hemoglobina e ferro sérico foram maiores no grupo controle do que nos doadores e tanto a ferritina sérica quanto a hemoglobina apresentaram correlação inversa com a frequência das doações. Os autores concluíram que doadores do sexo masculino com hemoglobina maior que $14,2 \mathrm{ug} / \mathrm{L}$ e ferritina maior que $57,2 \mathrm{ug} / \mathrm{L}$ podem doar sangue uma ou duas vezes por ano, já aqueles com hemoglobina 13,1 ug/L e ferritina 37,3 ug/L podem doar apenas uma vez ao ano.

Alguns trabalhos têm mostrado os benefícios da suplementação com ferro em doadores de sangue com hemoglobina e ferritina baixas. Em Gordeuk et al. (1990), os autores compararam o efeito da administração de $100 \mathrm{mg} /$ dia de ferro carbonil e placebo em 99 mulheres doadoras de sangue. Após 56 dias, os depósitos de ferro foram recuperados em $85 \%$ das mulheres que receberam ferro ao passo que somente $29 \%$ das que receberam placebo apresentaram recuperação. Assim, os autores concluíram que a reposição de ferro em um período pequeno é capaz de recuperar os estoques de ferro perdido com a doação de sangue e protege da deficiência de ferro.

Em Radtke et al. (2004), compararam os efeitos da suplementação de ferro em doadores de repetição. Foram analisados 289 homens que realizaram quatro doações de 
sangue num período de seis meses e em 237 mulheres que realizaram três doações num período de seis meses. Os doadores de ambos os sexos foram divididos em três grupos de acordo com a dose diária de ferro administrada: $40 \mathrm{mg}, 20 \mathrm{mg}$ e $0 \mathrm{mg}$ de gluconato de ferro. Os autores observaram que $20 \mathrm{mg} /$ dia de gluconato de ferro são suficientes para repor os estoques de ferro quando as doações forem realizadas na frequência estudada.

Por outro lado, é sabido que outros fatores também podem contribuir para a redução dos estoques de ferro em doadores de sangue tais como: ingestão insuficiente de ferro, perda aguda ou crônica de sangue, gestação, lactação, dentre outros. Segundo alguns autores, a mutação G277S do gene da transferrina em homozigose ou em heterozigose também é um fator de risco para a ocorrência de deficiência de ferro. Essa é a mutação mais comum do gene da transferrina e ocorre no éxon sete resultando na substituição do aminoácido asparagina (Asp) por glicina (Gly).

\subsection{Análise de Sobrevivência}

Técnicas estatísticas conhecidas como análise de sobrevivência (Colosimo, 2006) são amplamente utilizadas quando se pretende analisar um fenômeno em relação a um período, ou seja, o tempo transcorrido entre um evento inicial, no qual um indivíduo ou o objeto entra em um estado particular, e um evento final que modifica esse estado. Assim, descrevem não somente se indivíduos vivem ou morrem como também outra conclusão, como recaída a uma doença, desmame do lactente, etc. Foram usadas técnicas de análise de sobrevivência neste trabalho para analisar e discutir os resultados e conhecimentos obtidos pelo método de proveniência proposto. 
Qualquer que seja o tipo de estudo epidemiológico, geralmente há uma variável de interesse, denominada de dependente ou resposta. Essa variável pode ser o número de casos de uma determinada doença, ou sua incidência, ou a probabilidade de ocorrência, ou ainda outra medida que pretenda descrever qual a frequência de ocorrência da doença ou de um evento. Em alguns casos, a variável dependente de interesse é o tempo decorrido até o aparecimento do evento, e neste caso pode ser incluído no estudo de análise de sobrevivência. Existem também variáveis chamadas de independentes, preditoras ou covariáveis, que quando relacionadas à variável dependente acabam se tornando o objetivo do estudo epidemiológico. Nesse contexto, a análise quantitativa é muito importante, pois os modelos estatísticos expressam a variável dependente como uma função matemática conhecida das variáveis independentes.

Nos estudos voltados para a análise de sobrevivência, os indivíduos são acompanhados ao longo do tempo até o evento (como, diagnóstico de uma doença, a realização de cirurgia, nascimento, anemia, dentre outros). Em geral, os indivíduos são incluídos no estudo em diferentes períodos de tempo. Entretanto, ao serem analisados, todos os indivíduos têm seu tempo de sobrevivência contado a partir da entrada no estudo, considerado tempo zero. A observação de cada indivíduo começa a partir de um determinado momento, sem considerar os acontecimentos passados (Cox \& Oakes, 1984). Muitas vezes, o evento final corresponde à morte, ou a alguma variação biológica, ou a um determinado evento que indique a modificação do estado inicial, como, por exemplo, cura, recorrência, retorno ao trabalho, dentre outros (Bustamante-Teixeira et al., 2006). O evento final é conhecido como falha, pois frequentemente refere-se a eventos indesejáveis como o aparecimento da doença ou morte (Kleinbaum, 1995). 
Em estudos em que há seguimento, podem existir indivíduos com seu tempo de observação incompleto, conhecido como censura (Bustamante-Teixeira et al., 2006). Isso pode ocorrer quando os indivíduos permanecem sem mudança de estado ao término do estudo, ou falecem por causas não relacionadas com a doença de interesse, ou ainda abandonam o estudo (Bustamante-Teixeira et al., 2006). Algumas vezes, a cura e/ou recuperação também podem ser consideradas como censura na observação. Uma suposição importante é a de que os indivíduos censurados em determinado tempo $t$ são representativos de todos os indivíduos que estavam sujeitos ao risco de ter falha em $t$ (Szklo \& Nieto, 2000). 


\section{Capítulo 3}

\section{Modelo de Proveniência}

Como mostrado no Capítulo 2 à utilização de workflows vem sendo muito empregada para auxiliar na captura, gerenciamento e manipulação de proveniência de dados em diferentes projetos de pesquisa. Na maioria dos casos, os dados da proveniência são usados para validar resultados de experimentações in silico, recuperar a origem de um dado, ou até mesmo auxiliar no processo de decisões importantes na área médica (Silva et al., 2003; Álvarez et al., 2006). Foi mostrado também que muitos trabalhos estão empenhados em desenvolver modelos padronizados para descrever a proveniência de dados. Todavia, não há um modelo genérico que possa ser aplicado para a descrição da derivação dos dados ou de processos em qualquer tipo de abordagem. Isso é decorrente dos requisitos específicos que muitos trabalhos apresentam.

O OPM (Open Provenance Model) demonstrou ser o modelo mais abstrato dentre os apresentados no Capítulo anterior. Entretanto, sua utilização esta mais voltada à integração de fontes de dados heterogêneas e que possuam aplicações $W e b$, o que não é o caso desta tese. A intenção aqui não é propor um modelo genérico de proveniência de dados para registros da Fundação Pró-Sangue (FPS) e sim demonstrar a importância da 
descrição das etapas de processamento aplicadas aos dados para a obtenção de respostas mais confiáveis e conclusivas.

É sabido que o banco de dados da FPS não passou por processos de normalização e por isso está mais vulnerável a inconsistências de dados. A Figura 3.1 exemplifica alguns dos problemas encontrados nesse banco de dados. Para evitar que os erros herdados das fontes comprometessem a confiabilidade dos dados, foram desenvolvidos procedimentos com o objetivo de garantir sua precisão. A seleção de atributos é um procedimento que pode assegurar a precisão dos dados. Por isso, é importante utilizar apenas atributos nos quais os registros apresentam-se mais confiáveis, a fim de obter-se um conjunto de dados com maior qualidade.

Seleção dos Atributos. O banco de dados da FPS possui 23 atributos disponibilizados na tabela de triagens. Entretanto, nem todos possuem relacionamento com o tema desta pesquisa. Por isso, foram pré-selecionados somente atributos que podem conter dados significativos para este trabalho, são eles: sexo, raça, peso, altura, escolaridade, data da doação (composta de dia, mês e ano), tipo de doação e valores no teste de anemia (composta dos valores tanto de hematócrito - Hct quanto dos de hemoglobina - $\mathrm{Hb}$ ). Em seguida, foram estabelecidas ações para quantificar os dados armazenados em cada atributo. Assim, para verificar quais atributos estão mais adequados para serem analisados foram definidas duas medidas, dados úteis e confiabilidade. $\mathrm{Na}$ medida dados úteis é calculada a fração de entradas válidas em um atributo, isto é, as entradas que não são nulas. Já a confiabilidade tenta estimar quão subjetivo é um atributo. Nessa medida, é considerado apenas o modo como os dados foram coletados. Nesses casos, os atributos declarados apenas pelo indivíduo e não verificados são 
considerados mais subjetivos. Com essas medidas, foi possível chegar aos resultados apresentados na Tabela 3.1 para os atributos pré-selecionados.

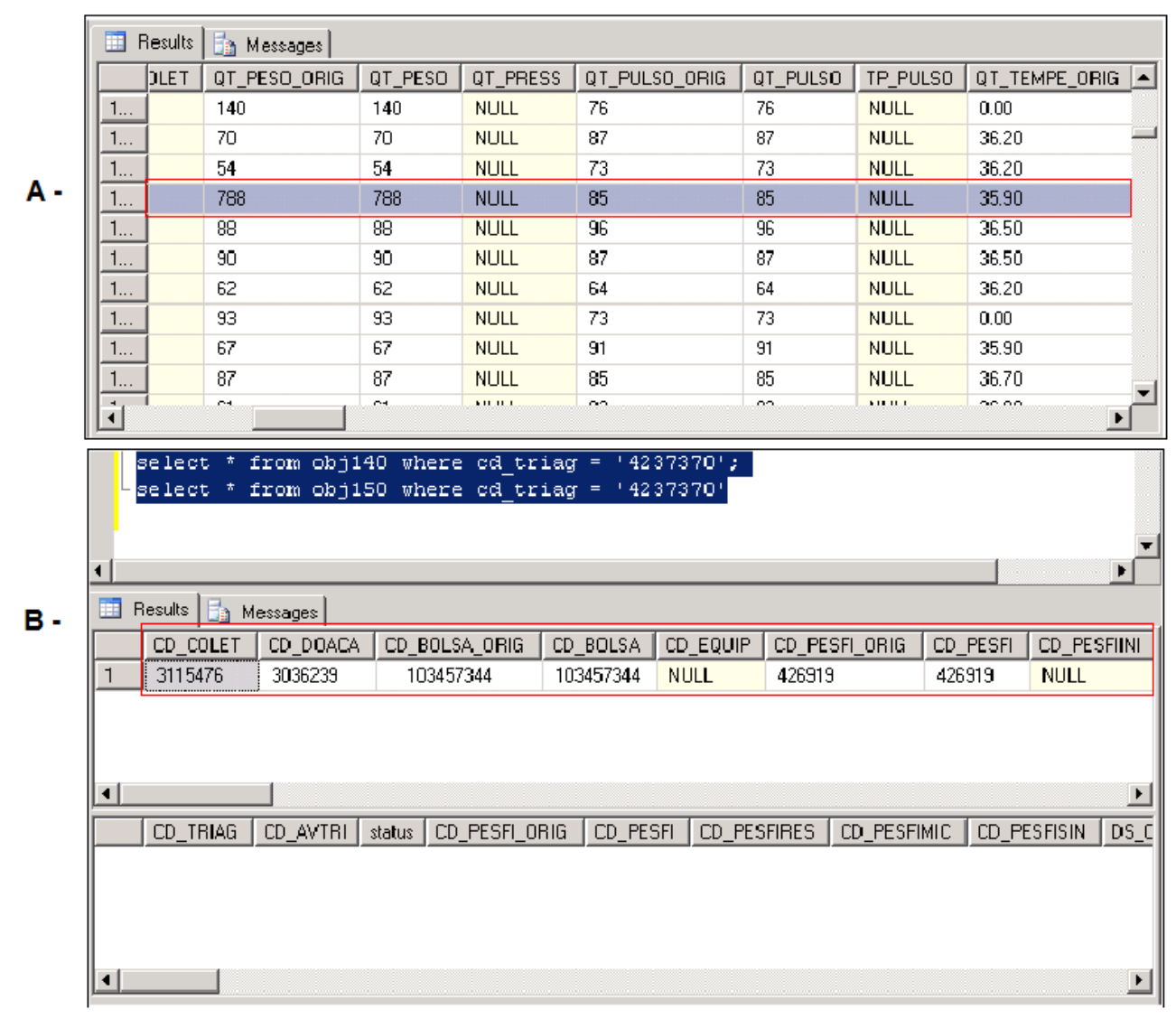

Figura 3.1. Exemplos de problemas recorrentes no banco de dados de doadores de sangue. (A) Erro de digitação na tabela 'qtpeso' (que armazena o peso dos indivíduos). $\mathrm{O}$ indivíduo apresenta um peso de $788 \mathrm{Kg}$, o que demonstra um erro grosseiro de digitação; (B) Exemplo de inconsistência. Neste caso, um indivíduo esta presente na tabela de doadores ('cd_doacao'), entretanto, não há nenhum registro do mesmo na tabela de triagens ('cd_triagem'). Isso não pode acontecer já que todos os indivíduos, obrigatoriamente, passam pela triagem antes de efetuar uma doação.

Como os atributos receberam classificação por meio de índices apresentados na Tabela 3.1, aqueles com dados úteis "maiores ou iguais" a $80 \%$ e que tiveram confiabilidade "alta" foram selecionados. Após esses procedimentos iniciais, foram 
projetadas e implementadas rotinas de tratamento, limpeza, normalização e extração dos dados. Nessas rotinas, foram considerados inválidos registros cujos valores apresentaram alguma irregularidade ou com problemas de acordo com os pesquisadores FPS. Um exemplo disso pode ser visto nos atributos que armazenam os valores de $\mathrm{Hct}$ e $\mathrm{Hb}$. Durante o período desse estudo a FPS usou dois métodos para verificar aptidão para uma doação de sangue; são eles, HemoCue, aplicado de 1996 a 2002 para medir Hb e o método de micro-hematócrito, adotado a partir de 2003 e usado até os dias de hoje. Esse último mede a porcentagem de Hct no sangue. Tais níveis são considerados inválidos quando o Hct está inferior a $30 \%$ e maior que $50 \%$, e quando o Hb está menor que $10 \mathrm{~g} / \mathrm{dl}$ e maior que $18 \mathrm{~g} / \mathrm{dl}$. Em tais casos, verificou-se que cerca de $0,89 \%$ do total das entrada de dados apresentaram registros inválidos para aqueles atributos. Isso viabilizou a remoção das triagens somente quando os dois campos (Hct e $\mathrm{Hb}$ ) apresentaram os valores com problema.

Tabela 3.1. Dados úteis e confiabilidade dos atributos pré-selecionados para análise.

\begin{tabular}{ccc}
\hline Atributo & Dados Úteis (\%) & Confiabilidade \\
\hline Sexo & 99,99 & Alta \\
\hline Raça & 52 & Baixa \\
\hline Escolaridade & 4,5 & Baixa \\
\hline Tipo de doação & 80 & Alta \\
\hline Dia da visita & 99,9 & Alta \\
\hline Mês da visita & 99,9 & Alta \\
\hline Ano da visita & 99,9 & Alta \\
\hline Peso & 92,5 & Baixa \\
\hline Altura & --- & Baixa \\
\hline Hematócrito & 89,9 & Alta \\
\hline Hemoglobina & 81,89 & Alta
\end{tabular}


Em uma análise descritiva, foi observado que para os mais de dois milhões de triagens analisadas, aproximadamente 218 mil registros apresentaram valores inválidos no atributo 'peso'. Apesar disso representar apenas 7,5\% do total do banco de dados (que tem mais de 2.8 milhões de dados registrados), optou-se pela exclusão dessa variável. Isso se deu, pois, apesar do atributo 'peso' apresentar um índice elevado de dados úteis, 92,5\%, o mesmo contém dados muito subjetivos (Tabela 3.1). Nesse caso, como o indivíduo não é pesado acaba tornando o atributo pouco confiável. O mesmo aconteceu com os atributos 'raça', 'peso'e 'escolaridade'.

O $1^{\circ}$ processo, "Seleção dos Dados - DS\#1", tem a finalidade de consultar o banco de dados e selecionar registros referentes ao período a ser estudado, neste caso de 1996 a 2006 (Figura 3.3). O $2^{\circ}$ processo, "Etapa de Transformação do Conjunto de Dados - DS\#2" é composto por um conjunto de atividades que possuem a finalidade de limpar e transformar os dados selecionados. A FPS possui uma considerável heterogeneidade de dados, e isso acontece devido à gradual substituição dos tipos de procedimentos aplicados na doação, desde a chegada do candidato a doação até a coleta do sangue. Nesta etapa além da remoção de registros inválidos de Hct e Hb também foram implementadas rotinas destinadas a: calcular a idade do indivíduo no dia de sua ida ao hemocentro; calcular o intervalo entre as doações de sangue, no qual foram calculados os intervalos de retorno ao hemocentro e; calcular a frequência de doação. Todos esses dados foram inseridos nos históricos. Entretanto, foram descartados do conjunto de dados indivíduos menores de 18 anos e com idade superior a 69 anos e, também calculada a quantidade de doações feita por cada doador. 


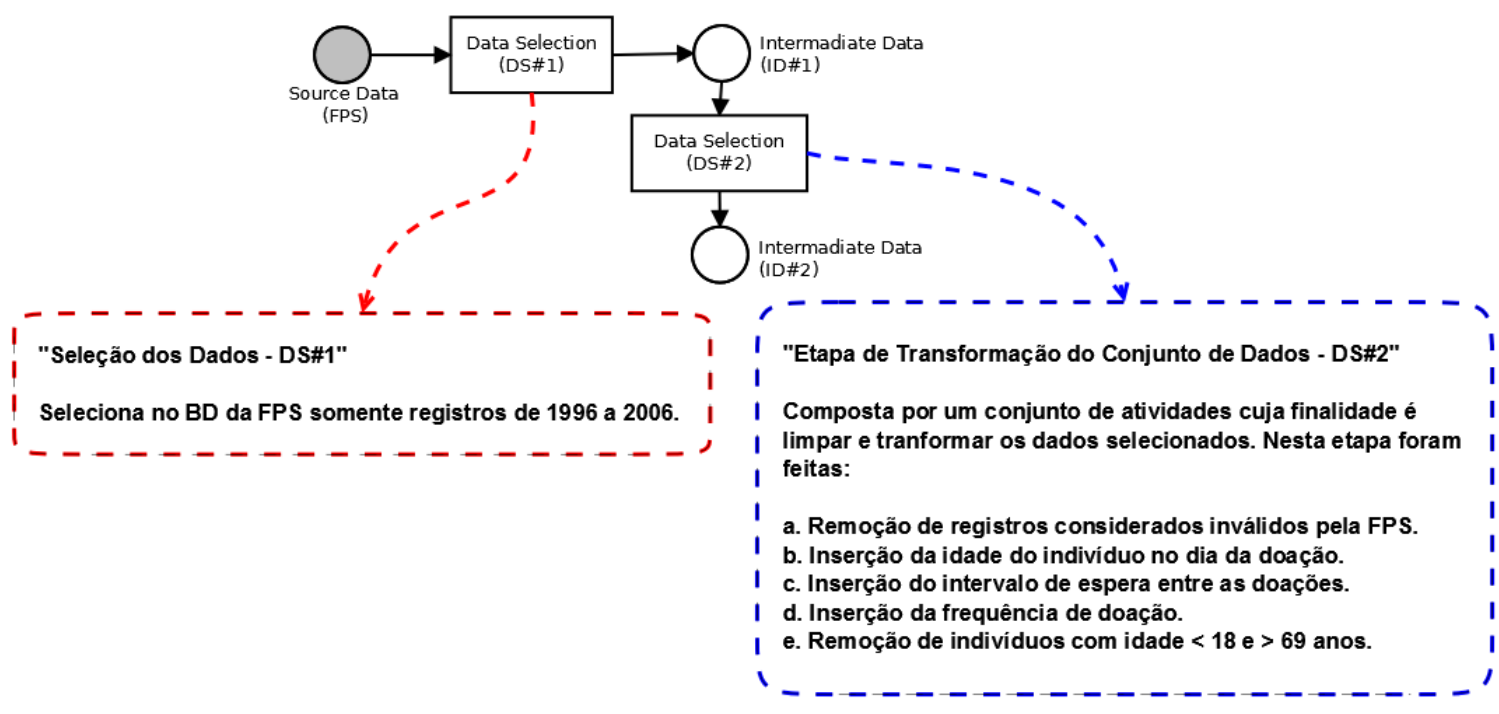

Figura 3.2. Grafo direcionado das atividades "Seleção de Dados - DS\#1" e "Etapa de Transformação do Conjunto de Dados - DS\#2". Os retângulos representam as atividades e os círculos representam os conjuntos de dados.

$\mathrm{O} 3^{\circ}$ processo refere-se a "Aplicação de filtros" e é demonstrado na Figura 3.3. Os filtros são alternativas criadas para representar os questionamentos e conceitos definidos pelos pesquisadores da FPS. Esses questionamentos representam os estágios de transformação e separação dos dados e também fazem parte de um conjunto de critérios usados para classificação. Nesse sentido, pode-se identificar caracterizar e separar o conjunto de dados de interesse, permitindo que análises mais confiáveis sejam feitas sobre dados curados.

Para representar o conjunto de requerimentos usados neste trabalho, foi feito um diagrama de atividades e dados. Esse digrama foi provido das informações e dos procedimentos que foram aplicados aos dados. A Figura 3.3 ilustra o diagrama criado para representar as principais características observadas e os conceitos que foram empregados na implementação do modelo de atividades (workflow) desenvolvido para 
este trabalho. Esse diagrama desconsidera particularidades de implementação e dá ênfase ao tipo de dados e ao ponto de vista do usuário criador do dado. Para a descrição da proveniência também foram usados critérios de separação e classificação desses dados. Esses critérios foram baseados em questionamentos, conceitos e raciocínios feitos pelos pesquisadores da FPS (descritos nas próximas seções).

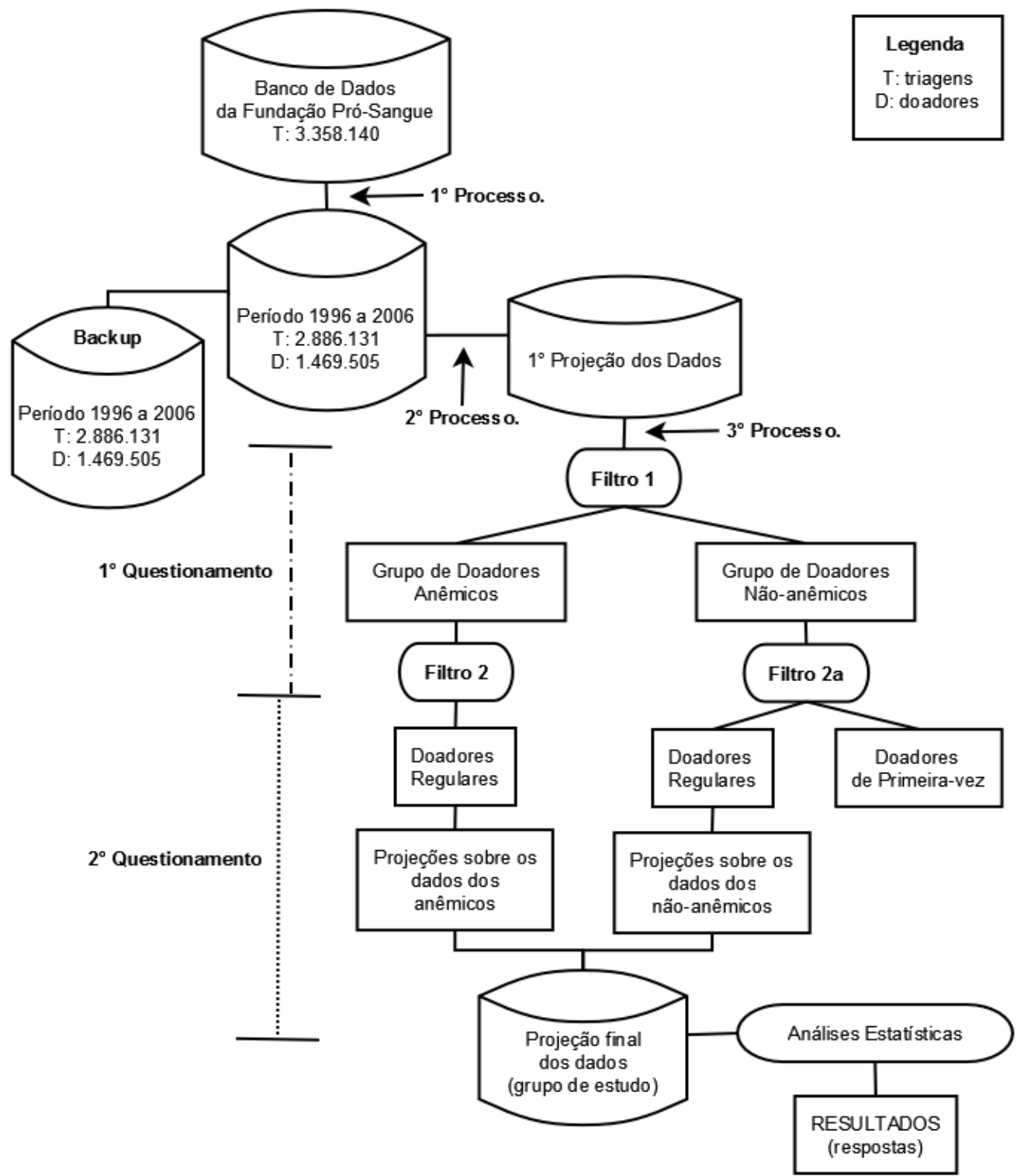

Figura 3.3. Diagrama de atividades e dados desenvolvido especificamente para o domínio de doadores de sangue da FPS. 


\subsection{Classificação dos Dados}

A contribuição dos pesquisadores neste tipo de experimento é estritamente necessária para auxiliar no processo de descrição dos dados. Suas observações sobre os dados além de auxiliarem nos processos de auditoria e validação também propiciam a geração de classes bem definidas. Com isso, a descrição da proveniência foi adotada para não somente auxiliar nos processos de limpeza e transformação dos dados de forma clara e precisa, mas também para permitir o controle de cada etapa do processamento dos dados. O que viabiliza a reexecução do experimento ou de qualquer atividade sempre que for necessário. Outro aspecto igualmente importante é o de assegurar que o armazenamento dos dados advindos de cada processo facilite sua auditoria. Todavia, esta tese não é composta somente dos processos que descrevem dados e capturam sua proveniência. A intenção é usar a descrição da proveniência para auxiliar no desenvolvimento de critérios de classificação dos dados, usando os conceitos semânticos que embasam os questionamentos.

Diferente dos métodos de classificação como seleção de características, SVM, dentre outros que são amplamente utilizados na área de reconhecimento de padrões, a técnica apresentada aqui consiste basicamente da criação de classes baseada em questionamentos. O método tem a intenção de definir uma estrutura que ajude na classificação e predição de amostras desconhecidas. Com base nos registros do conjunto de treinamento, foram adicionadas perguntas, e assim pode-se classificar a amostra sem a necessidade de testar todos os valores de seus atributos. Vale salientar que somente foram usados atributos previamente selecionados. Tais questionamentos constituem-se de 
decisões tomadas para a classificação do comportamento dos dados de acordo com critérios distintos. O intuito aqui é estabelecer classes de forma supervisionada e, essa supervisão é feita pelo próprio pesquisador. Para isso, foi necessário fazer um levantamento dos requisitos que são considerados indispensáveis para a classificação dos dados.

Com a eliminação das características menos representativas, eliminam-se também atributos que podem induzir a análises errôneas. Essa abordagem visa a gerar e avaliar padrões ou classes que tendem a causar um fato específico. Tendo isso em mente, foi observado que a adoção de tarefas computacionais aliadas ao conhecimento empírico dos especialistas em lidar com incertezas decorrentes da similaridade entre classes é fundamental. Assim, o objetivo aqui é estruturar um modelo, no qual cada processo e critérios de inclusão foram definidos para indicar os questionamentos ou consultas sobre um conjunto de dados. A escolha da declaração foi feita com base no maior ganho da informação, ou seja, na qualidade de classificação em cada pergunta. Com isso é permitido afirmar que o questionamento que melhor classifica os dados foi escolhido. $\mathrm{O}$ que foi feito aqui foi uma tentativa de emular o conhecimento humano, no caso dos pesquisadores da FPS. A abordagem utilizada tenta gerar e avaliar padrões ou classes com tendência a ocasionar um determinado fato e seus dados auxiliares visando às perguntas feitas para a classificação de potenciais grupos de doadores de sangue. Para cada pergunta foram implementadas rotinas cuja finalidade é extrair os dados requeridos, após cada extração os dados passaram por um processo de validação. A validação contou com análises descritivas do conjunto de dados gerado, como: média, variância, desvio padrão, porcentagem individual de doadores. Em cada etapa os resultados foram apresentados aos 
especialistas que analisaram e validaram os mesmos. Caso o processo fosse reconhecido como falho (que não apresenta resultados satisfatórios), foi feita a identificação dos prováveis erros. Em seguida, foi feito o rastreamento desses erros a fim de identificar em qual etapa ele foi introduzido ou não retirado. Para esse processo, foi usada a descrição da proveniência. Assim, quando um erro é identificado, uma nova rotina pode ser feita ou ajustada a fim de se adequar melhor ao tipo de pergunta estabelecida. Somente assim foi possível obter classes de doadores de sangue, denominadas de populações.

\subsubsection{Critérios de Inclusão}

Como foi mencionado anteriormente, o processo de descrição da proveniência é baseado em perguntas semânticas, isto implica que a sua construção foi baseada em questionamentos previamente determinados, são eles:

$1^{o}$ questionamento: "Qual a população de doadores de sangue que pode ser considerada de risco para o desenvolvimento de anemia ferropriva decorrente de múltiplas doações de sangue?".

$2^{o}$ questionamento: "Qual é o número de doações ou intervalo entre estas doações que aumentam as chances de deixar o(a) doador(a) com risco de desenvolver anemia?".

Entretanto, tais questionamentos não podem ser respondidos por meio de simples consultas ao banco de dados. Como uma forma de auxiliar na obtenção de respostas os questionamentos foram fragmentados em regras (Figura 3.4). Cada regra gerada compõe o critério de inclusão que puderam então ser implementados. 


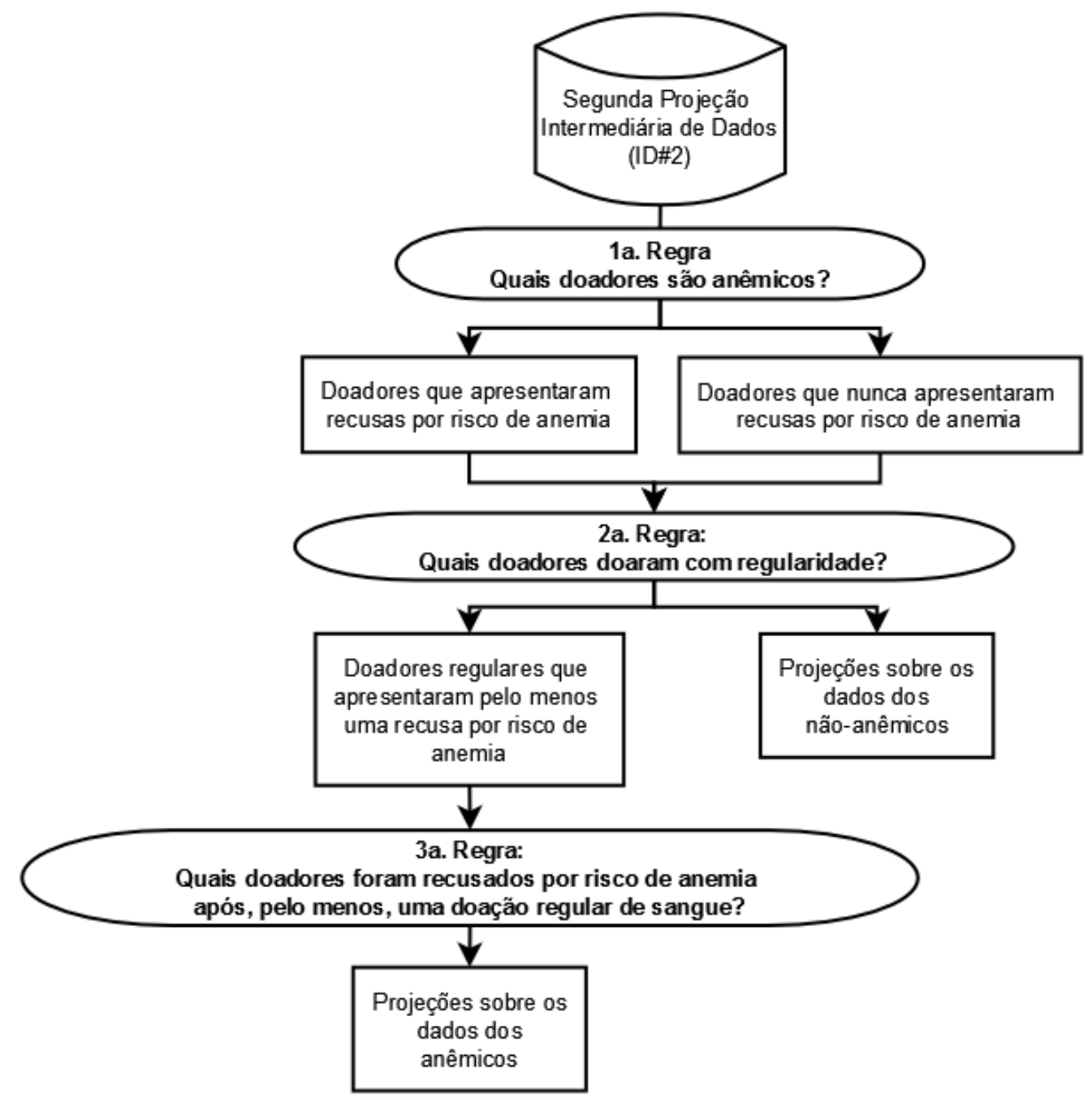

Figura 3.4. Diagrama que representa o conjunto de regras que (critérios de inclusão) e populações esperadas.

$1^{0}$ Critério de Inclusão. O primeiro critério de inclusão foi desenvolvido para classificar e separar os doadores entre anêmicos e não-anêmicos. Para essa classificação foi adotada a Portaria RDC 343 de Dezembro de 2002 regida pelo Ministério da Saúde que determinou os valores de corte (cut off) para Hct e Hb. Para homens o cut off 39\% para Hct e/ou 13g/dl para Hb, já para mulheres o cut off é $38 \%$ para Hct e $12,5 \mathrm{~g} / \mathrm{dl}$ para $\mathrm{Hb}$ (Agência Nacional de Vigilância Sanitária; Mendrone et al., 2009). Doadores que 
apresentaram índices abaixo dos valores de corte foram considerados doadores com baixo $\mathrm{Hct}$ ou $\mathrm{Hb}$ (que será referido aqui como LHct/Hb, do inglês low Hct/Hb). Neste trabalho, os termos "anêmico" e "não-anêmico" serão usados de forma didática. São apenas nomenclaturas adotadas para nomear os grupos de doadores de sangue. Com isso, não há relacionamento entre o termo adotado e o significado médico. Assim, o termo anêmico foi empregado para referir-se a indivíduos que apresentaram LHct/Hb. Por outro lado, o termo não-anêmico referir-se-á aos doadores que sempre apresentarão níveis aceitáveis de Hct ou $\mathrm{Hb}$ para doação. Após essa etapa, foi usada uma fórmula de conversão de $\mathrm{Hb}$ para Hct (Equação 1) a fim de normalizar os registros desses atributos:

$$
H c t(\%)=H b(g / d l) * 3
$$

Assim, conta-se apenas com um tipo de registro e ele independe do período no qual o dado foi coletado (P\#1 da Figura 3.5).

No primeiro período deste estudo (1996 - 2002), as mulheres com $\mathrm{Hb}$ entre 12,5 g/dl a 12,66 g/dl seriam elegíveis para doação de acordo com os critérios de aptidão para doação. Entretanto, foram incluídas no grupo de anêmicos, pois tais casos quando convertidos para Hct são inferiores a $38 \%$. Para o sexo masculino isso não aconteceu porque $13 \mathrm{~g} / \mathrm{dl} * 3$ é igual a $39 \%$. 


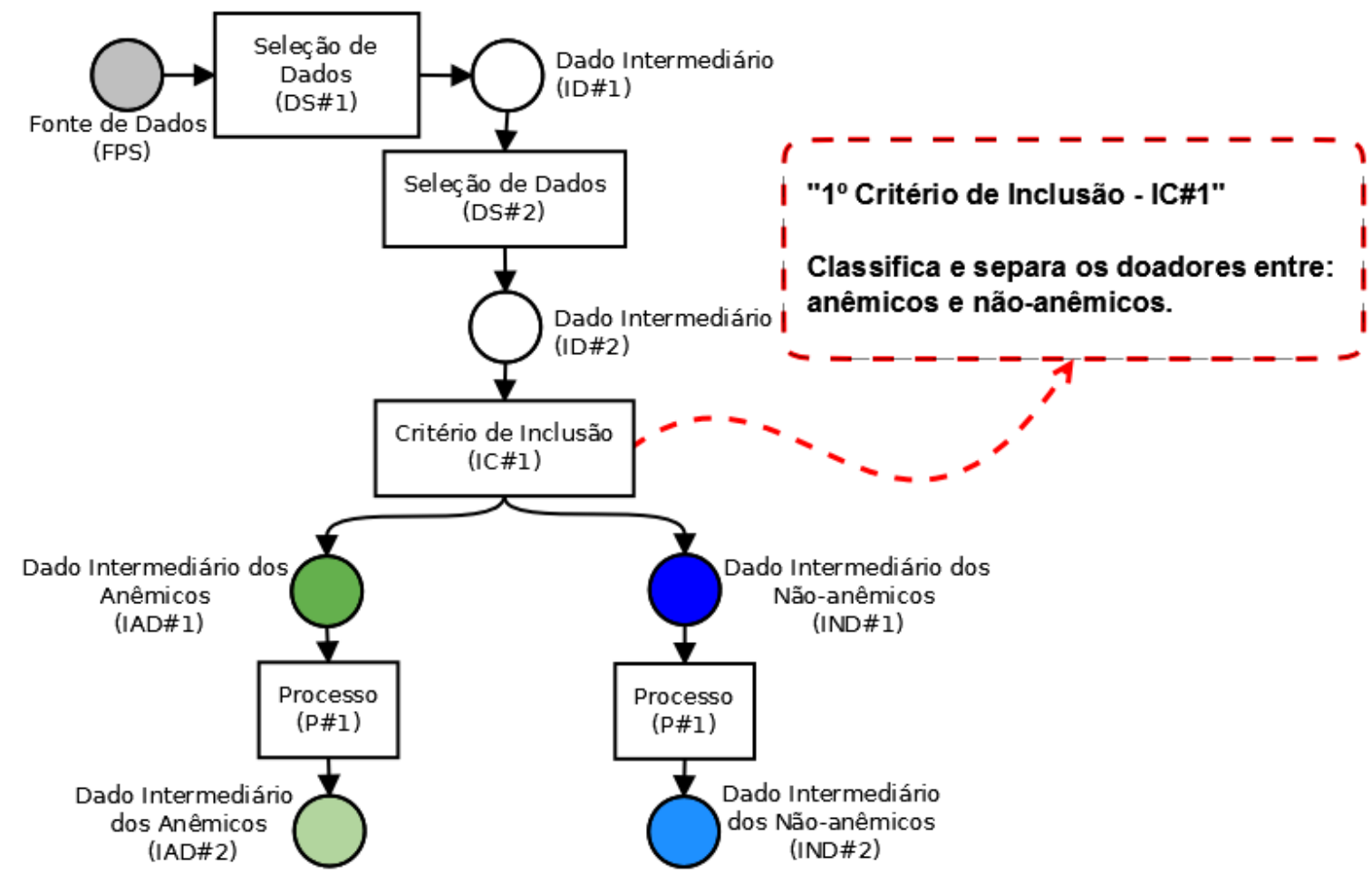

Figura 3.5. Grafo acíclico direcionado para representar o primeiro critério de inclusão (IC\#1) e o processo (P\#1) criado para transformar $\mathrm{Hb}$ em Hct. Os retângulos representam as atividades e os círculos representam os conjuntos de dados intermediários.

$2^{\circ}$ Critério de Inclusão. O segundo critério de inclusão é baseado na $2^{\circ}$ regra da Figura 3.4 e usa a frequência de doações para formar subgrupos de doadores anêmicos e nãoanêmicos. Nessa etapa os doadores foram diferenciados de acordo com a regularidade que doaram sangue. Assim, foram considerados doadores regulares aqueles indivíduos que efetuaram duas ou mais doações (frequência de doação $\geq 2$ ) (Figura 3.6). Com isso, foi possível classificar os doadores regulares e os doadores de primeira-vez, que são pessoas que, independente do número de visitas ao hemocentro e das recusas, executaram uma única doação de sangue. 


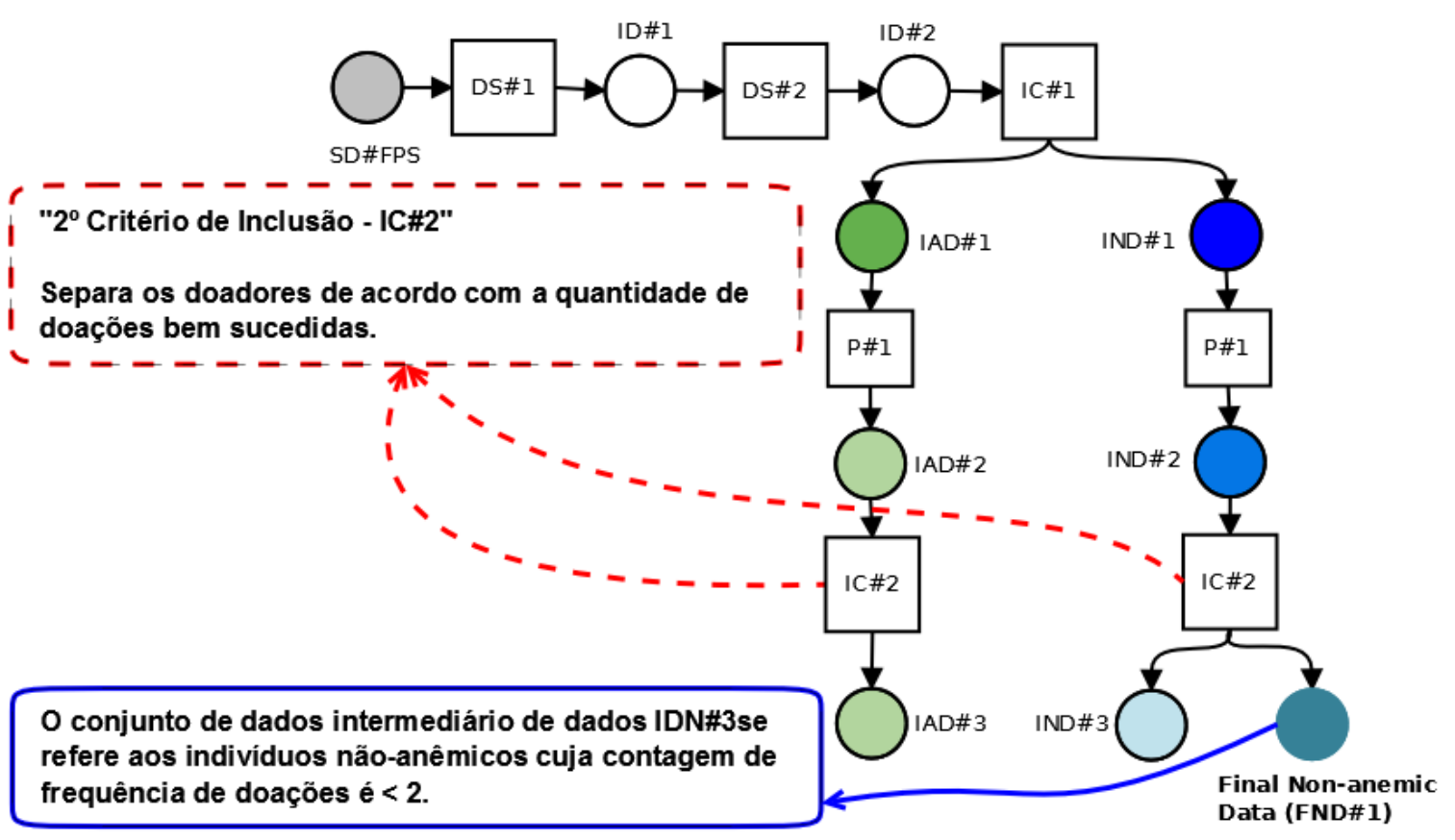

Figura 3.6. Grafo acíclico direcionado para representar o segundo critério de inclusão (IC\#2) e as projeções intermediárias de dados obtidas. Os retângulos representam as atividades e os círculos representam os conjuntos de dados intermediários.

$3^{0}$ Critério de Inclusão. Uma vez que é pretendido entender os fatores e influência da anemia na doação regular de sangue, foi desenvolvido o terceiro critério de inclusão. Entretanto, devido à existência de dois grupos bem definidos de doadores há a necessidade de observações distintas. Neste critério, é importante classificar somente a projeção do conjunto de dados dos doadores anêmicos regulares de acordo com a primeira recusa por LHct. Com isso foi possível obter a população de anêmicos de interesse para este estudo. Essa população é composta de indivíduos que foram aceitos na sua primeira doação de sangue, mas que nas tentativas seguintes podem ou não ter sido recusados. Tais indivíduos devem ter pelo menos uma recusa por LHct (risco de anemia). O segundo processo (Figura 3.7), possui uma rotina destinada à separação de um grupo de doadores que foram recusados na primeira tentativa de doação porque apresentaram 
LHct. Entretanto, tais indivíduos retornaram e foram bem sucedidos em suas posteriores doações. Esse grupo foi denominado de doadores anêmicos na primeira doação.

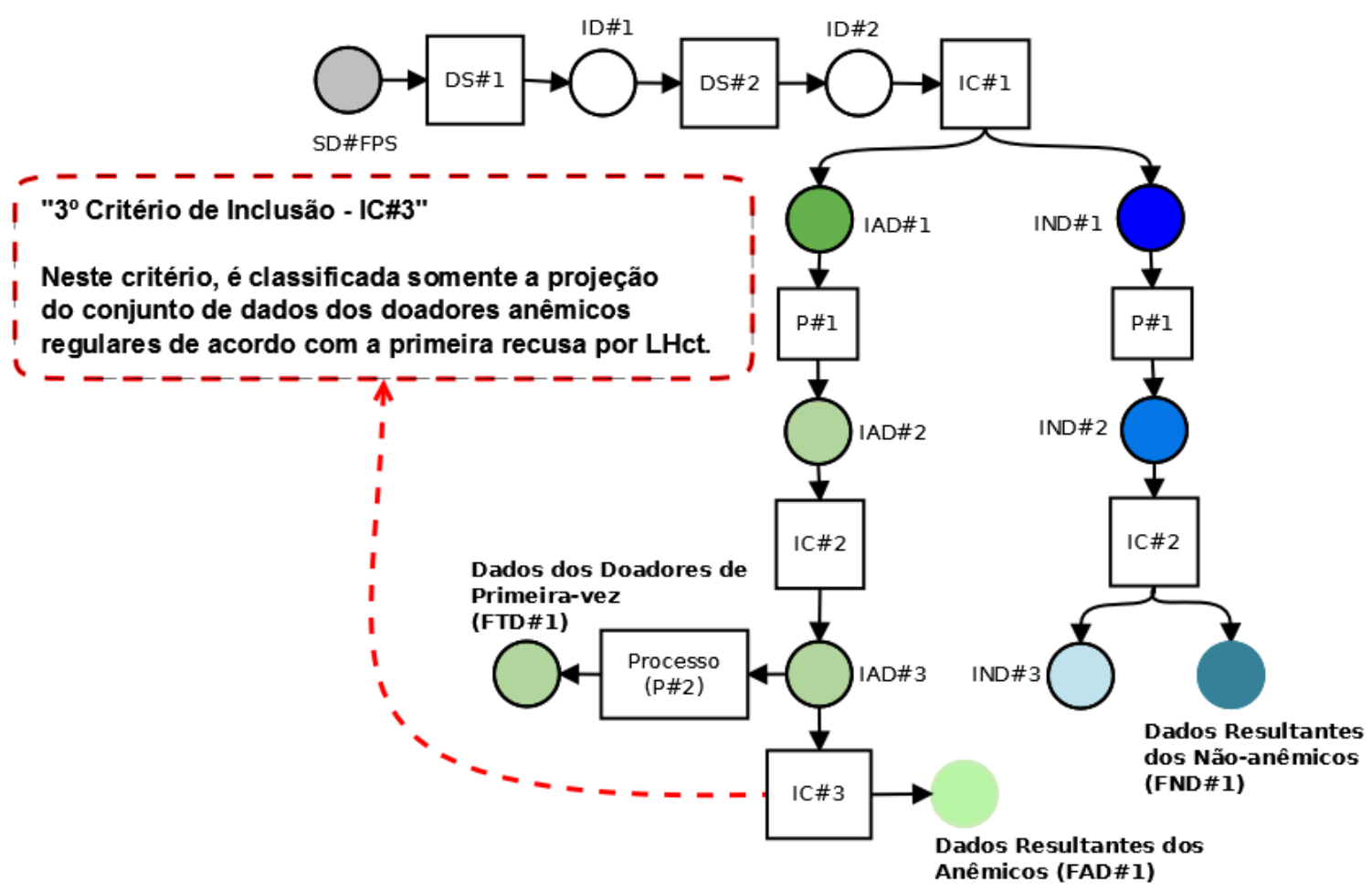

Figura 3.7. Grafo acíclico direcionado para representar o terceiro critério de inclusão (IC\#3). Os retângulos representam as atividades e os círculos representam os conjuntos de dados intermediários.

Com os filtros e rotinas descritos, pode-se obter uma explicação de todo o processo de derivação de dados. Tais registros e suas respectivas proveniências são essenciais para a validação e verificação de grupos resultantes (populações). Eles possibilitam uma melhor compreensão de um experimento e mais clareza durante todo o processo de análise. A Figura 3.8 apresenta o modelo para a implementação da proveniência descrito nesta tese. 


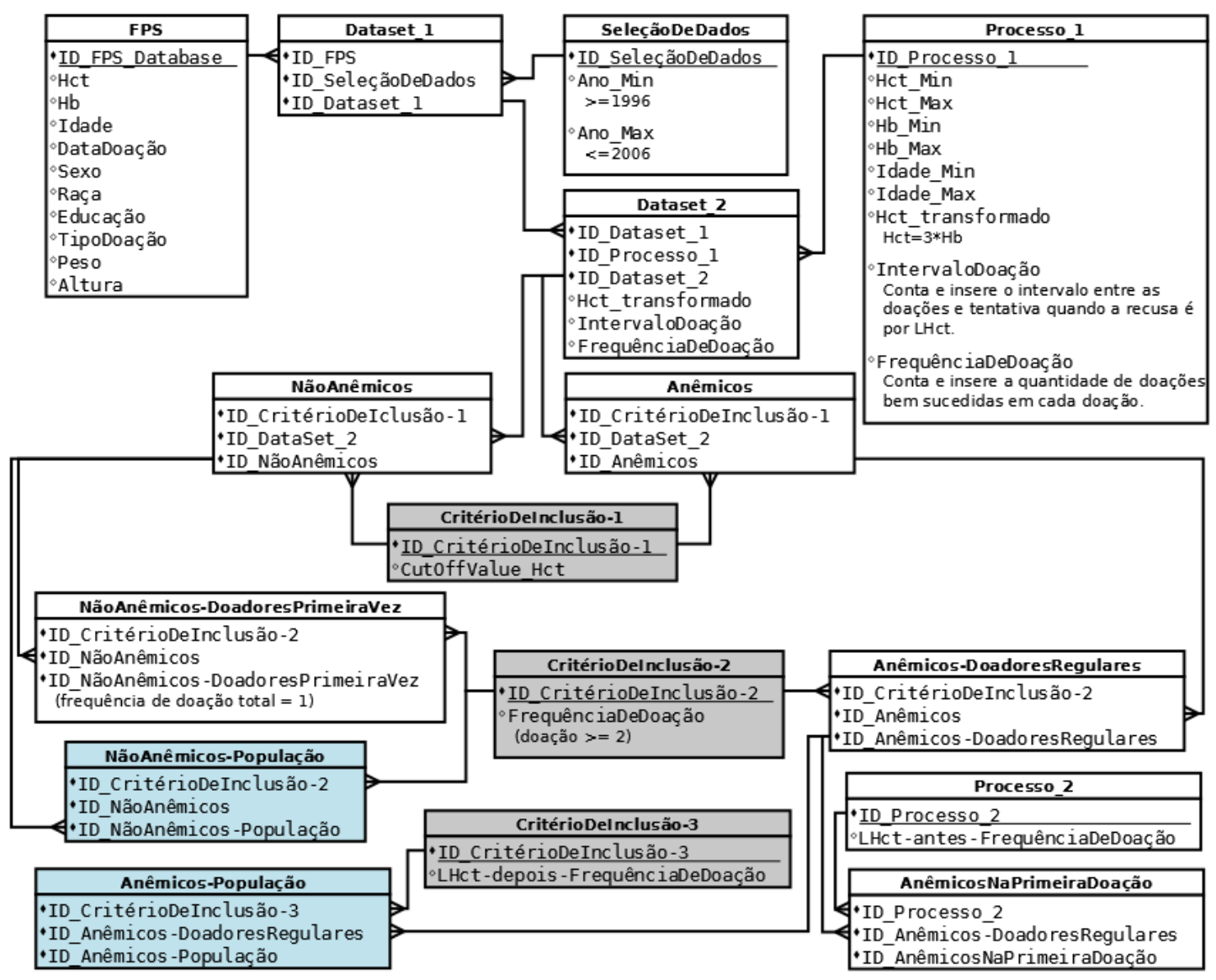

Figura 3.8. Modelo de proveniência gerado especificamente para analisar dados baseado nas declarações previamente definidas. Os filtros e regras são representados como processos. Em azul estão as populações de interesse geradas para este trabalho.

\subsection{Estágio de Validação e Análise dos Dados}

Cada projeção de dados teve que passar por um processo de validação. Nessa etapa, foi possível verificar a inserção de erros, como idade mínima -8008 e máxima de 99 anos ou registros de Hct entre $0.06 \%$ a $171.00 \%$. À medida que os erros eram encontrados, um novo processo de rastreamento era iniciado a fim de ajustar os dados e eliminar o problema. 
Nas projeções resultantes (populações de interesse) foram realizadas análises não paramétricas via generalização de Kaplan-Meier (Gentleman \& Geyer, 1994) adequadas para incorporar censura intervalar e Tabela de Vida (Hosmer et al., 2008) para o estudo do tempo de vida aplicado aos anêmicos. Como variável resposta, foi usado o tempo decorrido até o primeiro registro de LHct (ou seja, risco de anemia) e como censura, os doadores que nunca foram recusados por risco de desenvolver anemia. As generalizações da curva de Kaplan-Meier (curvas de sobrevivência estimada) foram feitas usando o tempo até o surgimento da primeira recusa por LHct para os seguintes atributos: sexo, idade, frequência de doação, nível de Hct e intervalo entre as doações (ou tentativa, que são as recusas por LHct). De acordo com as análises preliminares, mesmo contabilizando valores errados, os gráficos construídos sugerem a existência de uma fração de curados e a utilização de metodologias de análise multivariada para dados com fração de cura (Klein \& Moeschberger, 2003). Entretanto, tal metodologia não foi aplicada e pode ser colocada como próximo passo.

\subsection{Infra-estrutura de Software}

O banco de dados de doadores de sangue esta armazenado em SQL Server 2000. A implementação das rotinas de limpeza, transformação, bem como o desenvolvimento dos filtros, se deu pela criação de scripts em linguagem de programação PERL. Foi criado um workflow mantido também pelo SQL Server 2000 e, os scripts foram integrados a ele. As Análises de Sobrevivência foram feitas usando o programa $\mathrm{R}$ (The $R$ Project for Statistical Computing) e de estatística descritiva usando o OpenOffice.org. 


\section{Capítulo 4}

\section{Resultados}

De 1996 a 2006, 1.469.505 doadores foram responsáveis por 2.886.131 triagens no Hemocentro de São Paulo/Fundação Pró-Sangue (Figura 4.1). Esse valor representa registros de doações de sangue total, plaqueta, e recusas. Após a primeira etapa de limpeza e tratamento, cerca de $12,37 \%$ dos dados considerados com problemas foram descartados do banco de dados da FPS com objetivo de melhorar a qualidade da análise. No que se refere aos dados válidos, foram obtidos 433.397 (29,5\%) de doadores de sangue regulares e $878.019(59,7 \%)$ doadores de sangue de primeira-vez. Foram excluídos das análises todos os doadores que apresentaram LHct em sua primeira doação $(n=36.628)$ e também aqueles doadores que foram recusados devido a outras razões diferentes do risco de desenvolver anemia $(n=11.412)$ (Figura 4.1). Para as análises foram consideradas apenas as doações bem sucedidas até as recusas devido ao primeiro episódio de LHct. Já no processo destinado à classificação e separação dos doadores regulares, foram obtidos 374.815 doadores classificados como não-anêmicos e 58.582 classificados como anêmicos (LHct). Tais doadores totalizam 433.397 indivíduos que efetuaram mais de uma doação de sangue no período estudado. Desse total, foram obtidos 
$21.954(5,7 \%)$ doadores que tiveram suas doações adiadas devido à LHct pelo menos uma vez após uma doação bem sucedida (durante seu histórico como doador) e, destes: $3.850(1,5 \%)$ se referem ao sexo masculino e $18.104(13,6 \%)$ ao sexo feminino.

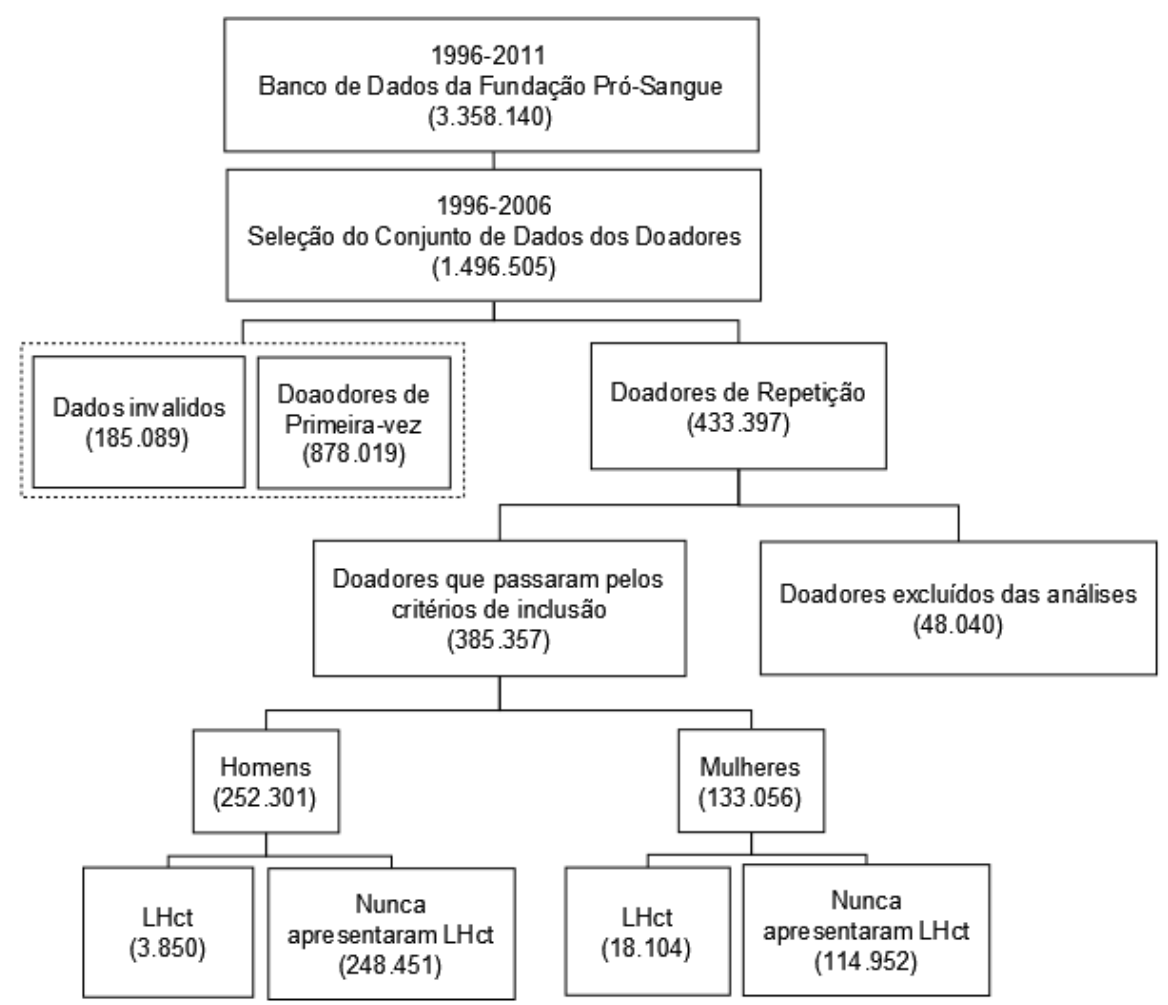

Figura 4.1. Descrição das populações de estudo da Fundação Pró-Sangue/Hemocentro de São Paulo, no período de 1996 a 2006.

Os resultados apresentados na Tabela 4.1 mostram as variáveis associadas com o desenvolvimento de LHct. Com essa tabela foi possível observar que os doadores do sexo feminino com Hct inicial menor que $41 \%$ apresentaram taxa de recusa três vezes maior do que aqueles cujos níveis iniciais foram maiores que 43\%. Para os homens, foi visto que mesmo as taxas de recusa sendo baixas, indivíduos não-anêmicos apresentaram taxa seis vezes maior do que os doadores recusados por LHct. Já as mulheres com menores índices de Hct foram recusadas quase três vezes mais (19,5 vs. 6,0\%). Mulheres com 
idade entre 18 a 49 anos apresentaram os maiores percentuais de desenvolvimento de anemia, dez vezes maior do que homens da mesma idade. Na Tabela 4.1 foi possível verificar também que mulheres mais jovens tendem a apresentar taxas de recusas mais elevadas do que mulheres com idade superior a 50 anos. Entretanto, o inverso foi observado nos homens que desenvolveram LHct, aqueles com idade mais avançada apresentaram taxas de recusa ligeiramente maior. Os homens apresentaram o mesmo padrão com uma diferença na taxa de recusa. Esses doadores tiveram taxa dezoito vezes maior do que aqueles cujo Hct foi maior quando comparados com os doadores recusados por LHct (0,5 vs. $9,0 \%)$.

Tabela 4.1. Número e porcentagem de doadores de repetição anêmicos nos 11 anos de seguimento pelo gênero, idade, intervalo entre as doações e Hct inicial e final.

\begin{tabular}{|c|c|c|c|c|c|c|c|}
\hline & \multicolumn{6}{|c|}{ LHct durante o período de seguimento } \\
\hline & & \multicolumn{3}{|c|}{ Mulheres } & \multicolumn{3}{|c|}{ Homens } \\
\hline & & $\mathbf{N}$ & $\%$ & Total & $\mathbf{N}$ & $\%$ & Total \\
\hline \multirow{3}{*}{ 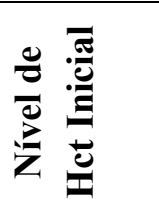 } & $<41$ & 12,544 & 19.5 & 64,2 & 1,164 & 6.6 & 17,765 \\
\hline & $41-43$ & 3,434 & 10.3 & 33,451 & 892 & 2.8 & 32,175 \\
\hline & $>43$ & 2,126 & 6.0 & 35,390 & 1,794 & 0.9 & 202,361 \\
\hline \multirow{3}{*}{ 总 } & $<41$ & 142,46 & 20.1 & 71, & 1,92 & 9.0 & 21,531 \\
\hline & $41-43$ & 2,561 & 8.1 & 31,443 & 909 & 2.5 & 35,839 \\
\hline & $>43$ & 1,297 & 4.2 & 30,568 & 996 & 0.5 & 194,931 \\
\hline \multirow{4}{*}{ 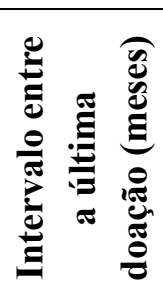 } & $<5$ & 6,765 & 19.9 & 34,0 & 1,860 & 3.2 & 58,973 \\
\hline & $5-12$ & 5,601 & 13.8 & 40,483 & 912 & 1.4 & 67,106 \\
\hline & $13-26$ & 3,029 & 10.3 & 29,482 & 505 & 0.9 & 58,730 \\
\hline & $>26$ & 2,709 & 9.3 & 29,029 & 573 & 0.8 & 67,492 \\
\hline \multirow{2}{*}{ 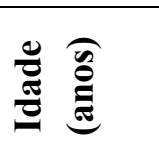 } & $18-49$ & 17,122 & 14.0 & 122,698 & 3,406 & 1.4 & 235,215 \\
\hline & $\geq 50$ & 982 & 9.5 & 10,358 & 444 & 2.6 & 17,086 \\
\hline
\end{tabular}


A Figura 4.2 apresenta a proporção acumulada dos doadores que se tornariam anêmicos caso todos os doadores voltassem ao hemocentro para efetuar uma doação regular de sangue. Para essa figura, foi calculada a proporção até a sétima doação. Foi visto que aproximadamente $35 \%$ das mulheres e $7,5 \%$ dos homens desenvolveriam LHct antes da oitava doação.

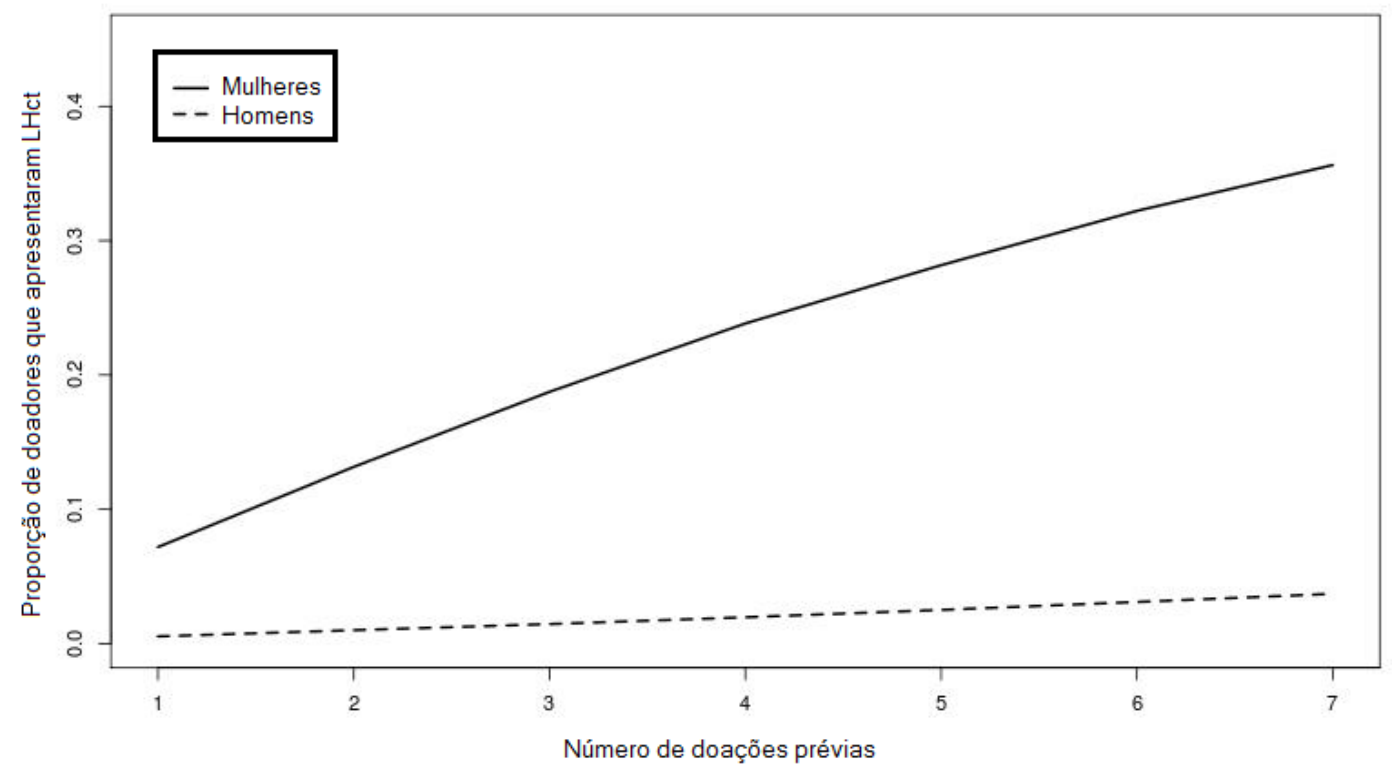

Figura 4.2. Proporção acumulada dos doadores que desenvolveram LHct, de acordo com o número de doações prévias.

$\mathrm{Na}$ Tabela 4.2 proporção acumulada dos doadores que desenvolveram LHct, de acordo com o número de doações prévias, foram calculadas as proporções para os doadores anêmicos utilizando a metodologia da Tabela de Vida (Hosmer et al., 2008). A proporção da população de doadores não-anêmicos pode ser interpretada como a probabilidade do doador não ser recusado por LHct a cada doação, como, por exemplo, na quarta doação (terceira linha na Tabela 4.2) a S(3) representa a probabilidade de um 
doador ser não-anêmico após três doações de sangue (antes da quarta doação). Já a proporção de anêmicos representa a porcentagem total dos doadores recusados por LHct até um número determinados de doações prévias. Nessa tabela, os resultados, assim como o apresentado anteriormente, indicam que os doadores do sexo feminino são recusados por LHct mais cedo que os doadores do sexo masculino (Tabela 4.2). A proporção de doadoras anêmicas na segunda tentativa de doação é maior quando comparada à dos homens. Embora o intervalo entre as doações de sangue de mulheres e homens seja alto, as mulheres tendem a apresentar risco de desenvolver anemia mais cedo que os homens. Entretanto, existem fatores associados à doação regular de sangue que podem influenciar no desenvolvimento da anemia em mulheres, por exemplo: a gravidez e a perda mensal de sangue pela menstruação, ausentes em doadores do sexo masculino. Nos homens, provavelmente, a contínua perda de sangue causada por algum tipo de sangramento associado à doação de sangue pode estar relacionado com o risco de desenvolver anemia. Porém, vale ressaltar que a quantidade de doações também é um fator que pode estar associado com o adiamento da doação regular por LHct nos homens.

Para avaliar o impacto do primeiro Hct e da idade na ocorrência de LHct entre as doações de sangue, a curva de sobrevivência estimada foi computada (Figura 4.3). Aqui, o evento de interesse é a ocorrência de doadores anêmicos que não desenvolveram LHct foram considerados como observações censuradas à direita. Por outro lado um regime de intervalo de censura foi considerado para os doadores que desenvolveram LHct. As curvas da Figura 4.3 indicam a proporção de doadores não-anêmicos ao longo do tempo, desde a primeira doação de sangue. O nível de Hct na primeira doação é claramente um fator importante e que pode ser utilizado como preditor da ocorrência de anemia. Foi 
observado que, doadores com níveis de Hct inferior a $41 \%$ possuem elevada probabilidade de se tornarem anêmicos, mesmo entre os homens. No caso dos doadores do sexo feminino, mesmo para níveis acima de $47 \%$, a proporção de LHct é relativamente alta. Quando a idade é analisada, verificou-se que homens com idade superior a 50 anos parecem ter probabilidade ligeiramente maior de se tornarem anêmicos. Entretanto, isso não é visto entre as mulheres. Nesses casos, a probabilidade de mulheres se tornarem anêmicas com idade acima de 50 anos foi baixa.

Tabela 4.2. Estimativas da tabela de vida para os grupos de doadores que atenderam aos critérios de inclusão.

\begin{tabular}{|c|c|c|c|c|c|c|c|c|}
\hline \multirow[b]{2}{*}{ Doações } & \multicolumn{4}{|c|}{ Feminino } & \multicolumn{4}{|c|}{ Masculino } \\
\hline & $\begin{array}{c}\mathrm{N}^{0} \text { em } \\
\text { risco }\end{array}$ & $\begin{array}{l}N^{0} \text { de } \\
\text { falhas }\end{array}$ & $S(t)$ & $1-S(t)$ & $\begin{array}{c}\mathrm{N}^{0} \text { em } \\
\text { risco }\end{array}$ & $\begin{array}{l}N^{0} \text { de } \\
\text { falhas }\end{array}$ & $\mathbf{S ( t )}$ & $1-S(t)$ \\
\hline$[1,2)$ & 114958 & 8263 & 1 & 0 & 248460 & 1336 & 1 & 0 \\
\hline$[2,3)$ & 58410 & 3921 & 0,92812157 & 0,0718784 & 133448 & 622 & 0,99462288 & 0,0053771 \\
\hline$[3,4)$ & 34305 & 2207 & 0,8684112 & 0,1315888 & 84257 & 385 & 0,98998695 & 0,0100130 \\
\hline$[4,5)$ & 21575 & 1351 & 0,81254228 & 0,1874577 & 57524 & 297 & 0,98546335 & 0,0145366 \\
\hline$[5,6)$ & 14237 & 811 & 0,76166188 & 0,2383381 & 41075 & 230 & 0,98037534 & 0,0196246 \\
\hline$[6,7)$ & 9645 & 543 & 0,71827438 & 0,2817256 & 30281 & 183 & 0,97488571 & 0,0251142 \\
\hline$[7,8)$ & 6679 & 336 & 0,67783654 & 0,3221634 & 22606 & 141 & 0,9689941 & 0,031005 \\
\hline$[8)$, & 4709 & 664 & 0,64373666 & 0,356263 & 17269 & 654 & 0,96295021 & 0,0370497 \\
\hline
\end{tabular}


(a) Curva de Sobrevivência Estimada - Primeiro Hct
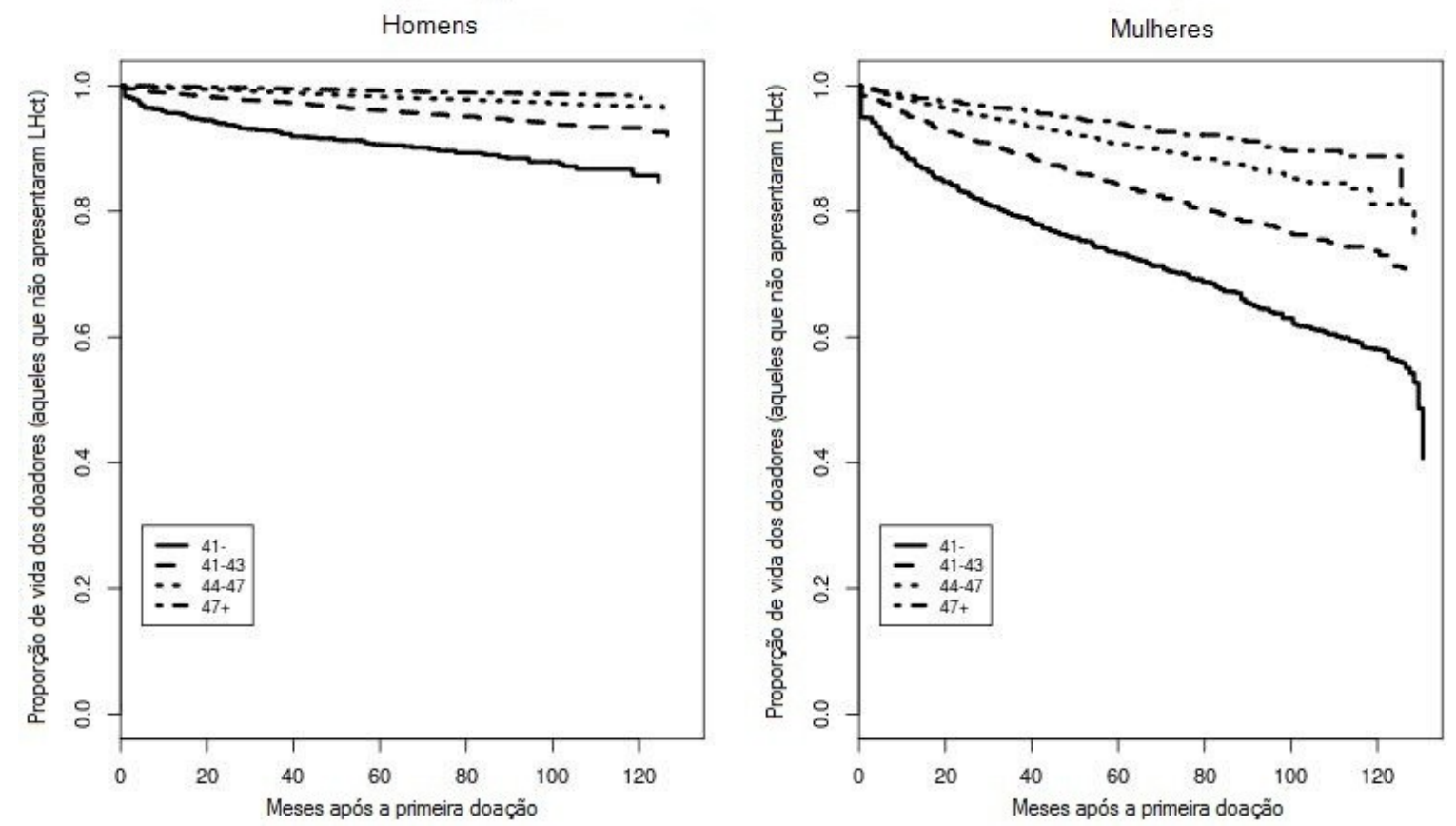

(b) Curva de Sobrevivência Estimada - Idade
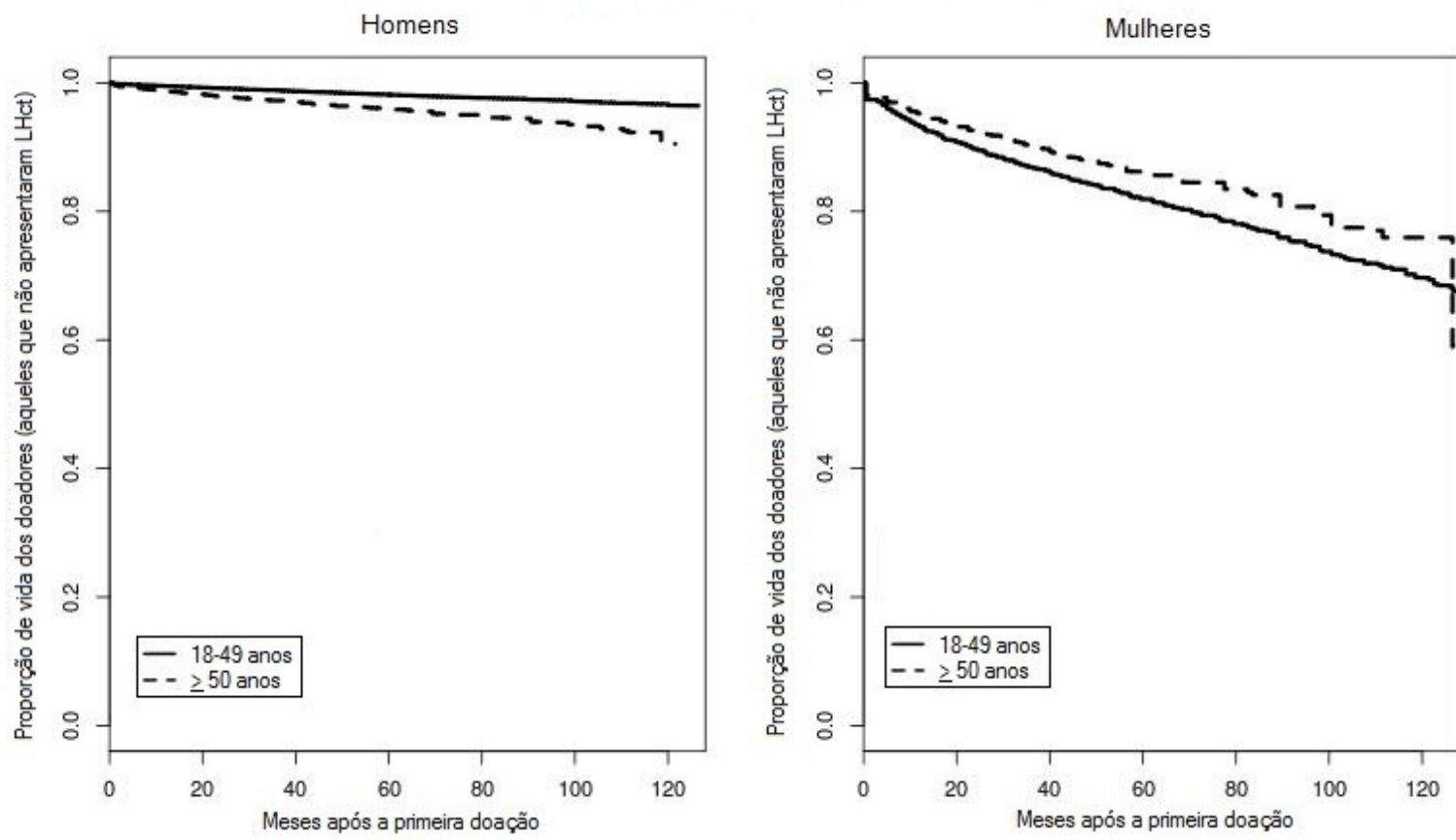

Figura 4.3. Curva de sobrevivência estimada de acordo com o primeiro nível de Hct (a) e idade (b). 
Na Figura 4.4, são apresentados os valores das médias do tempo decorrido entre sucessivas doações. A barra de erro possui $95 \%$ de intervalo de confiança para os valores das médias. Foram considerados, na Figura 4.4, somente doações de sangue total, descartadas as doações de plaquetas. Para a população de doadores não-anêmicos, a média do intervalo foi calculada usando o intervalo entre a primeira e segunda doação, para todos os doadores não-anêmicos na segunda doação. No caso da população de doadores anêmicos, a média do intervalo foi calculada entre a primeira e segunda tentativa de doação de sangue (isto é, quando o doador foi recusado por apresentar LHct). É importante observar que o número de doadores decresce à medida que o número de doações aumenta. No gráfico é possível ver que o intervalo entre as doações tendem a se aproximar de quatro meses sempre que o número de doações prévias aumenta. 
(a) Média do intervalo entre as doaçōes - Mulheres

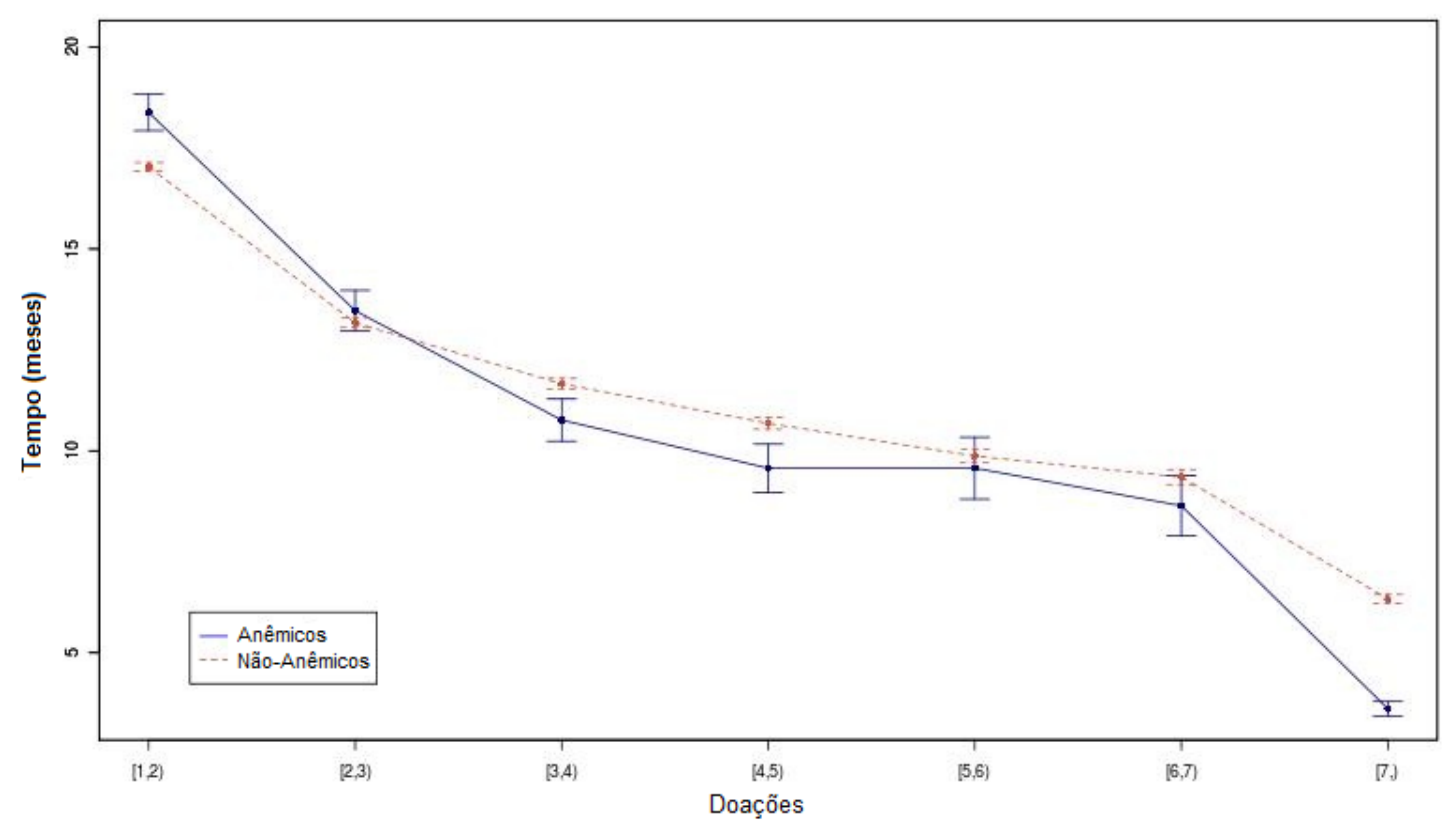

(b) Média do Intervalo entre as doações - Homens

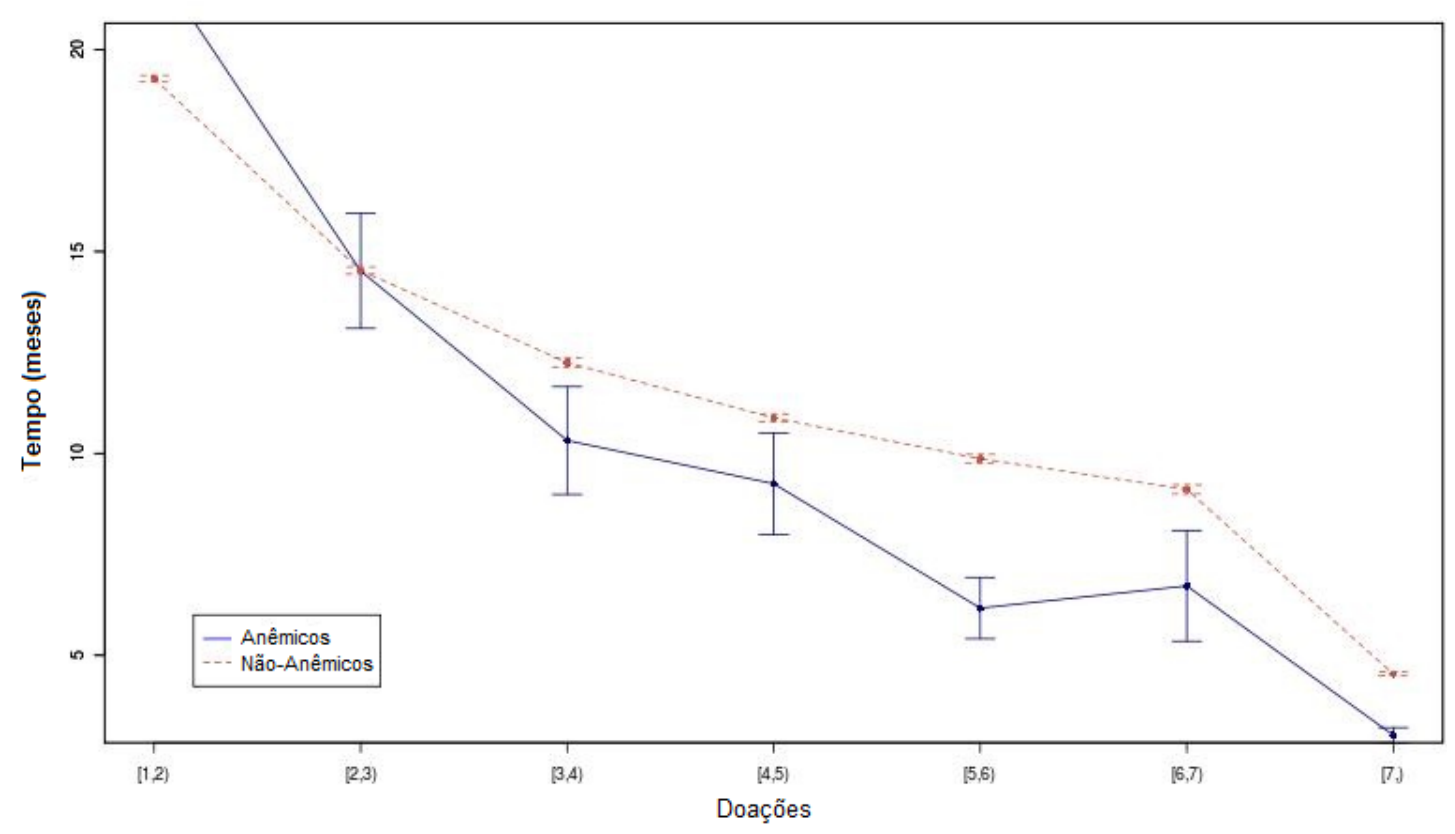

Figura 4.4. Média dos intervalos entre as doações para a população de doadores anêmicos e não-anêmicos de acordo com o número de doações executadas, separados pelo sexo. 
Ainda analisando a Figura 4.5 mostra graficamente a média dos níveis de Hct para todos os doadores estudados (barra de erro possui $95 \%$ de intervalo de confiança para os valores das médias.). Nessa figura, foram calculadas as médias até a décima segunda doação anterior (apenas contabilizadas doação de sangue total). Foi observado que parece não haver tendência nos níveis de Hct entre os doadores do sexo feminino (Figura 4.5a). Isso indica que a frequência de doações pode não ter influência sobre os níveis de Hct em mulheres. Quando esta comparação é feita entre mulheres de acordo com a faixa etária, notou-se que: mulheres entre 18 e 49 anos possuem níveis de Hct mais baixos do que mulheres acima de 50 anos. No entanto, como foi dito, nenhuma das curvas indica tendência nas médias dos níveis de Hct apresentados na Figura 4.5 (para mulheres). Para os doadores do sexo masculino, a situação foi oposta (Figura 4.5b). Nesses doadores, foram observados que, à medida que a quantidade de doações aumenta os níveis de Hct diminuem. Tais resultados indicam que quando tal índice estiver baixo na primeira doação a chance de recusa por LHct é maior entre esses doadores. Outro importante fator é que homens acima de 50 anos apresentam níveis de Hct menor do que aqueles entre 18 e 49 anos. Em tais casos o Hct pode atingir níveis inferiores a 44\%, caso as doações anteriores sejam aumentadas. 
(a) Gráfico da média do Hct - Mulheres

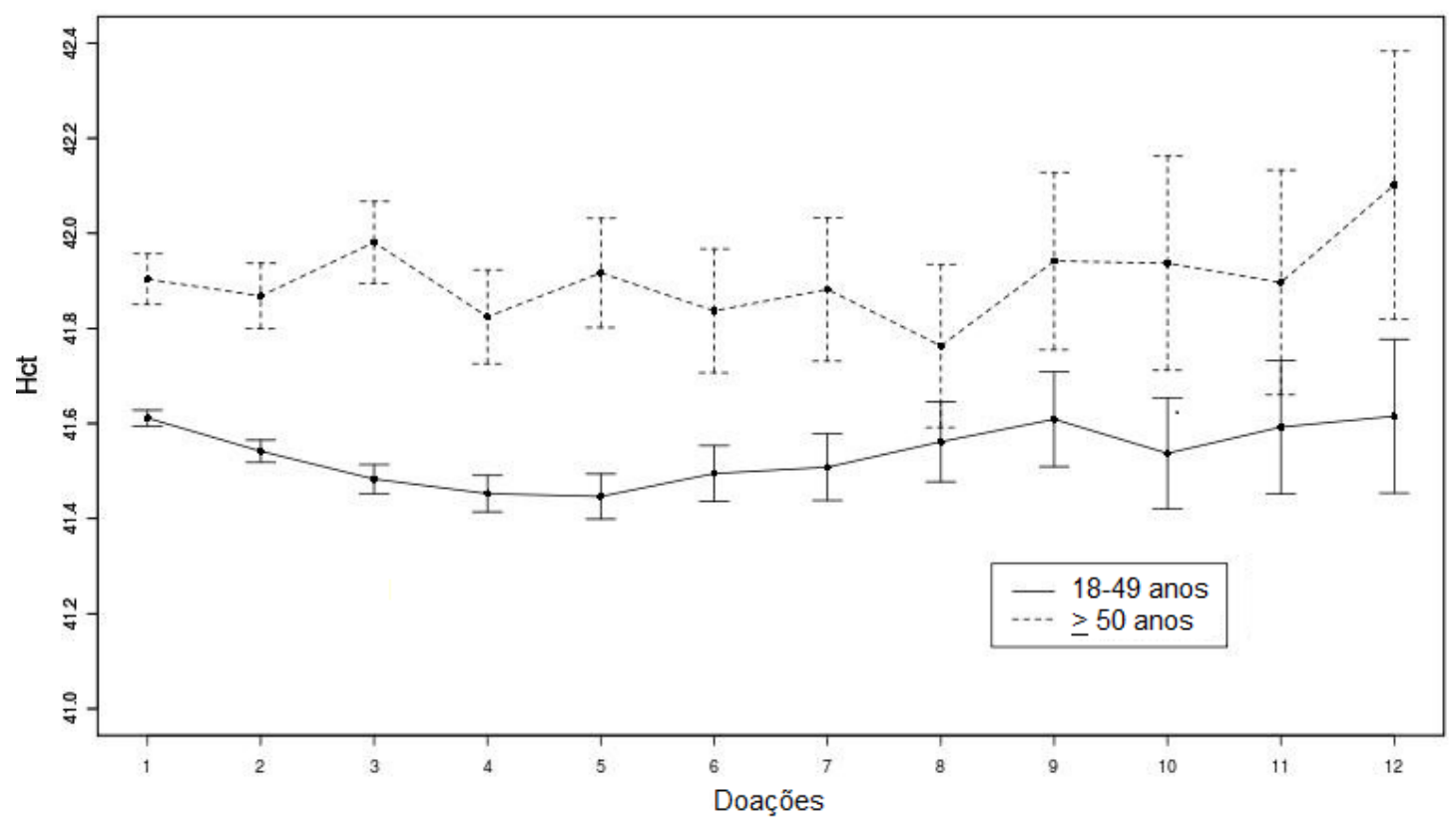

(b) Gráfico da média do Hct - Homens

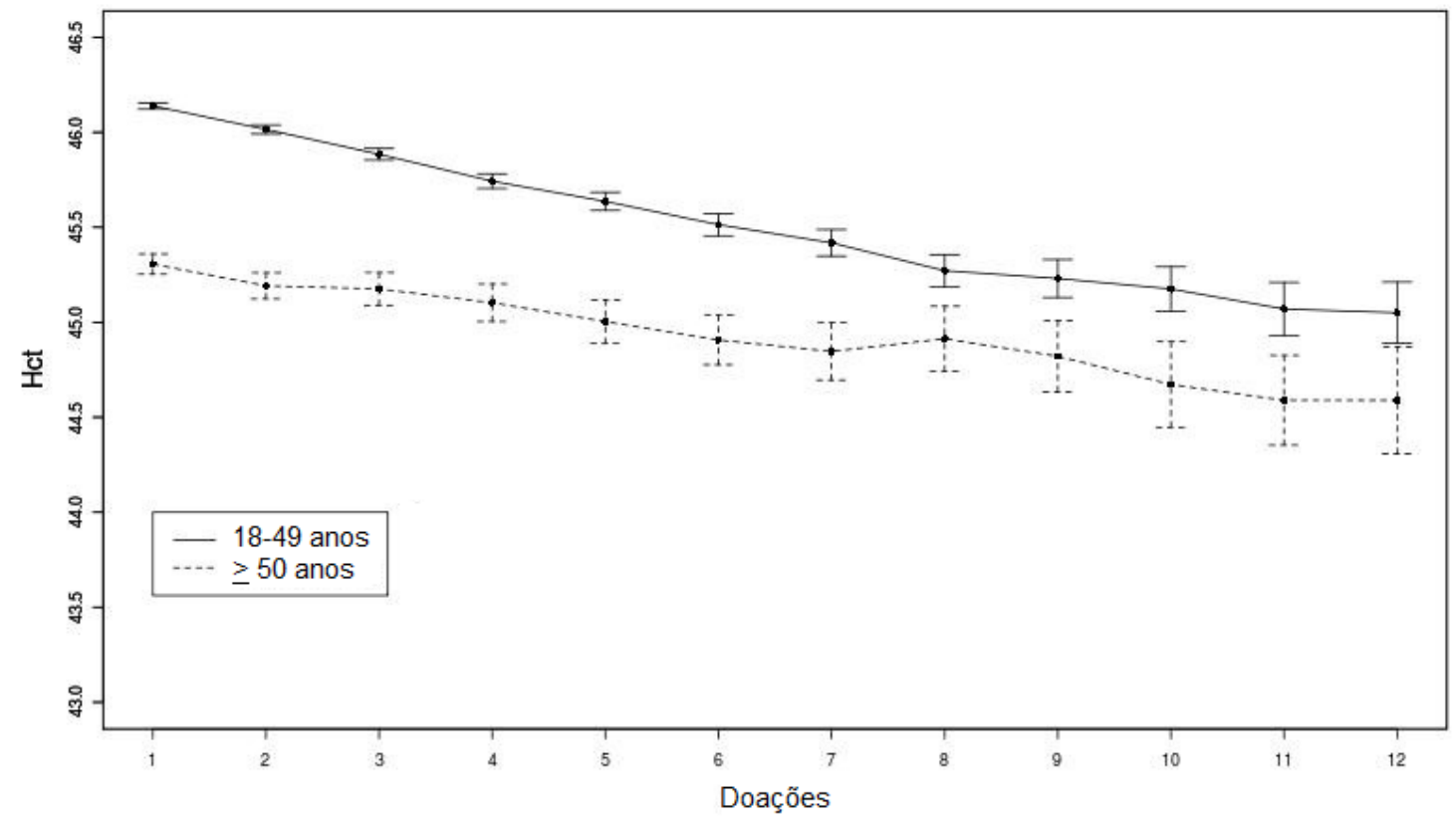

Figura 4.5. Médias do Hct, com intervalo de confiança de $95 \%$, entre doadores nãoanêmicos, separados por sexo.

Ainda analisando a Figura 4.5b, foi visto que o nível de Hct foi diminuindo nos doadores não-anêmicos durante o período de acompanhamento. Os níveis de Hct tiveram 
um decréscimo constante junto com o aumento do número de doações atingindo cerca de 0,5\% menos, após a décima segunda doação. Isso indica que os doadores possuem contínua queda dos níveis de Hct esgotando seus estoques de ferro.

Na Figura 4.6, as médias foram construídas de forma diferente. Foram calculados os valores médios para o Hct anterior à doação de sangue, ou seja, o penúltimo Hct, para as populações de estudo, os doadores anêmicos e não-anêmicos de ambos os sexos (barra de erro possui $95 \%$ de intervalo de confiança para os valores das médias.). Foi percebido que os doadores do sexo masculino seguem um padrão, conforme apresentado na Figura 4.6b. Esses doadores apresentam uma diminuição progressiva das médias dos níveis de Hct a medida que a freqüência de doação aumenta. No caso das mulheres, a situação é oposta àquela apresentada na Figura 4.5a. Nesses casos foi possível observar que os níveis de Hct na última doação tende a subir sempre que a frequência de doações aumenta (Figura 4.6a). Com base na Figura 4.6, outro resultado importante, tanto para homens quanto para mulheres, indicou que os doadores anêmicos apresentam níveis de Hct muito menor que os doadores não-anêmicos. 
(a) Gráfico da Média do Hct - Mulheres

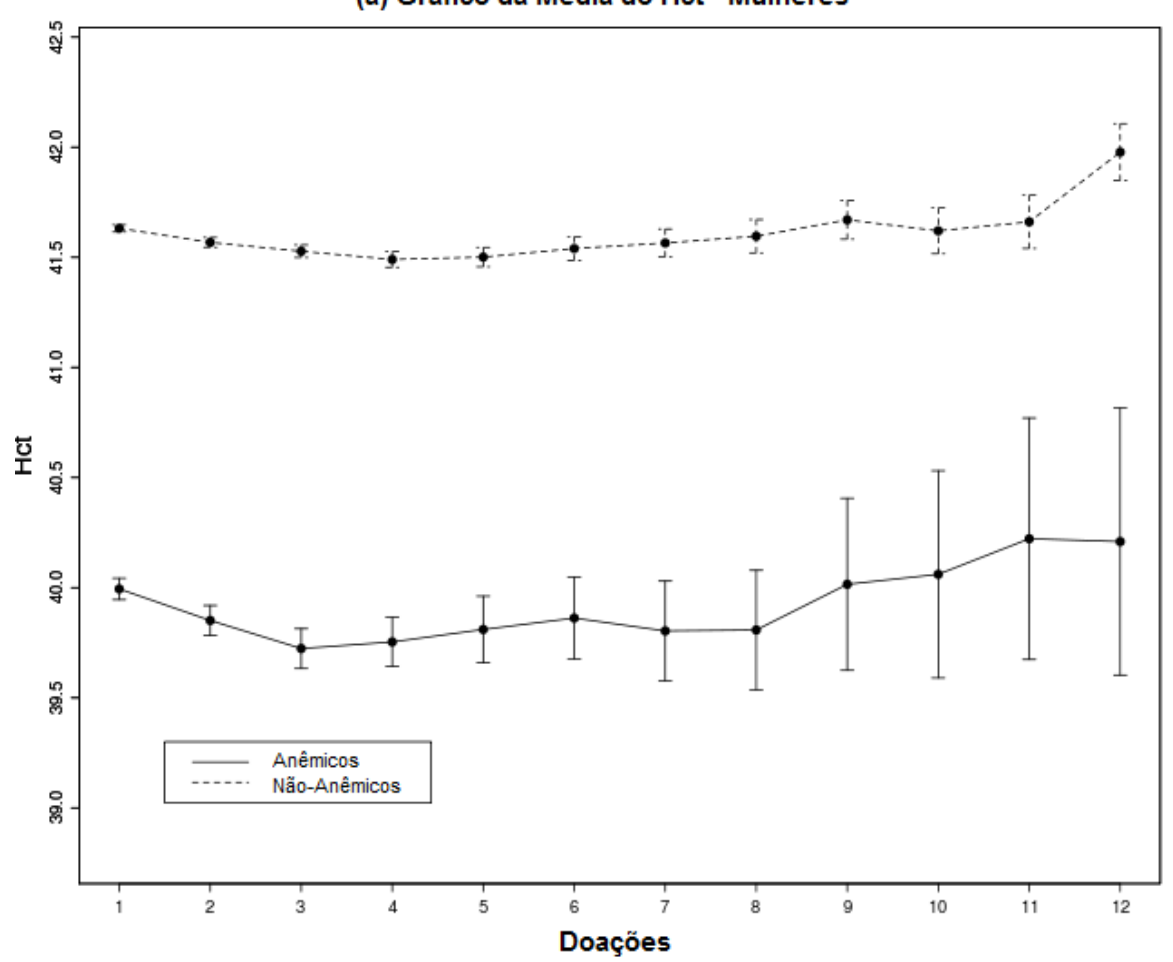

(b) Gráfico da Média do Hct - Homens

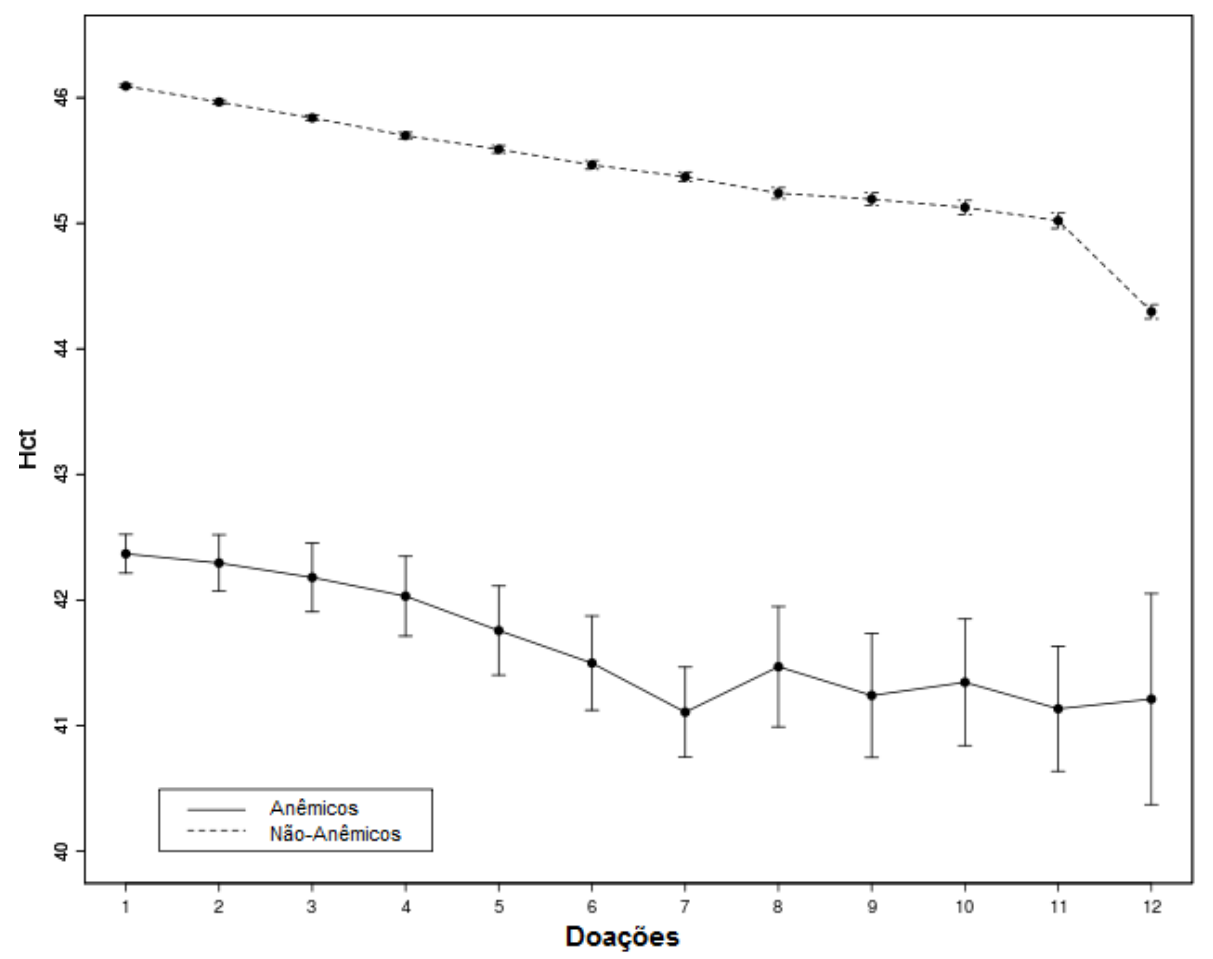

Figura 4.6. Média dos níveis de Hct encontrados na última doação para os doadores anêmicos e não-anêmicos, separados pelo sexo. 
Finalmente, para entender melhor como o tempo entre as doações influencia no desenvolvimento da anemia foi construído um gráfico com a frequência de recusas de acordo com o último intervalo entre doação ou visita para todos os doadores (intervalo/doador). Para a construção das curvas também foram usados os níveis de Hct antes da última doação/visita para ambos os sexos (Figura 4.7). Independente do intervalo entre doação, tanto em mulheres como homens, os indivíduos com menor Hct possuem maior proporção de recusas devido à anemia. Entretanto, a taxa de recusa diminuiu substancialmente após o período inicial de seis meses para ambos os sexos, especialmente para indivíduos com $\mathrm{Hct}<41$.

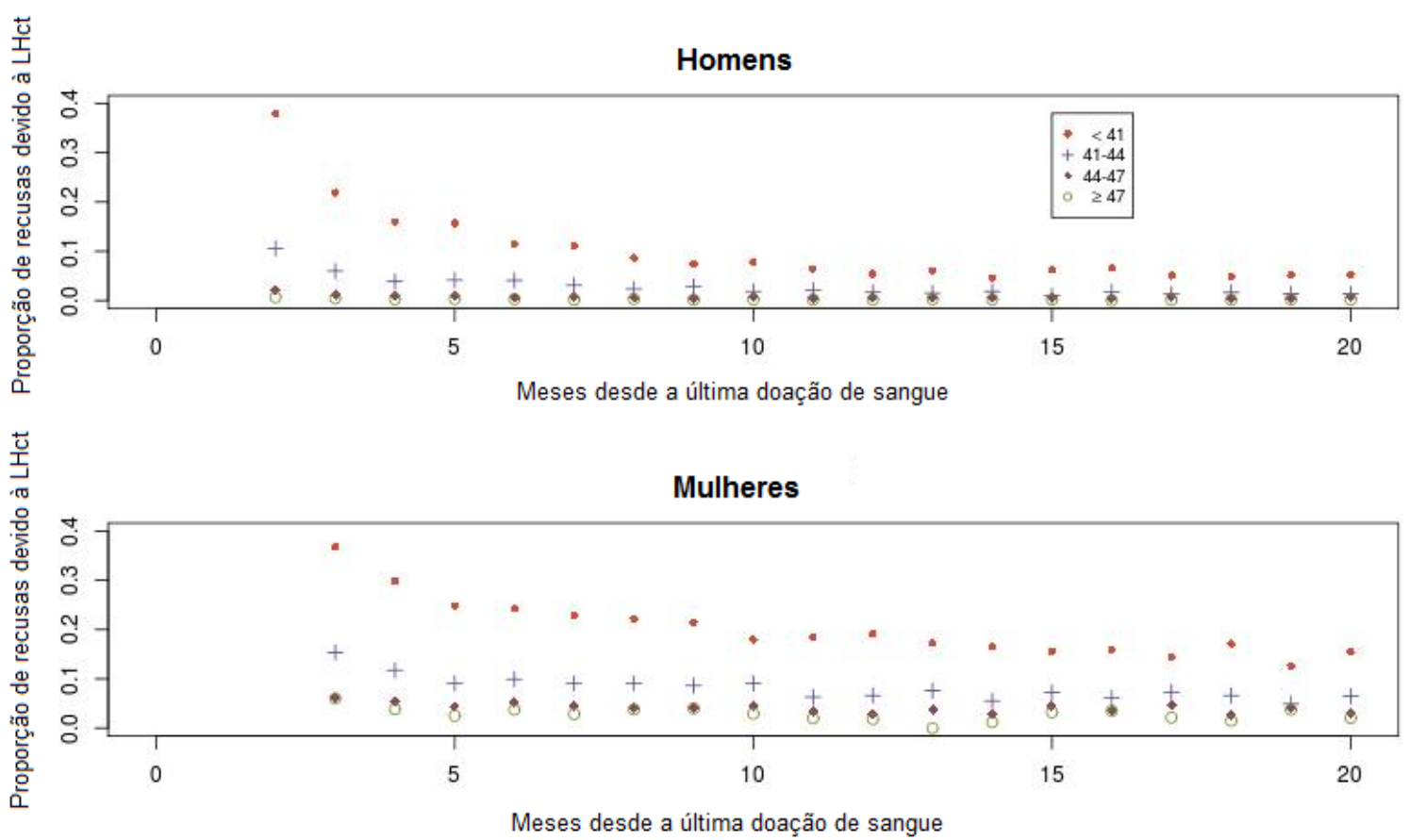

Figura 4.7. Proporção de recusas nos grupo de doadores de estudo de acordo com o ultimo intervalo entre as doações ou visitas. Para a construção destes gráficos foi computado o intervalo das doações, um por doador. Para os doadores não-anêmicos, foi computado o intervalo das doações da última doação de sangue total durante o período de estudo. Para os doadores anêmicos, foram computador os intervalos entre a última doação de sangue e visitas, na qual o doador foi recusado. Os doadores foram classificados de acordo com sexo, nível de Hct e doação antes da última visita/doação. 


\section{Capítulo 5}

\section{Análise e Discussão dos Resultados}

A crescente demanda por componentes sanguíneos tem aumentado a necessidade de doadores de repetição nos bancos de sangue. No entanto, a depleção de ferro é um efeito colateral comum nas doações de sangue total e representa uma preocupação e um desafio para os hemocentros (Finch et al., 1977; Conrad et al., 1999; Farrugia, 2007).

A partir do conjunto de dados obtidos pelo modelo de proveniência foi possível analisar preditores de Hct com referência na depleção de ferro, para identificar entre os doadores de repetição aqueles com maior risco de desenvolver LHct após repetidas doações de sangue total. O grupo de estudo contou com um total de 385.357 doadores de sangue, que foram analisados. As análises dos dados comprovaram que existe alta prevalência de recusas devido à LHct (5,7\%) durante o período de seguimento (1996 a 2006) em doadores de repetição do sexo masculino e feminino. Foi feita uma associação com o sexo, idade, nível de Hct no momento da última doação de sucesso e tempo até a última doação. Como observado anteriormente, as doadoras mais jovens do sexo feminino possuem risco significativo de desenvolver deficiência de ferro após a doação de sangue total (Simon et al., 1981; Newman, 2006). Um recente estudo no Brasil 
mostrou a alta taxa de anemia em doadores de sangue $(9,71 \%)$ com forte associação entre mulheres (Oliveira et al., 2011).

O estudo apresentado nesta tese corrobora os resultados apresentados em (Simon et al., 1981; Newman, 2006; Oliveira et al., 2011). Foi observado que mulheres em idade pré-menopausa são preditoras significativas de futuras recusas devido a LHct. Embora constituam menor população, as mulheres em idade pós-menopausa também apresentaram maior prevalência de LHct do que os homens. Essa análise também mostrou que os doadores do sexo masculino acima de 50 anos tiveram maiores chances de futuras recusas devido ao LHct. Portanto, parecem ter probabilidade ligeiramente maior de terem baixas nos estoques de ferro após contínuas doações de sangue. No entanto, esta observação pode estar relacionada com outros fatores que contribuem para a perda de ferro nessa faixa etária, especialmente problemas no trato gastrointestinal ou dificuldade para repor o ferro perdido nas doações (Garry et al., 1995; Annibale et al., 2001).

Além disso, os doadores do sexo masculino com idade entre 18 e 49 anos e que nunca foram recusados por LHct também apresentaram redução nas médias dos níveis de Hct após várias doações de sangue (Figura 4.5). Embora tais doadores nunca tenham sido recusados (por LHct), observou-se um declínio constante na sua linha de base. Estudos anteriores mostraram que repetidas doações, sem suplementação de ferro levam a depleção dos estoques de ferro em homens, sem incidência de deficiência de ferro e anemia (Farrugia, 2007; Rosvik et al., 2009). Os resultados apresentados nesta tese também estão em concordância com estes trabalhos. Apesar do Hct não ser considerado indicador sensível do esgotamento de ferro no corpo (Simon, 1981), a redução 
progressiva dos Hcts no período deste estudo podem representar indiretamente um crescente declínio das reservas de ferro. Como os homens mais jovens geralmente iniciam suas doações com altas reservas de ferro e nível de Hct, o impacto inicial dessas doações não é suficiente para levar à deficiência de ferro ou a LHct. Após contínuas doações de sangue, é provável que a perda e a absorção de ferro cheguem a um equilíbrio e, os estoques de ferro e Hct dos doadores frequentes serão mantidos relativamente inalterados, como observado no trabalho apresentado por Cable et al. (2011). Entretanto, estudos mais detalhados sobre os estoques de ferro nas populações de estudo necessitam ser feitos.

Nesta tese também foi observado que tanto o doador do sexo masculino quanto feminino, que possuíam nível inicial de Hct inferior a 41\%, possuem maiores chances de desenvolver LHct após repetidas doações de sangue (Figura 4.3). Tal verificação mostrou que níveis baixos de Hct na primeira doação de sangue ocasionarão recusas em suas futuras doações de sangue total. A mesma observação foi feita no estudo de Pasricha et al. (2011), no qual comprovaram que os doadores que desenvolveram anemia tinham nível de $\mathrm{Hb}$ significativamente menor em sua linha de base (Simon, 1981).

Como esperado, os níveis de Hct abaixo de $41 \%$ tiveram forte associação com as recusas devido ao LHct na próxima visita, em doadores de repetição de ambos os sexos. Essa é uma descoberta relevante. Em parte, isto pode ser explicado pelo facto de que o método utilizado é impreciso, de modo indivíduos perto do valor de corte possuem possibilidade maior de ser recusados por LHct se o teste for repetido ao longo do tempo. Contudo, isto não explicaria todo o processo, uma vez que o aumento do intervalo entre 
as doações diminuem as possibilidades do desenvolvimento de LHct (como mostrado na Figura 4.7).

A maioria dos hemocentros analisa somente o resultado real do teste de anemia aplicado na triagem para qualificar a aptidão dos indivíduos para a doação de sangue. Quando os valores estão acima do valor de corte é permitido que o candidato doe sangue. No entanto, de acordo com o que foi observado, é importante que os valores de Hct obtidos em visitas anteriores devam também ser levados em consideração. A qualificação dos doadores usando os níveis de $\mathrm{Hct} / \mathrm{Hb}$ (abaixo de 41\% e 13,5 g/dl, respectivamente) na visita corrente, auxilia na representação de um grupo de alto risco de doadores em triagem com recusas por risco de anemia em sua próxima visita. Tais doadores estão em situação de risco, pois podem vir a desenvolver anemia por deficiência de ferro. Por isso, esses doadores devem ser aconselhados a aumentar o intervalo até a próxima doação ou receber suplementação de ferro.

A análise dos resultados apresentados nesta tese comprovam que existe uma associação entre o tempo decorrido desde última doação e desenvolvimento de LHct para homens e mulheres. Foi visto que quanto mais curto o intervalo mais provável será a recusa por LHct. Esse é um resultado esperado e que foi também observado por outros autores (Rosvik et al., 2009; Cable et al., 2011).

A frequência das doações anteriores também foi associada com evolução do LHct. Isto foi comprovado por meio da utilização da análise de sobrevivência para modelo de regressão nos dados do tempo até o evento de interesse. Esse modelo indicou que um considerável número de doadores, predominante do sexo feminino, desenvolveriam LHct se doassem pelo menos 7 vezes, o que os tornaria incapazes de executar outra doação de 
sangue. A curva de sobrevivência, mostrada na Figura 4.2 do capítulo anterior, sugere que aproximadamente $35 \%$ das mulheres e $5 \%$ dos homens que repetem a doação seriam recusados por LHct em sua oitava tentativa. Entretanto, a frequência da doação não é independente do intervalo entre elas. Parte da relação observada aqui pode ser consequência do pequeno tempo de retorno entre os doadores de repetição. Isso, claramente, comprova que quanto mais frequentes são as doações de sangue, maior será a probabilidade de o indivíduo desenvolver LHct. Neste sentido, para evitar a deficiência de ferro, após contínuas doações de sangue, são sugeridas três possíveis estratégias de prevenção para os doadores de repetição considerados de alto risco:

\section{a. Aperfeiçoamento dos métodos para a detecção de doadores com deficiência de}

ferro. Uma forma de melhorar os métodos de triagem seria a adoção de índices para a medição sistemática de células vermelhas (Alexander et al., 2000; Radtke et al., 2005) ou, a verificação da ferritina sérica para doadores (O'Meara et al., 2011). Tais melhoras auxiliariam no processo de otimização da administração da deficiência de ferro. Porém, isso teria um impacto significativo sobre os custos das triagens de anemia o que poderia dificultar sua implementação.

b. Suplementação de ferro após a doação de sangue. Programas como a suplementação de ferro quando encontrado em doses baixas e administração em curto prazo de ferro carbonila, tem sido sugerido por alguns estudos (Gordeuk et al., 1990; Meyers et al., 2000). No entanto, a maioria dos bancos de sangue reluta em adotar a suplementação como método preventivo devido: $(i)$ risco de administrar ferro para indivíduos com hemocromatose hereditária não diagnosticada; (ii) risco de mascarar condições patológicas associadas com a perda de sangue e seus efeitos colaterais e, 
(iii) a existência de estudos que indicam que as pessoas podem ser mais saudáveis com estoques mais baixos de ferro, particularmente em relação à aterosclerose (Pasricha et al., 2011).

c. Aumento do intervalo de espera entre as doações de sangue. Embora o incremento do intervalo entre as doações de sangue seja visto como uma opção fácil, especialmente para o grupo de doadores de alto risco, ainda necessita de cuidadosa discussão. A consequência negativa da adoção dessa melhora pode acarretar o comprometimento do abastecimento de sangue nos hemocentros. Todavia, como uma tentativa de proteger a saúde do doador, a introdução de um intervalo de doação variável poderia ser prático e benéfico. Doadores com LHct deveriam ser encorajados a aumentar o tempo de regresso ao hemocentro. Isso provavelmente teria impacto sobre o fornecimento de sangue, mas esse efeito poderia ser minimizado. 


\section{Capítulo 6}

\section{Conclusão}

\subsection{Considerações Finais}

Este trabalho apresentou um método de descrição e análise de dados que pode ser aplicado a sistemas de informação no domínio de hemoterapia. Como foi dito nos capítulos anteriores, mesmo digitalizados, os dados da FPS não apresentaram a qualidade requerida para a aplicação das técnicas de análise. Outra questão importante é o volume de dados armazenado, que muitas vezes torna inviável a modificação da estrutura de um banco de dados visando a melhorar a qualidade dos seus dados.

Para analisar os dados disponibilizados pela FPS, foi proposto um modelo de descrição de dados usando a abordagem de proveniência. Este trabalho mostrou que a descrição da proveniência foi importante para gerar um conjunto de dados reduzido. A proveniência foi usada para extrair e minerar conhecimento de um grande volume de dados, quando ajustada a esse domínio.

A causa mais frequente de anemia é a deficiência de ferro. Esse problema está associado a diferentes fatores, dentre os mais comuns, a carência nutricional é um dos 
motivos mais conhecidos. Entretanto, a perda de sangue, pela doação, também pode ser um fator desencadeante. Sabe-se que ao efetuar uma doação de sangue o doador perde pequena quantidade de ferro que está estocado no organismo. Normalmente, esses estoques são recuperados após um período de dois a três meses, apenas com alimentação. No entanto, candidatos à doação de sangue que apresentam ferro abaixo do normal podem vir a desenvolver anemia. Porém, o teste que verifica níveis de ferritina no sangue não é feito no ato da doação. A maioria dos hemocentros brasileiros usa os níveis de Hct para impedir doações com riscos e assegurar a qualidade do sangue doado. Todavia, os testes que medem Hct não são capazes de verificar os níveis de ferritina. Mas é possível associar níveis de Hct com níveis de ferritina, mesmo não tendo esse último dado. Alguns estudos demonstram que, na maioria dos casos, indivíduos que apresentam níveis baixos de Hct também possuem níveis de ferritina baixo (Yousefinejad et al., 2010). Isso viabilizou estudos sobre o comportamento do Hct em doadores de sangue.

O modelo proposto aqui agregou informações semânticas para obter conhecimento sobre o banco de dados do Hemocentro de São Paulo. Esse é o principal diferencial deste estudo. Uma das principais finalidades foi desenvolver uma abordagem baseada em questionamentos como uma tentativa de entender os motivos das recusas por LHct entre os doadores de repetição da FPS. Para isso, foi imprescindível gerar um conjunto de dados confiável. Assim, o modelo descrito nesta tese agregou uma riqueza de informações em cada processo gerado e executado, os critérios de inclusão. Todo o processo foi fundamentado no raciocínio lógico dos pesquisadores da FPS e, isso contribuiu para um refinamento das informações capturadas.

O modelo apresentado nesta tese permite se necessário, que consultas à 
proveniência sejam executadas, o que viabiliza a criação de um processo de auditoria dos dados. Também há a possibilidade de que outros pesquisadores possam empregar o mesmo modelo a qualquer banco de dados de hemoterapia e refazer esse experimento ou ainda gerar outros tipos de análises e conhecimentos.

A proveniência demonstrada aqui não foi definida tomando como base os modelos de proveniência já conhecidos como, OPM, por exemplo. Trabalhos que visam à criação de modelos tidos como genéricos são criados para atender a uma demanda tecnológica específica relacionada a um tipo de processamento ou serviço. Na maioria dos casos tais modelos não podem ser reaproveitados em outros projetos, como foi o caso desta tese. Outra observação importante que pode ser feita é que nenhum dos trabalhos citados neste estudo descreve a utilização da proveniência baseada em declarações semânticas com o intuito de obter dados confiáveis. Também não oferecem informações sobre a descrição de um dado consumido durante a criação ou execução de um workflow ou de alguma tarefa específica. Essas carências podem influenciar não somente na validação de um produto como de um processo.

Após o desenvolvimento e implementação das técnicas apresentadas, o modelo foi capaz de identificar diferentes grupos de doadores de sangue, dentre eles, aqueles que efetuam doações regulares de sangue e aqueles que doam apenas uma única vez. Isso ajudou a excluir das análises aqueles grupos considerados contaminantes. No entanto, o método se mostrou eficiente, já que foi capaz de gerar grupos de doadores baseados em critérios semânticos. A utilização das técnicas de análise de sobrevivência foi imprescindível para analisar com maior clareza o conjunto de dados. Com esta técnica foi possível fazer inferências acerca do tempo, desde a entrada do indivíduo no estudo (data 
da primeira doação) até a ocorrência do evento de interesse (primeira ocorrência de anemia), ou até a censura na observação.

A análise apresentada nesta tese mostrou que o atraso da doação devido aos níveis reduzidos de Hct em doadores de repetição é um gênero altamente prevalente e que, idade, Hct inicial e final e frequência de doações anteriores estão fortemente associadas com esses resultados. Com isso, é necessário estabelecer um regime de doação que proteja os doadores de repetição de desenvolver problemas relacionados com a deficiência de ferro, com ou sem anemia concomitante. Entretanto, o impacto de assegurar suprimento de sangue adequado alterando a frequência de doação dos grupos que apresentarem níveis de Hct mais baixos continua a ser avaliada.

Por fim, com a validação dos resultados obtidos a partir do conjunto de dados gerado, foi possível ter mais compreensão sobre o domínio de dados do Hemocentro de São Paulo. Tais resultados podem servir de ajuda a outros hemocentros brasileiros, e assim, melhorar análises; proporcionar que diferentes grupos de pesquisa que analisam doação de sangue tenham uma visão beneficiada dos grupos de doadores pertencentes a seus hemocentros; e, consequentemente, elevar a qualidade das doações de sangue e criar métodos preventivos contra a evasão dos doadores. 


\subsection{Contribuições}

\subsubsection{Trabalhos Publicados em Anais de Eventos (completo)}

X-Meeting, 2011.

Provenance Description to Extract Knowledge from Hemotherapy Information Systems In: 7th International Conference of the Brazilian Association for Bioinformatics and Computational Biology - X-Meeting, 2011, Florianopolis.

XXX CSBC, 2010.

Aplicando Procedência de Dados para Análise dos Perfis de Doadores de Sangue. In: IV Brazilian E-Science workshop em conjunto com XXX CSBC, 2010, Belo Horizonte.

\subsubsection{Trabalhos Publicados em Anais de Eventos (resumo)}

\section{X-Meeting Electronic Abstracts Book 2009, 2009.}

Using Data Provenance to Analyse Blood Databases in São Paulo, Brazil. In: 5th International Conference of the Brazilian Association for Bioinformatics and Computational Biology, 2009, Angra dos Reis - Rio de Janeiro.

\subsubsection{Artigos Completos Submetidos}

Journal: BMC Genomics (http://www.biomedcentral.com/bmcgenomics/). Provenance Description to Extract Knowledge from Hemotherapy Information Systems. 
(Em processo de revisão)

Vox (http://www.wiley.com/bw/journal.asp?ref=0042-9007).

Predictors of low hematocrit among repeat donors in São Paulo, Brazil: eleven year longitudinal analysis.

(Em processo de revisão)

\subsection{Direcionamentos Futuros}

- Automatizar o processo de descrição dos dados e integrá-lo ao processo de análise e validação;

- Aplicar ao conjunto de dados o modelo variado de sobrevivência com fração de cura;

- Integrar novos hemocentros e usar a abordagem definida nesta tese para gerar os mesmo tipos de análises;

- Analisar a viabilidade das propostas sugeridas como métodos preventivos

- Elaborar novas análises com o intuito de fidelizar e melhorar o quadro de doações de sangue dos hemocentros brasileiros. 


\section{Referências Bibliográficas}

[Alexander et al. (2000)]

Alexander HD, Sherlock JP, Bharucha C. Red cell indices as predictors of iron depletion in blood donors. Clin Lab Haematol; 22: 253-8, 2000.

[Almeida et al. (2010)]

Almeida FN, Silva PPSB, Mendrone A Jr, Sabino EC, Ferreira JF: Aplicando Procedência de Dados para Análise dos Perfis de Doadores de Sangue. Em IV Brazilian E-Science Workshop em conjunto com XXX CSBC, Belo Horizonte, Brasil. julho 2010, 2005.

[Álvarez et al. (2006)]

Álvarez S, Vazquez J, Kifor T, Varga LZ, Willmott S. Applying Provenance in Distributed Organ Transplant Management. Em IPAW, páginas 28-36, 2006.

[Annibale et al. (2011)]

Annibale B, Capurso G, Chistolini A, D'Ambra G, DiGiulio E, Monarca B, elleFave

G. Gastrointestinal causes of refractory iron deficiency anemia in patients without gastrointestinal symptoms. Am J Med, 111: 439-45, 2001.

\section{[Barga \& Digiampietri (2008)]}

Barga RS e Digiampietri LA. Automatic capture and efficient storage of escience experiment provenance. Em: Concurrency and Computation: Practice and Experience, 20(5), 2008. 
[Bavoil et al. (2005)]

Bavoil L, Callahan SP, Scheidegger CE, Crossno P, Freire J, Silva CT, Vo HT. VisTrails: Enabling Interactive Multiple-View Visualizations. Em IEEE, 135 - 142, 2005.

\section{[Benjelloun et al. (2006)]}

Benjelloun, O, Sarma, AD., Halevy, AY., Widom, J. ULDBs: Databases with uncertainty and lineage. Em: Proc. of the VLDB, páginas 953-964, 2006.

\section{[Bhagwat et al. (2004)]}

Bhagwat D, Chiticariu L, Tan WC, Vijayvargiya G. An annotation management system for relational databases. Em Proc. of the VLDB, páginas 900-911, 2004.

\section{[Bose (2002)]}

Bose R. A Conceptual Framework for Composing and Managing Scientific Data Lineage. Em International Conference on Scientific and Statistical Database Management, Edinburgh, Scotland, páginas 15-19, July, 2002, Proceedings.

\section{[Bowers et al. (2006)]}

Bowers S, McPhillips T, Ludaescher B, Cohen S, Davidson SB. A model for useroriented data provenance in pipelined scientific workflows. Em Proceedings of the International Provenance and Annotation Workshop (IPAW'2006), páginas 4145:133-147, 2006, Lecture Notes in Computer Science.

\section{[Bowers et al. (2007)]}

Bowers S, McPhillips T, Wu M, Ludaescher B. Project histories: Managing data provenance across collection-oriented scientific workflow runs. Em Proc. of the Intl. 
Workshop on Data Integration in the Life Sciences (DILS), páginas: 4544:122-138, 2007, Lecture Notes in Computer Science.

[Bowers et al. (2008)]

Bowers S, McPhillips TM, Ludaescher B. Provenance in collection-oriented scientific workflows. Concurrency and Computation: Practice and Experience, 20(5), 2008.

\section{[Braga \& Banon (2008)]}

Braga JC, Banon GJF. Data Provenance: Theory and Application to Image Processing. Em Latin America Transactions, 6(2)207 - 214, 2008, IEEE

\section{[Brown \& Stonebraker (1995)]}

Brown P, Stonebraker, M. A System for the Management of Earth Science Data. Em: International Conference of Very Large Data Bases, 21., 1995, Zurich, Switzerland. Proceedings. páginas 720-728, 1995.

[Buneman et al. (2000)]

Buneman P, Khanna S, Tan W. Data Provenance: Some Basic Issues. Em Foundations of Software Technology and Theoretical Computer Science (FST TCS), New Delhi, India, (1974)9. dezembro 2000, Proceedings. Springer-Verlag.

[Buneman et al. (2001)]

Buneman P, Khanna S, Tan W. Why and Where: A Characterization of Data Provenance. Em International Conference on Database Theory; London, United Kingdom. 15, janeiro 2001, Proceedings. On-line.

[Bustamante-Teixeira et al. (2002)] 
Bustamante-Teixeira MT, Faerstein E, Latorre MR. Técnicas de análise de sobrevida (Survival analysis techniques). Cad. Saúde Pública, Rio de Janeiro, 18(3):579-594, 2002.

[Cable et al. (2011)]

Cable RG, Glynn SA, Kiss JE, Mast AE, Steele WR, Murphy EL, Wright DJ, Sacher RA, Gottschall JL, Tobler LH, Simon TL. Iron deficiency in blood donors: the REDSII Donor Iron Status Evaluation (RISE) study. Transfusion, 2011.

[Cançado et al. (2001)]

Cançado RD, Chiattone CS, Alonso FF, Langhi Jr, DM, Alve RC. S. Iron deficiency in blood donors. São Paulo Med. J. (119)4:132-4, 2001.

[Chapman et al. (2008)]

Chapman A e Jagadish HV. Provenance and the price of identity. Em Second International Provenance and Annotation Workshop (IPAW'2008), páginas: (5272)106-119, junho 2008, Lecture Notes in Computer Science.

[Clardy et al. (2006)]

Clardy SL, Earley CJ, Allen RP, Connor JR. Ferritin subunits in CFF are decreased in restless legs syndrome. J. Lab. Clin. Méd., páginas: (147) 2:67-73, 2006.

[Clifford et al. (2008)]

Clifford B, Foster I, Hategan M, Stef-Praun T, Wilde M, Zhao Y. Tracking provenance in a virtual data grid. Em Concurrency and Computation: Practice and Experience, 20(5):565-575, 2008.

[Colosimo \& Giolo (2006)] 
Colosimo EA, Giolo SR. Análise de Sobrevivência Aplicada. Brasil: Edgard Blücher. ABE - Projeto Fisher. ISBN: 8521203845.

\section{[Conrad et al. (1999)]}

Conrad ME, Umbreit JN, Moore EG. Iron absorption and transport. Am J Med Sci; páginas: (318):213-29, 1999.

[Cook et al. (1992)]

Cook JD, Baynes RD, Skikne BS. Iron deficiency and the measurement of iron status. Nutr Res Rev, 5: 189-202, 1992.

\section{[Cox \& Oakes (1984)]}

Cox DR, Oakes D. Analysis of Survival Data. London, Chapman \& Hall, 1984.

[Djalali et al. (2006)]

Djalali M, Neyestani TR, Bateni J, Siassi F.The effect of repeated blood donations on the iron status of Iranian blood donors attending the Iranian blood transfusion organization. Int J Vitam Nutr Res, 76(3):132-7, 2006.

\section{[EBI]}

EBI. European Bioinformatics Institute. http://www.ebi.ac.uk/. [Acesso em 03 de março de 2012].

[Eltabakh et al. (2007)]

Eltabakh MY, Ouzzani M, Aref WG. Bdbms - a database management system for biological data. In: Proc. of the CIDR, 2007.

\section{[International Foundation]}


International Foundation, EUROTRANSPLANT, http://www.eurotransplant.nl/. [Acesso em 03 de março de 2012].

\section{[Farrugia (2007)]}

Farrugia A. Iron and blood donation- an under-recognised safety issue. Dev Biol (Basel), páginas: (127):137-46, 2007.

[Finch et al. (1977)]

Finch CA, Cook JD, Labbe RF, Culala M. Effect of blood donation on iron stores as evaluated by serum ferritin. Blood, páginas (50):441-7, 1977.

[Freire et al. (2008)]

Freire J, Koop D, Santos E, Silva CT: Provenance for Computational Tasks: A Survey. Computing in Science and Engineering, páginas 11-21, 2008.

[Garry et al. (1995)]

Garry PJ, Koehler KM, Simon TL. Iron stores and iron absorption: effects of repeated blood donations. Am J Clin Nutr, páginas (62):611-20, 1995.

[Geerts et al. (2006)]

Geerts F, Kementsietsidis A, Milano DM. Annotating and querying databases through colors and blocks. Em: Proc. of the ICDE, páginas 82-92, 2006.

\section{[GeneBank]}

GeneBank, http://www.ncbi.nlm.nih.gov/genbank/. [Acesso em 03 de março de 2012].

\section{[Gentleman \& Geyer (1994)]}

Gentleman R e Geyer CJ. Maximum likelihood for interval censored data: consistency and computation. Biometrika, 81:618-623, 1994. 
[Gordeuk et al (1990)]

Gordeuk VR, Brittenham GM, Bravo J, Hughes MA, Keating LJ. Prevention of iron deficiency with carbonyl iron in female blood donors. Transfusion. 30(3):239-45, 1990.

[Gordeuk et al. (1990)]

Gordeuk VR, Brittenham GM, Bravo J, Hughes MA, Keating LJ. Prevention of iron deficiency with carbonyl iron in female blood donors. Transfusion, 30: 239-45, 1990.

[Greenwood et al. (2003)]

Greenwood M, Goble C, Stevens R, Zhao J, Addis M, Marvin D, Moreau L, Oinn T. Provenance of e-Science Experiments - Experience from Bioinformatics. Em $U K$ OST e-Science second All Hands Meeting, (AHM'03), Nottingham, UK. páginas 4, 2003. Proceedings.

[Groth et al., (2006)]

Groth P, Jiang S, Miles S, Munroe S, Tan V, Tsasakou S, Moreau L. An architecture for provenance systems. Technical Report http://eprints.ecs.soton.ac.uk/13216/, University of Southampton, novembro, 2006.

[Hallberg et al. (1991)]

Hallberg L, Rossander-Hultén L. Iron requirements in menstruating women. Em The American journal of clinical nutrition, 54(6):1047-58. dezembro, 1991.

[Holland et al. (2008)]

Holland DA, Seltzer M, Braun U, Muniswamy-Reddy KK. Pass-ing the provenance challenge. Em Concurrency and Computation: Practice and Experience, 20(5), 2008.

[Hosmer et al. (2008)] 
Hosmer DW, Lemeshow S, May S. Applied Survival Analysis: Regression Modeling of Time to Event Data. Wiley: 2nd edition; 2008.

\section{[Ikeda \& Widom (2010)]}

Ikeda R e Widom J. Panda: A System for Provenance and Data. Em Bulletin of the IEEE Computer Society Technical Committee on Data Engineering, 2010.

\section{[Klein \& Moeschberger (2003)]}

Klein JP e Moeschberger ML: Survival Analysis: Statistical Methods for Censored and Truncated Data. Springer: 2nd Edition; 2003.

\section{[Kleinbaum (1995)]}

Kleinbaum DG. Survival Analysis: A Self-Learning Text. New York: Springer, 1995.

[Lamas et al. (1994)]

Lamas HMC, Pérez-Lanzac LJC, Arrojo PI, Gordo SF, Christensen AE, Font SE. Determination of serum ferritin: ideas for avoiding induced ferropenia in blood donors. Sangre (Barc), 39(1):9-14, fevereiro, 1994.

\section{[Lanter (1991)]}

Lanter DP. Design of the Lineage-Based Meta-Data Base for GIS. Em Cartography and Geographic Information Systems, v. 18, 1991.

\section{[Lee (1998a)]}

Lee JR. Microcitose e as anemias associadas com síntese prejudicada da hemoglobina. Em Lee GR et al. Wintrobe - Hematologia Clínica. São Paulo, Mir; páginas 884-919, 1998.

[Lee (1998b)] 
Lee JR. Deficiência de ferro e anemia ferropriva. Em Lee GR et al. Wintrobe Hematologia Clínica, São Paulo, Mir, páginas 884-919, 1998.

[Li et al. (2008)]

Li Q, Labrinidis A, Chrysanthis PK. User-centric Annotation Management for Biological Data. Em The Second International Provenance and Annotation Workshop (IPAW'08), Salt Lake City, Utah, páginas 54-61, 978-3-540-89964-8, Junho 2008.

[Maguire et al. (2007)]

Maguire JL, deVeber G, Parkin PC. Association between iron deficiency anemia and stroke in young children. Pediatrics, páginas 120(5):1053-7, 2007

[Mendrone et al. (2009)]

Mendrone AJr, Sabino EC, Sampaio L, Neto CA, Schreiber GB, Chamone Dde A, Dorlhiac-Llacer PE. Anemia screening in potential female blood donors: comparison of two different quantitative methods. Transfusion, 49(4):662-8, 2009.

\section{[Meyers (2000)]}

Meyers DG. The iron hypothesis:does iron play a role in atherosclerosis? Transfusion, 40: 1023-9, 2000.

[Miles et al. (2007)]

Miles S, Deelman E, Groth P, Vahi K, Mehta G, Moreau L. Connecting scientific data to scientific experiments with provenance. Em Proceedings of the third IEEE International Conference on e-Science and Grid Computing (e-Science'07), Bangalore, India, páginas 179-186, December 2007.

[Milman et al. (1983)] 
Milman N, Pedersen NS, Visfeldt J. Serum ferritin in healthy Danes: relation to marrow haemosiderin iron stores. Danish Medical Bulletin, 30(2):115-20, 1983.

[Milman et al. (1984)]

Milman N e Sondergard M. Iron stores in male donors evaluated by serum ferritin. Transfusion, 24:464-8, 1984.

[Milman et al. (1991)]

Milman N e Kirchoff M. Influence of blood donation on iron stores assessed by serum ferritin and hemoglobin in a population survey of 1433 Danish males. Eur J Hematol, 47:134-9, 1991.

[Milman et al. (1998)]

Milman N, Clausen J, Byg KE. Iron status in 268 Danish women aged 18-30 years: influence of menstruation, contraceptive method, and iron supplementation. Ann Hematol, 77(1-2):13-9, Jul-Aug, 1998.

[Milman et al. (1999)]

Milman N, Ovesen L, Byg K, Graudal N. Iron status in Danes updated 1994. I: prevalence of iron deficiency and iron overload in 1332 men aged 40-70 years. Influence Of blood donation, alcohol intake, and iron supplementation. Ann Hematol, 78(9):393-400, setembro, 1999.

\section{[Ministério da Saúde]}

Ministério da Saúde, Portaria $n^{o} 1353$ de 14 de junho de 2011. Brasil: Ministério da Saúde. http://portal.saude.gov.br/portal/arquivos/pdf/portaria_1353_140611.pd. [Acesso em 03 de março de 2012]. 
[Mittal et al. (2006)]

Mittal R, Marwaha N, Basu S, Mohan H, Ravi Kumar A. Evaluation of iron stores in blood donors by serum ferritin. Indian J Med Res, páginas 124:641-646, dezembro 2006

[Moreau et al. (2000)]

Moreau L, Ludäscher B, Altintas I, Barga RS, Bowers S, Callahan S, Goble C, Golbeck J, Groth P, Holl A, Jiang S, Kim J, Koop D, Krenek A, Mcphillips T, Mehta G, Miles S, Metzger D, Munroe S, Plale B, Podhorszki N, Santos E, Scheidegger C, Schuchardt K, Seltzer M, Yogesh L, Silva C, Slaughter P, Stevens R, Turi D, Vo H, Wilde M, Zhao J, Zhao Y, et al. The First Provenance Challenge. Concurrency Computat. Pract. Exper. 00:1-7 Prepared using cpeauth.cls [Version: 2002/09/19 v2.02], 2000.

[Moreau et al. (2006)]

Moreau L e Foster I. IPAW, LNCS, Springer, Heidelberg, 4145:8, 2006.

[Moreau et al. (2007a)]

Moreau L, Freire J, Futrelle J, McGrath RE, Myers J, Paulson P. The open provenance model (v1.00). Technical report, University of Southampton, dezembro 2007.

[Moreau et al. (2007b)]

Moreau L, Groth P, Miles S, Vazquez-Salceda J, Ibbotson J, Jiang S, Munroe S, Rana O, Schreiber A, Tan V, Varga L. The provenance of electronic data. Communications of the ACM 2007, 4:52-58, 2007. 
[Moreau et al. (2008)]

Moreau L, Freire J, Futrelle J, McGrath RE, Myers J, Paulson P. The Open Provenance Model: An Overview. IPAW, LNCS 5272, páginas. 323-326, 2008, Springer-Verlag Berlin Heidelberg.

[Moreau et al. (2009)]

Moreau L, Kwasnikowska N, Bussche JV. A formal account of the open provenance model. Technical report, University of Southampton, April, 2009.

[Munroe et al. (2006)]

Munroe S, Miles S, Moreau L, V'azquez-Salceda J. PrIMe: A software engineering methodology for developing provenance aware applications. Em ACM Digital Proceedings of the Software Engineering and Middleware Workshop (SEM'06), New York, NY, USA, páginas 39-46, 2006. ACM.

\section{[NCBI]}

NCBI, National Center for Biotechnology Information. www.ncbi.nlm.nih.org. [Acesso em 03 de março de 2012].

\section{[Newman (2006)]}

Newman B. Iron depletion by whole-blood donation harms menstruating females: the current whole-blood-collection paradigm needs to be changed. Transfusion; 46: 1667$81,2006$.

[Nojilana et al. (2007)] 
Nojilana B, Norman R, Dhansay MA, Labadarios D, van Stuijvenberg ME, Bradshaw D. Estimating the Burden of disease attributable to iron deficiency anaemia in South África in 2000. S. Afr. Méd. J, 97(8 pt2):741-6, 2007.

\section{[Oinn et al. (2006)]}

Oinn T, Greenwood M, Addis M, Alpdemir MN, Ferris J, Glover K, Goble C, Goderis A, Hull D, Marvin D, Li P, Lord P, Pocock MR, Senger M, Stevens R, Wipat A, Wroe AC. Taverna: Lessons in creating a workflow environment for the Life Sciences. Concurr Comp: Pract E, 18:1067-100, 2006.

[Oliveira et al. (2011)]

Oliveira CD, Martins G, Custer B, Proietti FA, Carneiro-Proietti AB, Cesar CC. Hierarchical analysis of anaemia deferral in blood donor candidates: the individual in the population perspective. Transfus Med, 21: 371-7, 2011.

[O'Meara et al. (2011)]

O'Meara A, Infanti L, Stebler C, Ruesch M, Sigle JP, Stern M, Buser A. The value of routine ferritin measurement in blood donors. Transfusion, 51: 2183-8, 2011.

[Pasricha et al. (2011)]

Pasricha SR, McQuilten ZK, Keller AJ, Wood EM. Hemoglobin and iron indices in nonanemic premenopausal blood donors predict future deferral from whole blood donation. Transfusion, 51:2709-13, 2011.

\section{[Passos et al. (2005)]}

Passos LNM, Yurtserver MSF, Silva UG, Cordeiro GWO, Machado LF, Vasquez F, Figueiredo MS. Sideropenia sem anemia em doadores de sangue do Hemocentro do Amazonas. Rev. Brás. Hematol. Hemoter, (27)1:48-52, 2005. 
[PDB]

PDB, http://www.rcsb.org/pdb/home/home.do. [Acesso em 03 de março de 2012].

[Radtke et al. (2004)]

Radtke H, Tegtmeier J, Röcker L, Salama A, Kiesewetter H. Daily doses of 20 mg of elemental iron compensate for iron loss in regular blood donors: a randomized, double-blind, placebo-controlled study. Transfusion, 44(10):1427-32, Oct 2004.

[Radtke et al. (2005)]

Radtke H, Meyer T, Kalus U, Rocker L, Salama A, Kiesewetter H, Latza R. Rapid identification of iron deficiency in blood donors with red cell indexes provided by Advia 120. Transfusion, 45: 5-10, 2005.

[Rosvik et al. (2009)]

Rosvik AS, Ulvik RJ, Wentzel-Larsen T, Hervig T. The effect of blood donation frequency on iron status. Transfus Apher Sci; 41:165-9, 2009

[Scheidegger et al. (2008)]

Carlos E. Scheidegger, Huy T. Vo, David Koop, Juliana Freire, and Claudio T. Silva. Querying and re-using workflows with vistrails. Em SIGMOD'08 8, ACM SIGMOD international conference on Management of data, páginas 1251-1254, New York, NY, USA, 2008. ACM.

[Silva et al. (2003)]

Silva PPD, McGuinness DL, McCool R. Knowledge Provenance Infrastructure. Em Proceedings of IEEE Data Eng. Bull, 26-32, 2003.

[Simmhan et al. (2005)] 
Simmhan YL, Plale B, Gannon D. A Survey of Data Provenance Techniques. Em Technical Report TR-618: Computer Science Department; Indiana University, 2005.

[Simon et al. (1981)]

Simon TL, Garry PJ, Hooper EM. Iron stores in blood donors. JAMA; 245: 2038-43, 1981.

[Spery et al. (1999)]

Spery L, Claramunt C, Libourel T. A Lineage MetaData Model for the Temporal Management of a Cad astre Application. Em International Workshop on Database and Expert Systems Applications, Florence, Italy. Proceedings. p. 466-474, setembro, 1999. [S.1] IEEE Computer Society.

[Srivastava et al. (2007)]

Srivastava D e Velegrakis Y. Intensional associations between data and metadata. Em Proc. of ACM SIGMOD Conference, página 401-412, 2007.

[Stevens et al. (2007)]

Stevens R, Zhao J, Goble C. Using provenance to manage knowledge of in silico experiments. Brief Bioinform, 8:183-94, 2007.

\section{[Stolzfus (2001)]}

Stolzfus RJ. Defining Iron-Deficiency Anemian Public health Terms: A Time for Reflection. J. Nutr. 131:565S-7S, supplement, 2001.

\section{[Szklo \& Nieto (2000)]}

Szklo M e Nieto FJ. Epidemiology: Beyond the Basics. Annapolis: Aspen Publishers, 2000. 
[Tan (2008)]

Tan WC. Provenance in Databases: Past, Current and Future. Em IEEE Data Eng. Bull, 30(4): 3-12, 2008.

\section{[Tannem (2008)]}

Tannem V. Provenance for Database Transformations. Em IPAW 2008, LNCS 5272, página 1,2008

[Tardtong et al. (2000)]

Tardtong P, Sthabunswadigarn S, Atamasirikul K, Chaunsumrit A, Suwannuruk R. Iron stores in Thai blood donors. J Med Assoc Thai, (83)1:S146-51 Suppl, março, 2000.

[The Provenance Project, Project Enabling and Supporting Provenance in Grids for

\section{Complex Problems (IST 511085)]}

The Provenance Project, Project Enabling and Supporting Provenance in Grids for Complex Problems (IST 511085), http://www.gridprovenance.org/. [Acesso em 03 de março de 2012].

\section{[The R Project for Statistical Computing]}

The R Project for Statistical Computing, The R Project http://www.r-project.org/. [Acesso em 03 de março de 2012].

\section{[UniProt]}

UniProt, Universal Protein Resource. http://www.uniprot.org/. [Acesso em 03 de março de 2012].

[Wong et al. (2005)] 
Wong SC, Miles S, Fang W, Groth P, Moreau L. Provenance-based validation of escience experiments. Em Proceedings of the 4th International Semantic Web Conference, Galway, Ireland, (3729) 801-15, novembro, 2005.

[Woodruff et al. (1997)]

Woodruff A, Stonebraker M: Supporting Fine-Grained Data Lineage in a Database Visualization. Em International Conference on Data Engineering; Birmingham, UK. 1997:15, april 1997, Proceedings:

\section{[Worwood (1996)]}

Worwood M. Regulação do metabolismo do ferro.Anais Nestlé; 52: 1-10, 1996.

[Yousefinejad et al. (2010)]

Yousefinejad V, Darvishi N, Arabzadeh M, Soori M, Magsudlu M, Shafiayan M. The evaluation of iron deficiency and anemia in male blood donors with other related factors. Asian J Transfus Sci, 4(2):123-7, 2010.

[Zhao et al. (2003)]

Zhao J, Goble C, Greenwood M, Wroe C, Stevens R. Annotating, linking and browsing provenance logs for e-Science. Em Workshop on Semantic Web Technologies for Searching and Retrieving Scientific Data, Oxford Road, Manchester, página: 6, Oct. 2003. Proceedings. 